\title{
A Pedagogical Study of Selected Piano Music of Miguel del Aguila
}

\author{
Sornsuang Tangsinmonkong
}

Follow this and additional works at: https://researchrepository.wvu.edu/etd

\section{Recommended Citation}

Tangsinmonkong, Sornsuang, "A Pedagogical Study of Selected Piano Music of Miguel del Aguila" (2017). Graduate Theses, Dissertations, and Problem Reports. 6772.

https://researchrepository.wvu.edu/etd/6772

This Dissertation is protected by copyright and/or related rights. It has been brought to you by the The Research Repository @ WVU with permission from the rights-holder(s). You are free to use this Dissertation in any way that is permitted by the copyright and related rights legislation that applies to your use. For other uses you must obtain permission from the rights-holder(s) directly, unless additional rights are indicated by a Creative Commons license in the record and/ or on the work itself. This Dissertation has been accepted for inclusion in WVU Graduate Theses, Dissertations, and Problem Reports collection by an authorized administrator of The Research Repository @ WVU.

For more information, please contact researchrepository@mail.wvu.edu. 


\section{A Pedagogical Study of Selected Piano Music of Miguel del Aguila}

Sornsuang Tangsinmonkong

A Doctoral Research Project submitted to

College of Creative Arts

at West Virginia University

in partial fulfillment of the requirements for the degree of

Doctor of Musical Arts

in

Piano Performance

James Miltenberger, D.M.A, Committee Chair, Research Advisor Peter Amstutz, D.M.A.

Keith Jackson, D.M.A.

William Haller, D.M.A.

Penprapa S. Klinkhachorn, D.V.M, Ph.D.

School of Music

Morgantown, West Virginia

2017

Keywords: Miguel del Aguila, piano, “Toccata”, Piano Sonata No. 2, Conga, Piano Concerto, "Vals Brutal”, "Nocturne”, "Music in a Bottle”, "Half of Me”, Pedagogical study

Copyright 2017 Sornsuang Tangsinmonkong 


\section{ABSTRACT \\ A Pedagogical Study of Selected Piano Music of Miguel del Aguila Sornsuang Tangsinmonkong}

Miguel del Aguila (b. 1957) is an Uruguayan American composer who was nominated three times for Grammy Awards. He considers himself a postmodernist composer. His music shows various stylistic traits and strong influence from Latin American folk dances.

This research project focuses on the pedagogical study of eight piano compositions of Miguel del Aguila:

“Toccata”, Op. 23 (1988)

Piano Sonata No.2, Op. 29 (1988)

Conga, Op. 39 (1993)

"Vals Brutal”, Op. 48 (1995)

Piano Concerto, Op. 57 (1997)

"Nocturne", Op. 62 (1998)

"Music in a Bottle", Op. 67 (1999)

"Half of Me", Op. 68 (2000)

This study includes a discussion of del Aguila's education background, career and piano music, as well as analyses of the selected piano works and suggestions for addressing pedagogical concerns. 


\section{ACKNOWLEDGEMENTS}

Firstly, I would like to express my special appreciation to Miguel del Aguila for his insightful information and various perspectives of his piano compositions through his interviewing, piano masterclass and email correspondence.

I would like to express my sincere gratitude to my advisor Dr. James Miltenberger for his continuous support to my doctoral study and research project, for his guidance, patience, motivation, and valuable knowledge. He suggested the piece Miguel del Aguila's Conga which made me appreciate del Aguila's music and inspired me to research on this topic.

Besides my advisor, I would like to thank the rest of my thesis committee: Dr. Keith Jackson, Dr. Peter Amstutz, Dr. William Haller and Dr. Penprapa S. Klinkhachorn for valuable comments and suggestions.

Finally, I would like to express my gratitude to my parents, my husband and friends for endless supporting and encouragement throughout my years of study. Without them, this research would not be accomplished.

Sornsuang Tangsinmonkong

May 2017 


\section{TABLE OF CONTENTS}

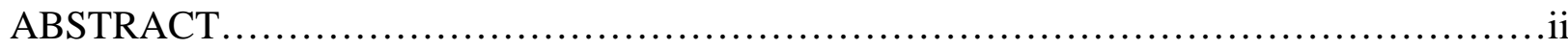

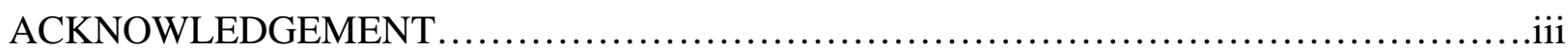

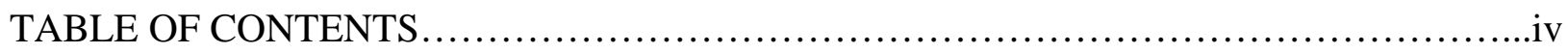

CHAPTER I: INTRODUCTION.................................................... 1

i) Overview.................................................................. 1

ii) Purpose and Scope of Project................................................ 2

iii) Review of Literature.......................................................

iv) Layout of the Study..............................................................

CHAPTER II: URUGUAYAN CLASSICAL MUSIC AND MIGUEL DEL AGUILA......... 10

i) Significant Uruguayan Pianists and Composer............................... 10

ii) Biography of Miguel del Aguila.......................................... 14

iii) General Characteristics of Miguel del Aguila's Piano Music.....................17

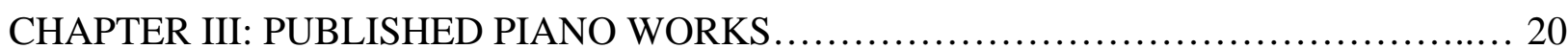

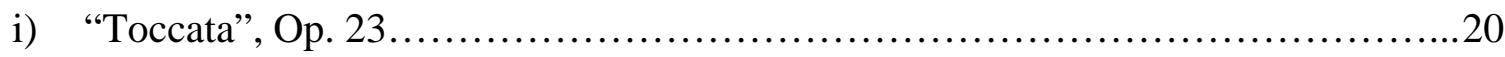

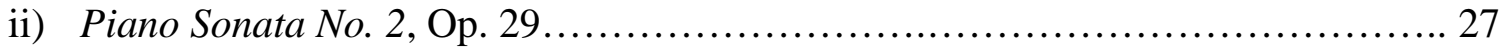

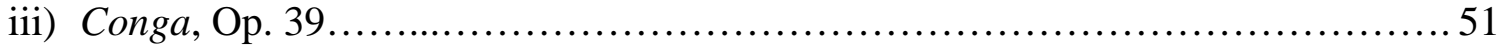

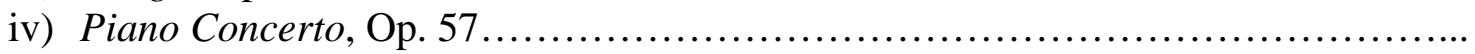

CHAPTER IV: UNPUBLISHD PIANO WORKS...................................... 80

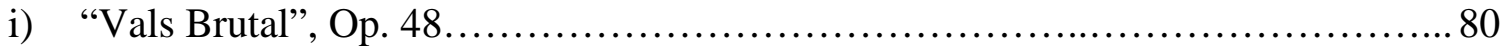

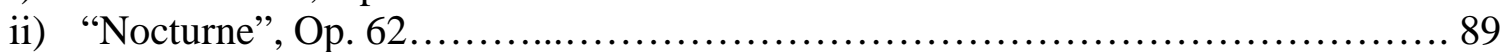

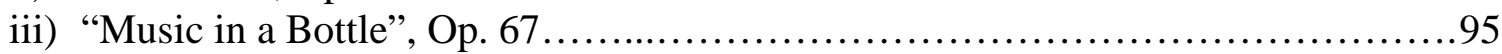

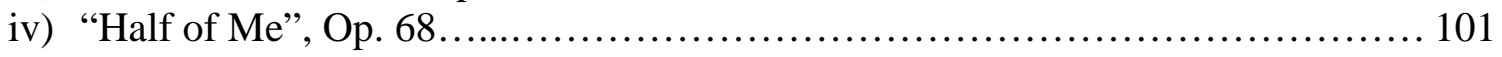

CHAPTER V: CONCLUSIONS AND

RECOMMENDATIONS FOR FUTURE RESEARCH................................. 112

BIBLIOGRAPHY ................................................................ 117

APPENDIX I: Notation errors from del Aguila’s Piano Sonata No. 2, Op. 29 score........... 120

APPENDIX II: Detailed orchestration in the Piano Concerto, Op. 57..................... 121

APPENDIX III: Miguel del Aguila’s Contact........................................... 122

APPENDIX IV: Permission for using excerpt from Ginastera’s Piano Sonata No. 1, Op. 22.. 123 


\section{CHAPTER I \\ INTRODUCTION}

\section{i) Overview}

Today, twentieth-century music is a significant part of many piano recitals.

The largest body of twentieth-century music that is performed frequently was composed by European and American composers. Some of the most notable composers of twentieth-century piano music include Claude Debussy (1862-1918), Sergei Prokofiev (1891-1953), Dmitri Shostakovich (1906-1975), Igor Stravinsky (1882-1971) Arnold Schoenberg (1874-1951), Béla Bartók (1881-1945), Samuel Barber (1910-1981), and Aaron Copland (1910-1990).

However, twentieth-century piano music is not limited to European and American composers. Latin American composers have also composed significant piano works and their music is becoming popular for teaching and performance. Latin American music developed primarily from music in European traditions, especially from Spain and Portugal. In addition, the combination of African and Amerindian musical traditions was often utilized to create unique music qualities. A variety of dances, for example, are essential elements in Latin American music. In the late nineteenth century and early twentieth century, nationalist ideas dominated Latin American music. Significant Latin American composers in the early twentieth century were Alberto Ginastera (1916-1983) of Argentina, Heitor Villa-Lobos (1887-1959) of Brazil, and Carlos Chávez (1899-1978) of Mexico. Their musical styles reflect the ideas of nationalism by using folk dances. Moreover, musical trends from Europe in the early twentieth century were often applied to their compositions; for example, Ginastera applied twelve-tone techniques to his Piano Sonata No. 1, Op. 22. 
The focus of this research is Miguel del Aguila (b. 1957), a Uruguayan-born American pianist and composer. He is an active composer who has won numerous awards, including three Latin Grammy nominations. His compositions are significant because they demonstrate the sense of Latin American nationalism by using Latin American dance, combined with influences of European and American traditions. In addition, much of his music reveals his relationship to other Latin American composers, especially Ginastera. Del Aguila composed music in many genres, including chamber, vocal, and solo works. He composed fifteen piano works: nine solo piano pieces, one piano concerto, and five piano-ensemble pieces. This research will be focused on eight of his piano pieces: seven of his solo piano pieces and the piano concerto. It is my hope that his piano works will become interesting repertoire for pianists and piano students who want to fill their recital program with remarkable, lesser-known piano repertoire composed at the end of twentieth century.

\section{ii) Purpose and Scope of Project}

The first purpose of this research is to discuss the general characteristics of Latin American and Uruguayan classical music. The second purpose is to survey and study pedagogical aspects of del Aguila’s piano music so that they may be successfully taught to advanced piano students. His eight major piano works, “Toccata”, Piano Sonata No. 2, Conga, Piano Concerto, “Vals Brutal”, “Nocturne”, “Music in a Bottle” and "Half of Me”, have been selected for this project. The last purpose of this research is to promote and encourage performances of del Aguila's piano music and to explore the influence of Latin American music in del Aguila’s piano music. 
As stated above, this project will cover eight compositions of Miguel del Aguila's piano music. Other piano compositions, such as the two-piano and six-piano works, will not be included in this research. This study will consist of a discussion of general ideas of each piece as well as its pedagogical aspects. Form, technique, texture, articulation, phrasing, pedal, dynamics, rhythm, and any other interesting aspects of the music will be studied. However, a detailed formal analysis of each composition will not be included.

\section{iii) Review of Literature}

There are not many works of scholarly literature that directly relate to Miguel del Aguila. In order to cover more information associated with del Aguila’s life and his compositions, Latin American music, especially Uruguayan music, will be a major focus. However, only English language sources will be chosen for this research. Literature from other languages will not be included. Ten sources from dictionaries, dissertations, monographs, journals and websites are chosen for the literature review.

\section{Dictionary Sources}

A very brief biography and a list of selected works of del Aguila are presented on page four of Latin American Classical Composers: A Biographical Dictionary. ${ }^{1}$ This dictionary was written by Miguel Ficher, Martha Furman Schleifer and John M. Furman and published by Scarecrow Press, Lanham, MD in 1996. This dictionary provides interesting information about del Aguila. His teachers; Santiago Baranda Reyes and Vicente Ascone are mentioned. Ascone

\footnotetext{
${ }^{1}$ Miguel Ficher, Martha Furman Schleifer, and John M. Furman, Latin American Classical Composers: A Biographical Dictionary. Lanham, MD: Scarecrow Press, 1996, 4.
} 
was a prominent Uruguayan composer and his name appears in many Latin American music monographs.

\section{$\underline{\text { Dissertations }}$}

“A Brief Evaluation of Selected Solo Piano Music by Latin American Composers,” a doctoral dissertation written by Moonson Choi in 1995 at Ohio State University, presents selected piano works by significant Latin American composers, including Alberto Ginastera, Carlos Chávez, and Heitor Villa-Lobos. A history and brief overview of Latin American music is discussed in its second chapter, "Understanding Latin American Music.” Moreover, an evaluation of piano pieces is covered in its third chapter, including the categories of pedaling, techniques, performance problems, and difficulty ratings. This dissertation gives interesting concepts and guidelines for studying Latin American piano music.

The doctoral dissertation "An Introduction to the Solo Piano Works of Three Latin American Composers: Miguel del Aguila, Tania Leon, and Juan Maria Solare" by Yew Choong Cheong is a great source for this research. In the second chapter of Cheong's dissertation, del Aguila’s biography and piano music are discussed. A useful overview and analysis of del Aguila's piano music is provided, covering general stylistic traits, lists of piano works, and brief analyses of selected piano works. However, this dissertation did not focus on any pedagogical aspects of this music.

There is another related study found in "Pedagogical and Performance Aspects of Three American Compositions for Solo Piano: John Corigliano’s Fantasia on an Ostinato, Miguel del Aguila’s Conga for Piano, and William Bolcom’s Nine New Bagatelles,” a doctoral dissertation written by Tse Wei Chai in 2016. In its third chapter, del Aguila’s biography and stylistic traits 
of his Conga for Piano were studied. Interesting rhythmic patterns, structural analysis, and pedagogical aspects were examined.

\section{Monographs}

There are three significant monographs that cover ideas of Latin American music and Uruguayan music. The first book is Music in Latin America: An Introduction by Gerard Béhague from Englewood Cliffs, NJ: Prentice-Hall in 1979. This book divided into three parts by periods: "The Colonial Period," "The Rise of Nationalism” and “Counter-Currents in the Twentieth Century.” Each of these parts is divided by specific trends and countries, and Uruguayan music is paired with Argentinian music. This source provides useful information about the start of classical music in Latin America and its continuation to a nationalistic trend in the nineteenth and twentieth centuries. One essential aspect of this book is that it provides the names of significant composers and their compositions. Classical music in Uruguay started with a nationalistic trend in the nineteenth century and changed to a neoclassic and post-romantic trend during the early 1930s and 1940s. After the 1950s, serialism, total serialism, and electronic music were the main musical streams that dominated Uruguayan classical music. The primary nationalist Uruguayan composers are Alfonso Broqua (1876-1946), Luis Cluzeau Mortet (18891957), Eduardo Fabini (1882-1950), Vincente Ascone (1897-1979) and Carlos Pedrell (18781941). During the 1930s and 1940s, important neoclassic composers included Carlos Estrada (1909-1970), Héctor Tosar (Errecart) (1923-2002), and Guido Santórsola (1904-1994). A variety of styles were presented during the 1960s. León Biriotti (b. 1929) wrote his music in total serialist and electronic styles, while Antonio Mastrogiovanni (1936-2010), José Serebrier (b. 1938) and Sergio Cervetti (b. 1941) were composing experimental, avant-garde music. 
The second book is Music of Latin America. It was written in 1946 by Nicolas Slonimsky and was published by Thomas Y. Crowell Company, New York. The content is focused on twentieth-century Latin American music. There are two parts in this book: "Panorama of Latin American Music" and "Music in the Twenty Republics." Uruguayan music is in the second part. This book organizes musical traits by countries in alphabetical order.

Music of Uruguay can be found in pages 282-287. Uruguayan music is primarily inspired by European traditions, especially Italian, and there are also some influences from African and Amerindian music. Furthermore, Argentinian music played an important role in developing Uruguayan music. Some dances which originated from the Spanish heritage can be found in both Argentina and Uruguay, such as triste, cielito, triunfo, milonga, tango, vidala and pericón. $^{2}$

This book also includes biographies of significant Uruguayan composers and musicologists such as Carlos Pedrell, Alfonso Broqua, Eduardo Fabini, Cluzeau Mortet, Carlos Estrada, Luis Pedro Mondino, Guido Santórsola, Hector Tosar Errecart and Francisco Curt Lange (1903-1997).

The final source is The Garland Handbook of Latin American Music written by Dale A. Olsen and Daniel E. Sheely, published by Garland Publisher, New York in 2000. This source presents the main concepts of Latin American music, explaining the influences which can be traced to European music, especially German, Italian and British musical traditions. In addition to Amerindian influence, African and other immigrants brought their cultures into Latin America. For instance, the guitar was a significant instrument used to create rhythms. Unfortunately, the information in this book is focused on Latin America's traditional and folk

\footnotetext{
${ }^{2}$ Nicolas Slonimsky, "Uruguay," In Music of Latin America, (New York: Thomas Y. Crowell Company, 1946), 282.
} 
music rather than on its classical music. Thus, the content inside did not relate directly to Uruguayan classical music or Miguel del Aguila.

$\underline{\text { Journals }}$

The interview with Miguel del Aguila "Composer Miguel Del Aguila: Rhythm, Romance, and Reality," by Robert Schulslaper from Fanfare magazine, is an essential source that demonstrates del Aguila's compositional style and promotes his compositions in the CD Salón Buenos Aires. ${ }^{3}$ In this interview, del Aguila talks a little about his life and education. He also discusses the rejection of twelve-tone techniques in his compositions. Additionally, he mentions how Latin American culture and dance influenced his music. His compositions First Piano Suite, Salón Buenos Aires, Charango Capriccioso, Clocks, Presto II, Conga Line in Hell, and Life is a Dream were discussed briefly in this interview.

\section{$\underline{\text { Websites }}$}

There are not many websites that provide essential information about del Aguila's music and his background. The best one comes from the composer's website www.migueldelaguila.com. It probably gives the most valuable and updated information that relates to the topic. On the Program Notes page, he provides significant information about his major compositions, including his piano music. The style and background of each piece is explained clearly on this page. Del Aguila's short and long biographies are presented on his Biography page. On the Other Works pages, all of his works are presented in chronological order

\footnotetext{
${ }^{3}$ Robert Schulslaper, "Composer Miguel Del Aguila: Rhythm, Romance, and Reality," Fanfare: The Magazine for Serious Record Collectors 33, no. 5 (May 2010): 162-167.
} 
with opus numbers and performance times of each composition. Moreover, the del Aguila website gives the way to contact him directly for further information via his Contact page.

RILM Music Encyclopedias is another valuable online source that gives some interesting information about Latin American music. Jeff Kaliss wrote about the topic "Latin America" in Encyclopedia of Music in the 20th Century from page 358-363. In this entry Kaliss talks about the ways that Uruguayan music has derived great influence from Argentina and Brazil as their neighboring countries, and also the influence of Spain and Portugal. Furthermore, this source describes the ways that dance forms such as comparsas de Carnaval and camdombe were received from Africa, while folk music came from creóle or mestizo origins and were accompanied by the guitar and drums. The prominent classical composers in Uruguay in the early twentieth century are also mentioned, including Eduardo Fabini and Cluzeau Mortet, who also composed in a nationalist style.

\section{iv) Layout of the Study}

This study is divided into five chapters. Chapter 1 , the introduction, consists of five sections: overview, purpose and scope of project, review of literature and layout of the study. Chapter 2, Uruguayan Classical Piano Music and Miguel del Aguila, will focus in particular on significant Uruguayan pianists and composers, Miguel del Aguila’s biography and general characteristics of Miguel del Aguila’s piano music. Chapter 3, Published Piano Works, will consist of an examination of four pieces: “Toccata”, Op. 23; Piano Sonata No.2, Op. 29; Conga Op. 39; and Piano Concerto, Op. 57. Chapter 4, Selected Unpublished Piano Works, will also consist of four pieces: "Vals Brutal”, Op. 48; "Nocturne”, Op. 62; “Music in a Bottle”, Op. 67; and "Half of Me", Op. 68. The list of del Aguila’s piano music in both chapters three and four 
will be arranged in chronological order. Background information will be provided about each composition, and pedagogical concerns such as form, technique, texture, articulation, phrasing, pedal, dynamics, rhythm and any other interesting aspects will be discussed through the significant musical elements. The last chapter Chapter 5: Conclusion and Recommendation for Further Research will summarize the research and give suggestions for further research. 


\section{CHAPTER II}

\section{URUGUAYAN CLASSICAL MUSIC AND MIGUEL DEL AGUILA}

The music of Miguel del Aguila reflects his great admiration for Latin American music; especially the music of Uruguay, his birthplace. To better understand del Aguila's piano music from different perspectives, this chapter is divided into three sections. The first section focuses on the historical background of Uruguayan classical music and its significant pianists and composers, a biography of del Aguila will be presented in the second section, and the last section will be a discussion of the general characteristics of del Aguila's piano music.

\section{i) Siginificant Uruguayan Pianists and Composers - Miguel del Aguila's Predecessors}

Uruguay is a country which is located in the southeast of South America and serves as a buffer territory between Argentina and Brazil. Montevideo is the capital and the largest city of Uruguay. It is located on the southeast coast where many European musicians have settled. Thus, Uruguayan musical traits mainly follow European traditions, particularly Spanish characteristics. As a result of these influences, the guitar became a very important and iconic instrument used in Latin American music. In the nineteenth century, many Italian composers migrated to Montevideo, and the subsequent influence from Italian opera began to appear in Uruguayan classical music. This influence can even be seen in the National Anthem of Uruguay, composed in 1848 by Fernando Quijano (1805-1871). ${ }^{4}$

The musical trends in Uruguay are similar to the trends in other countries in Latin America, which can be categorized into eight musical periods; colonial, nationalism, European postromanticism, neoclassicism, serialism, avant-garde and experimental music. Colonial music

\footnotetext{
${ }^{4}$ Slonimsky, op. cit., 283.
} 
is not mentioned in this research because it is beyond the scope of this project. In the early twentieth century, one of the most significant musical movements was Nationalism. Uruguayan composers who were active during 1920-1940 also followed this trend. ${ }^{5}$ According to Nicolas Slonimsky, "Musically speaking, Uruguay is a dependency of Argentina." ${ }^{6}$ The songs and dances of Argentina are the folklore of Uruguay. ${ }^{7}$ Popular tunes and folk dances which are derived from Argentina such as triste, cielito, triunfo, milonga, tango, vilada and pericón were great resources for composing nationalist music. ${ }^{8}$ Pericón and gaucho are unique forms of Uruguayan dance. Significant composers in this period were Alfonso Broqua, Luis Cluzeau Mortet, Eduardo Fabini, Vicente Ascone and Carlos Pedrell. Examples of music of this period include Evocaciones criollas, a collection of folk songs for guitar including vilada, chacarera and zamba by Broqua; Pericón (1918), a piano piece by Mortet; La isla de los ceibos (19241926) by Fabini; and the opera Paraná Guazú (1931) by Ascone. Throughout these pieces one can trace rhythmic and melodic elements from folk music, and influence from Amerindian, Spanish, and Mestizo peoples. Broqua and Pedrell were recognized as the composers who began Uruguay's modern era.

\section{0s and 1930s}

There were some composers in Uruguay who followed the European postromantic style. Three composers, Eduardo Fabini, Alfonso Broqua and Luis Cluzeau Mortet, persued the European postromantic trend during 1920s and 1930s. ${ }^{9}$ Two other composers, César Cortinas (1890-1918) and Carmen Barradas (1888-1963), also went after this trend. César Cortinas (1890-

\footnotetext{
${ }^{5}$ Gerard Béhague, "The Twentieth Century: Brazil and the River Plate Area." in Music in Latin America: An Introduction, ed. H. Wiley Hitchcock, (Englewood Cliffs, NJ: Prentice-Hall, 1979), 182.

${ }^{6}$ Slonimsky, op. cit. 282.

${ }^{7}$ Ibid.

${ }^{8}$ Ibid.

${ }^{9}$ Béhague, op. cit., 241.
} 
1918) studied in Berlin with Max Bruch. His music is very eclectic. In his opera La última gaviota (1915), the expressive libretto captured the quintessential spirit of nineteenth-century romanticism. ${ }^{10}$ Carmen Barradas composed music primarily for the piano, and she was interested in experimental music and also used innovative ideas for music notation. ${ }^{11}$ Fabricación (1922), a piece that replicates the noise from a working factory, is an example of her unusual works for the piano. $^{12}$

\section{0s and 1940s}

Neoclassicism became the driving aesthetic during the 1930s and 1940s, ${ }^{13}$ and three significant composers in Uruguay during this time were Carlos Estrada (1909-1970), Héctor Tosar (Errecart) (1923-2002) and Guido Santórsola (1904-1994). Estrada follows the European romantic tradition, which maintains traditional formal design and is rich in harmony. ${ }^{14}$ Tosar was a pianist and composer who studied composition under Aaron Copland, Arthur Honegger, and Darius Milhaud. The Toccata for orchestra (1940), Oda a Artigas (1951), and Danza criolla (1940) for piano are some of his compositions during this period. Guido Santórsola was a violist and conductor who turned away from Brazilian folk music to Uruguayan folk music.

\section{0s}

During the 1960s, a variety of musical styles were explored and several composers became interested in serialism, avant-garde styles, and experimental music. These composers

\footnotetext{
${ }^{10}$ Ibid.

${ }^{11}$ Ibid.

${ }^{12}$ Susana Salgado, "Barradas, Carmen," Grove Music Online. Oxford Music Online, Oxford University Press, accessed September 2, 2016, http://www.oxfordmusiconline.com/subscriber/article/grove/music/44195.

${ }_{13}$ Gerard Béhague, "The 1930s and 1940s," in Music in Latin America: An Introduction, ed. H. Wiley Hitchcock, (Englewood Cliffs, NJ: Prentice-Hall, 1979), 277-278.

${ }^{14}$ Ibid., 277.
} 
included León Biriotti (b. 1929), Antonio Mastrogiovanni (1936-2010), José Serebrier (b.1938) and Sergio Cervetti (b. 1941). ${ }^{15}$

León Biriotti composed total serialist music and electronic music. Examples of his compositions are Espectros (1969) for three orchestras, and Permutaciones (1970) for chamber orchestra. ${ }^{16}$ Mastrogiovanni, a student of Tosar and Estrada, also used serial technique in his compositions, which can be seen in Secuencial I (1970) and in Reflejos (1970), for seven instruments. ${ }^{17}$ The next composer is Serebrier, who now resides in the United States. His music is inspired by Latin American music and demonstrates a sophisticated treatment of rhythm, mixed-media and serialist techniques. He composed many pieces for unusual groups of instruments; for example, Variation on a Theme from Childhood (1964), for trombone with string quartet, and Passagalia and Perpetuum Mobile, for accordion and chamber orchestra. The last composer is Cervetti, who has also settled in the United States. He studied at the Peabody Conservatory with Stefan Grové (b. 1922) and Ernst Krenek (1900-1991). During the 1960s and 1970s, he was interested in avant-garde music, serialism, experimental techniques, electronic music, chance operation and mixed media. ${ }^{18}$ His most well-known works are Cocktail Party, Oulum, and Alberti Bass-Alberti Bouce. Graphic notations such as those found in Graffiti and Orbitas gave him an international reputation in the Symposium and Exhibition of Music Notation in Rome, Italy in $1972 .^{19}$

\footnotetext{
${ }^{15}$ Gerard Béhague, "Countercurrents: Since 1950," in Music in Latin America: An Introduction, ed. H. Wiley Hitchcock, (Englewood Cliffs, NJ: Prentice-Hall, 1979), 340-342.

16 Ibid.

${ }^{17}$ Ibid., 341.

${ }^{18}$ Ibid., 342.

${ }^{19}$ Sergio Cervetti, "Biography," accessed September 2, 2016. http://www.sergiocervetti.com/biography.php.
} 


\section{ii) Biography of Miguel del Aguila}

Miguel del Aguila is an Uruguayan-American composer who was born on September 15, 1957 in Montevideo, Uruguay. He immigrated to the United States in 1978 and is now one of the most outstanding composers in the West Coast area of the United States. His music has received positive reviews from many music critics. Fanfare wrote about his music, "Vibrant, colorful music, often pulsating with a tremendous rhythmic vitality”. ${ }^{20}$ The New York Times wrote, “..elegant and affectionate music ... delicious send-up of Minimalism ...with genuine wit.."21

Del Aguila's early music education started at the age of five, when he participated in a children’s choir directed by an Austrian musicologist, Kurt Pahlen (1907-2003). ${ }^{22}$ Later, he took piano lessons with Santiago Baranda Reyes (1910-1982), a well-known Uruguayan composer, teacher, and pianist who had been a student of Guido Santórsola. He also studied composition with Vincente Ascone, a significant Italian-born Uruguayan composer whose compositions focus on nationalistic traits. During the 1970s, Uruguay was under control by the civic-military dictatorship. Due to his political opposition to the military dictatorship, del Aguila's performances were outlawed, causing him to face the threat by the Uruguayan government. ${ }^{23} \mathrm{He}$ and his family lost everything from the military dictatorship, so they decided to move to the United States in $1978 .^{24}$

After moving to the United States, del Aguila received additional musical training. He studied piano with Paul Hersh at the San Francisco Conservatory of Music from 1979 to

\footnotetext{
${ }^{20}$ Miguel del Aguila, "Press Quotes," accessed July 25, 2016, http://www.migueldelaguila.com/press-quotes.html. ${ }^{21}$ Ibid.

${ }^{22}$ Yew Choong Cheong, "An Introduction to the Solo Piano Works of Three Latin American Composers: Miguel Del Aguila, Tania Leon, and Juan Maria Solare," (DMA diss., West Virginia University, 2009), 38.

${ }^{23}$ Ibid., 39.

${ }^{24}$ Ibid.
} 
1982. ${ }^{25,26}$ He continued his composition studies with Enrich Urbanner (b. 1936), an Austrian composer, at the Hochschule für Musik and Konservatorium in Vienna from 1982-1986. ${ }^{27}$ While living in Vienna, he was working as an active composer, pianist, and theory instructor, and as an accompanist at the Vienna State Opera. ${ }^{28}$ Del Aguila had been living in Vienna for ten years before he returned to the United States and began to work in Southern California in 1992. Del Aguila premiered most of his piano compositions himself. He performed in many outstanding concert halls, such as Carnegie Hall in New York and Bösendorfersaal in Vienna.

\section{Awards}

Del Aguila was a nomination of the Latin American Grammy Award three times in 2015 for his cello concerto, Concierto en Tango, and in 2010 for his CD Salón Buenos Aires, and for his composition Clocks. As a very successful composer, del Aguila received numerous awards and honors including:

- Jeunesses Musicales Award, Montevideo (1978)

- $\quad$ First prize in the Olympiad of the Arts Competition, California (1984)

- AEMUS Fellowship, Montevideo (1978)

- First prize in the United Students of the Americas Competition, New York (1988)

- $\quad$ Meet the Composer Awards (1993, 1994, 1995, 1996, 1997 and 1998)

- City of Ventura Artist Fellowships (1994, 1995 and 1997)

- $\quad$ The Kennedy Center Friedheim Award (1995)

- Several California Arts Council Composer Fellowships and Residencies (1996-2000)

- The Argosy Foundation for Contemporary Music (2005)

\footnotetext{
${ }^{25}$ Ficher et al., op. cit., 8.

${ }^{26}$ E-mail correspondence with Miguel del Aguila, December 6, 2016.

${ }^{27}$ Ibid.

${ }^{28}$ Cheong, op. cit. , 38.
} 
- $\quad$ The Copland Foundation Award (2005)

- The Lancaster Symphony Orchestra Composer’s Award (2008)

- $\quad$ Meet The Composer: Opus Magnum Award (2008)

- The Copland Foundation Recording Award (2009)

\section{Del Aguila’s Stylistic Traits}

The term "Postmodernism” fits to del Aguila stylistic traits. ${ }^{29}$ Del Aguila’s music is strictly tonal. However, the use of augmented, diminished, and extended chords produces unique sonorities in his compositions. Nationalistic ideas, including rhythmic patterns from Latin American dance and irregular rhythms, also add a special character to his music. The repetitive patterns from the Latin American dances even add a minimalistic flair to his music. ${ }^{30}$ A mixture of popular idioms, Latin dances, and jazz styles is clearly displayed in his musical ideas. Rather than being limited to fun and lively music, his works also demonstrate his brilliance in composing lyrical intensity and romantic ideas which display musical depth and drama.

\section{Composition Genres}

Del Aguila was the composer-in-residence at the Chautauqua Institution, New York (2000-2004), and the New Mexico Symphony Orchestra (2005-2006). ${ }^{31}$ He is not only a renowned composer, but also an active pianist who regularly performs with many chamber orchestras. Currently, del Aguila is a faculty member of Ventura College in California, teaching composition and piano. He has composed more than 115 works including orchestral works, solo instrument or voice with orchestra, stage works, and music for dance, film, and television. It is important to note that his music has been performed all over the world, as 21 orchestras performed his music in 2015 alone. Del Aguila publishes his compositions with Peermusic

\footnotetext{
${ }^{29}$ Ibid.

${ }^{30}$ Miguel del Aguila, "Biography," accessed August 31, 2016, http://www.migueldelaguila.com/biography.html.

${ }^{31}$ Cheong, op. cit., 39.
} 
Classical. Additionally, 33 CDs in different labels such as Naxos, Dorian, Telarc, New Albion, Albany, Bridge Records, Centaur and Eroica have been published with recordings of his music. ${ }^{32}$

\section{iii) General Characteristics of Miguel del Aguila’s Piano Music}

As a virtuosic pianist and composer, most of del Aguila's piano works were premiered by del Aguila himself. Significant technical challenges are found in his piano compositions. Miguel del Aguila composed fifteen piano works during 1987-2001, which consist of ten solo piano pieces, one piano concerto, and four piano ensemble pieces. Only four of them were published with Peermusic Classical: “Toccata”, Op. 23; Piano Sonata No.2, Op. 29; Conga, Op. 39; and Piano Concerto, Op.57. Most of his works are character pieces. Table 1 provides a list of Miguel del Aguila’s piano music.

Table 1: List of Miguel del Aguila’s works

\begin{tabular}{|c|c|c|c|c|c|c|}
\hline No. & Op. & $\begin{array}{l}\text { Piano solo and } \\
\text { piano concerto }\end{array}$ & $\begin{array}{c}\text { Piano } \\
\text { ensemble }\end{array}$ & Year & Premiered by & Published \\
\hline 1 & 15 & Piano sonata No. 1 & - & 1987 & Del Aguila/ 1988 & $x$ \\
\hline 2 & 19 & Dance Suite & - & 1988 & Del Aguila/ 1988 & $x$ \\
\hline 3 & 22 & Four Spanish Songs & - & 1988 & Del Aguila/ 1988 & $x$ \\
\hline 4 & 23 & "Toccata" & - & 1988 & Del Aguila/ 1988 & $\checkmark$ \\
\hline 5 & 29 & Piano Sonata No. 2 & - & 1988 & Del Aguila/ 1989 & $\checkmark$ \\
\hline 6 & 39 & Conga & - & 1993 & Eileen Huang/ 1994 & $\checkmark$ \\
\hline 7 & 48 & "Vals Brutal" & - & 1995 & Del Aguila/ 1995 & $x$ \\
\hline 8 & 51 & - & $\begin{array}{l}\text { Caribbean } \\
\text { Bacchanal } \\
\text { for two } \\
\text { pianos/ } \\
\text { eight hands }\end{array}$ & 1995 & $\begin{array}{c}\text { E.Francis,N.Friedman, } \\
\text { E.Kinsley, } \\
\text { M.Aguila/ } 1995\end{array}$ & $x$ \\
\hline 9 & 57 & Piano Concerto & - & 1997 & Del Aguila/ 1997 & $\checkmark$ \\
\hline 10 & 62 & "Nocturne" & - & 1998 & Karen Corbett/ 1998 & $x$ \\
\hline 11 & 67 & "Music in a Bottle" & - & 1999 & $\begin{array}{c}\text { James Miltenberger/ } \\
1999\end{array}$ & $x$ \\
\hline 12 & 68 & & "Four Hand & 1999 & (not premiered) & $x$ \\
\hline
\end{tabular}

\footnotetext{
${ }^{32}$ Miguel del Aguila, "Recoding Discography," accessed Aug 31, 2016, http://www.migueldelaguila.com/recordings---buy.html.
} 


\begin{tabular}{|c|c|c|l|l|l|c|}
\hline 13 & 70 & $\begin{array}{l}\text { "Half of Me" for left } \\
\text { hand }\end{array}$ & - & 2000 & $\begin{array}{c}\text { 2000 Van Cliburn } \\
\text { International Piano } \\
\text { Competition } \\
\text { (will premier in April } \\
\text { 22, 2017 by Sornsuang } \\
\text { Tangsinmonkong) }\end{array}$ & $x$ \\
\hline 14 & 73 & - & $\begin{array}{l}\text { Conga-line } \\
\text { in Hell } \\
\text { arranged for } \\
\text { six pianos }\end{array}$ & 2000 & Piano Circus/ 2000 & $x$ \\
\hline 15 & 75 & & $\begin{array}{l}\text { Lieutenant } \\
\text { Kije (from } \\
\text { Sergei } \\
\text { Prokofiev } \\
\text { Suite) } \\
\text { arranged for } \\
\text { two pianos/ } \\
\text { four hands }\end{array}$ & 2001 & N. Friedman/ 2008 & $x$ \\
\hline
\end{tabular}

Del Aguila’s musical ideas are largely based on rhythm. Rhythmic ideas from Latin folk dances, especially Argentinian and Uruguayan dances, serve as great influences in his piano music. Repetitive figures, ostinato-like patterns, and short motives create musical drive and drama in the music. Syncopation, asymmetrical rhythmic grouping, shifting meters, irregular rhythm, and abrupt rhythmic changes are found throughout his compositions. In addition, rhythmic distortion (the shortening or lengthening of musical phrases by cutting or adding motives) is another distinctive quality of his music. It is very interesting that the length of the musical forms is created by the compilation of short motives, repetition, sequences and variations, which show the continuation of the compositional styles of Beethoven, Schumann, Bartok, Stravinsky and Ginastera. ${ }^{33}$

Del Aguila's music relies on tonal harmony. Tonal centers are found in all of his piano works. Chords are freely used between functional and non-functional harmonies with colorful

\footnotetext{
${ }^{33}$ Cheong, op. cit., 42.
} 
extended sevenths, ninths, eleventh chords, and augmented chords. Thick chords and clusters are used for climactic parts. Furthermore, much of his piano music uses his own unique scale, which will be discussed in detail in the third and fourth chapter.

Most of del Aguila’s piano pieces are character pieces. Sonata form, ABA form, and extended ABA form are the basic templates for his piano works. Some of his piano pieces bring back material from his former compositions; for instance, "Half of me” for Left hand (2000) took the theme from his "Nocturne” (1998). Romanticism is conveyed through moving expression, especially in the slower pieces, movements, and sections. In lively and fun pieces, del Aguila's compositional style also combines the styles of Latin American dances and the principles of classical form. It is interesting that excessive repetition of Latin American dance patterns in most of his piano music can lead many audiences think that his music is minimalistic. The integration of musical styles he employed for his piano music includes minimalism, along with Latin American folk dance styles, romanticism, nationalism, and jazz. In conclusion, there are many stylistic traits of del Aguila's music which could be considered postmodern. These traits include an aesthetic that accepts a diverse range of sounds, eclecticism, the reappraisal of consonance, and an innovative approach to tonality. ${ }^{34}$

\footnotetext{
${ }^{34}$ Jann Pasler, "Postmodernism," Grove Music Online. Oxford Music Online, Oxford University Press, accessed July 29, 2016, http://www.oxfordmusiconline.com/subscriber/article/grove/music/40721.
} 


\section{CHAPTER III \\ PUBLISHED PIANO WORKS}

Chapter Three examines four selected published piano works with Peermusic Classical: “Toccata”, Op. 23; Piano Sonata No. 2, Op. 29; Conga, Op. 39; and Piano Concerto, Op. 57. Each piece will be discussed according to its general characteristics, form, and pedagogical concerns. Pedagogical concerns will include significant elements in the piece such as melody, harmony, rhythm, dynamics, texture, etc.

\section{i) “Toccata”, Op. 23}

\section{Overview and General Characteristics}

This toccata was composed in 1988 and includes three versions for piano, harpsichord, and orchestra with different Op. numbers (Op. 23, Op. 27, Op. 28 and 28-A). The first version, Op. 23, for solo piano was premiered by the composer at Bösendorfersaal, Vienna. The length of piece is five minutes and thirty seconds. The second version, Op. 27, for harpsichord was premiered by Marinka Brecelj at Palais Wilhelminenhoff one year later in 1989 and recorded by KKM Vienna Records. The length is three minutes and thirty seconds. The third and fourth versions for are for orchestra (Op. 28 and Op. 28-A). Op. 28 was arranged for six percussionists, piano, and strings, and it was premiered in 1989 by the American Music Ensemble, Vienna, conducted by $\mathrm{H}$. Earl. The other version was arranged for three percussionists, piano, and strings and was premiered by the Cosmopolitan Symphony Orchestra at Town Hall New York City, conducted by Tania León in 1991. Miguel del Aguila expressed his emotional confusion through 
this composition after he found out that his close friend had been infected with HIV. ${ }^{35}$ This toccata is a virtuosic piece with perpetual motions, which is a common nineteenth-century concept. The significant composers of the nineteenth century who composed toccatas according to this concept are Carl Czerny (1791-1857) and Robert Schumann (1810-1856). The introduction section presents the theme in a lyrical blues style. This section was also inspired by the rhythms of Uruguayan candombe, a kind of fast African-Uruguayan dance accompanied by the candombe drum. ${ }^{36}$ Del Aguila provided some suggestions on how to play his toccata in his program notes: "In the Toccata, the performer uses his hands on the piano similar to the way the candombe drums player would play his instrument."37 The drama and intensity of the piece is based on the irregular rhythm (6/8 and 7/8) and increasing dynamic of the rhythmic ostinato, before falling down to extreme softness, which represents the farewell in the darkness and sadness at the end of the piece in the recitando. ${ }^{38}$

\section{$\underline{\text { Form }}$}

The structure of "Toccata” is divided into three sections; introduction, toccata, and coda (Table 3.1).

Table 3.1: Structure of “Toccata” as introduction-toccata-coda

\begin{tabular}{|l|l|l|}
\hline Introduction & Toccata & Coda \\
\hline Lento & Presto & Andante, Lento and Allegro \\
\hline mm. 1-15 & mm. 16-145 & mm. 146-159 \\
\hline
\end{tabular}

\footnotetext{
${ }^{35}$ Cheong, op. cit., 42.

${ }^{36}$ E-mail correspondence with Miguel del Aguila, March 23, 2016.

${ }^{37}$ E-mail correspondence with Miguel del Aguila, March 13, 2016.

${ }^{38}$ E-mail correspondence with Miguel del Aguila, March 23, 2016.
} 
The slow introduction (Lento), mm. 1-15, introduces the theme in E mixolydian which becomes the material for the entire piece (Figure 3.1.1). The end of this section is in E major, which is a dominant preparation for the toccata, presto.

Figure 3.1.1: Slow Introduction, mm. 1-14

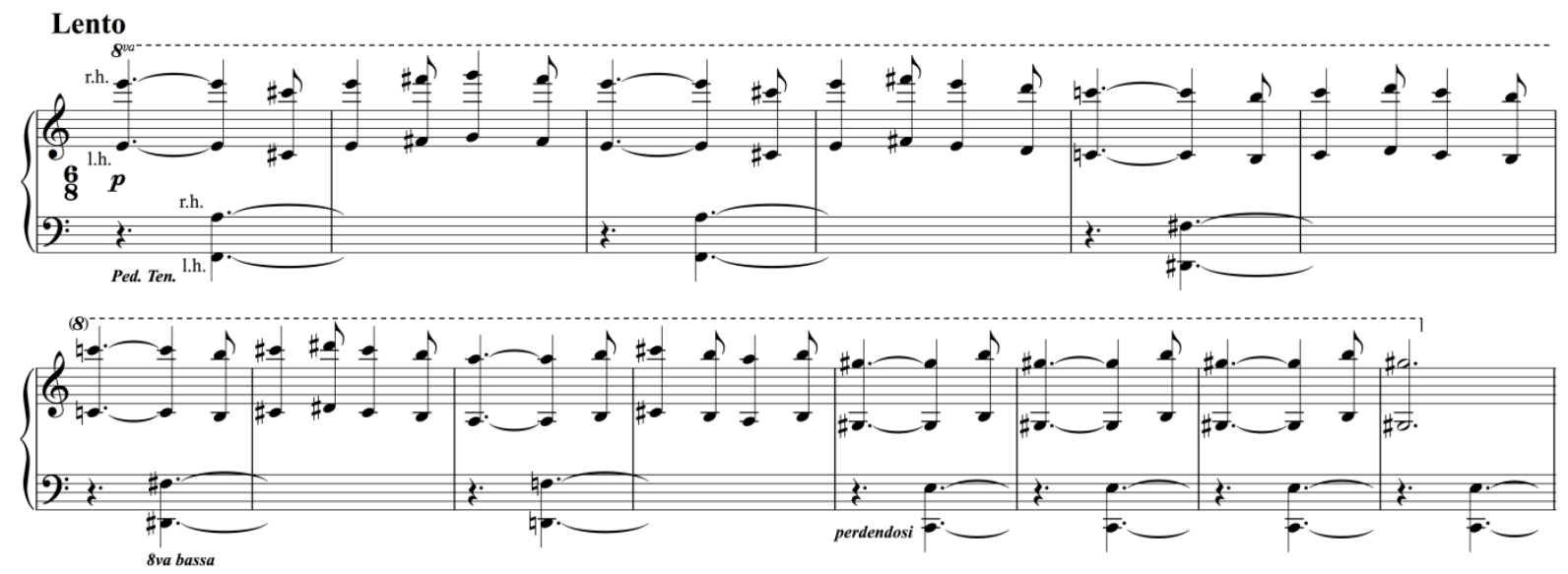

The next section, toccata (presto), mm. 16-145, is based on the theme from the slow introduction. The character takes on a percussive quality. The rhythm of this section alternates between 7/8 and 6/8. The Uruguayan candombe is presented in this section (Figure 3.1.2). Candombe is a dance and a song genre that developed from African cultures and originated in Montevideo, Uruguay. There are three types of rhythmic patterns of tambor (candombe drum): chico (high), repique (middle), and piano (bass). Del Aguila imitated all of the different rhythms of each tambor into both hands. Figure 3.1.3 shows the clave of candombe. This section presents the climax of the piece by using clusters in the left hand in mm. 44-46 (Figure 3.1.4).

Figure 3.1.2: Uruguayan candombe in “Toccata”, mm. 16-18

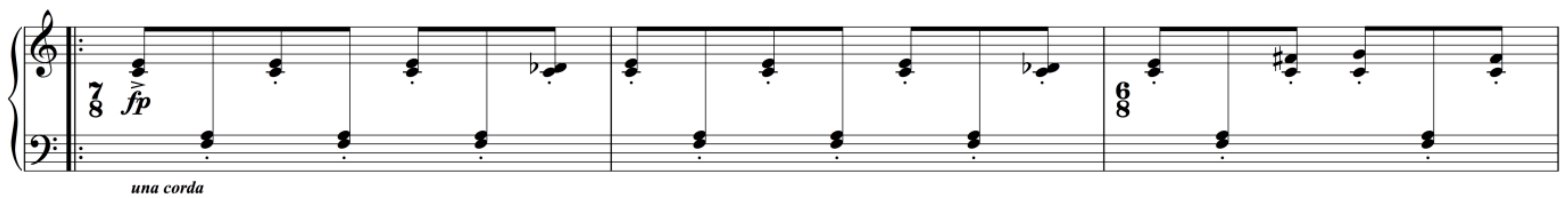


Figure 3.1.3: Candombe clave ${ }^{39}$

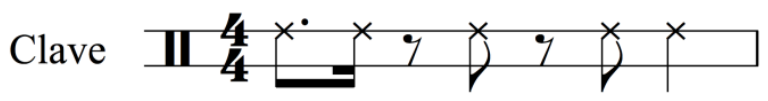

Figure 3.1.4: Left-hand clusters for climactic part, m. 143

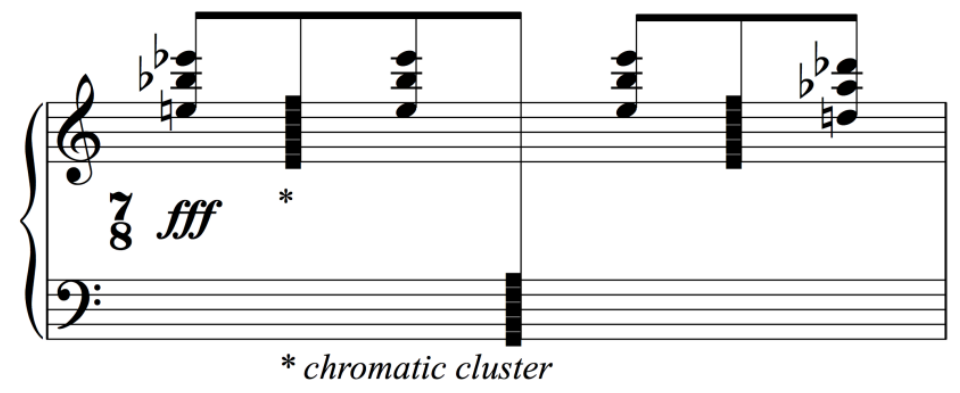

The coda, mm. 146-159, includes the recurrence of the theme, Andante, and the conclusion of this piece in Lento and Allegro.

\section{$\underline{\text { Pedagogical Concerns }}$}

\section{Melody and Articulation}

The introduction should be played with a dreamy atmosphere. The performer must consider shaping and phrasing in order to present the direction of melodies.

In the presto, the character dramatically changes to a percussive sonority similar to playing a candombe drum. Therefore, this section should be played with a short staccato articulation to create a crisp and active character. The melody appears in the top notes in the right hand. The performer should carefully bring out the upper notes in the right hand (Figure 3.1.5).

\footnotetext{
${ }^{39}$ Martín Rocamora, "Automatic Transciption and Analysis of Percussion Music, the Afro -Uruguayan Candombe Drumming as a Case Study: Candombe in Uruguayan Culture," accessed September 6, 2016, http://iie.fing.edu.uy/ rocamora/phdthesis/candombe.html.
} 
Figure 3.1.5: Top note melody in the right hand, m. 16-18

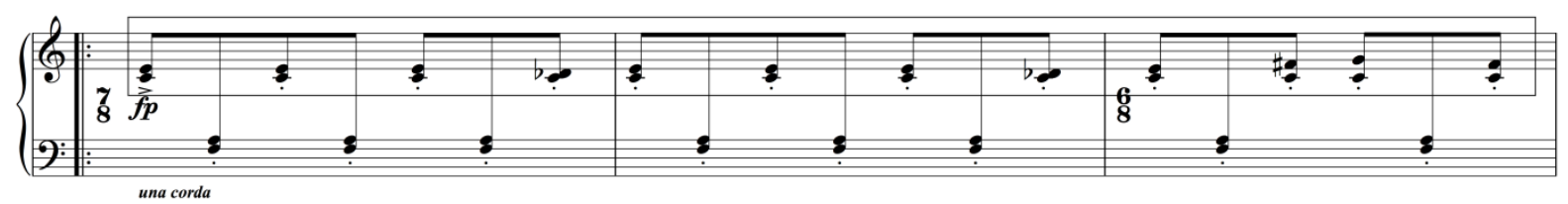

\section{Pedaling}

In the introduction, lento in mm. 1-15, Ped. Ten. is indicated in the score, which means that the performer should use one long sustain pedal to capture the resonance of the melodies in the upper register.

In the presto (mm. 16-146), una corda pedals are indicated in many places such as $\mathrm{m} .16$ and $\mathrm{m} .36$ to change color. The sustain pedal is barely used in presto except for the accent at the first beat of m. 16 and for the clusters to create intensity at the end of this section in mm. 143146 (Figure 3.1.6).

Figure 3.1.6: Using sustain pedal for cluster in the end of presto, mm. 143-146

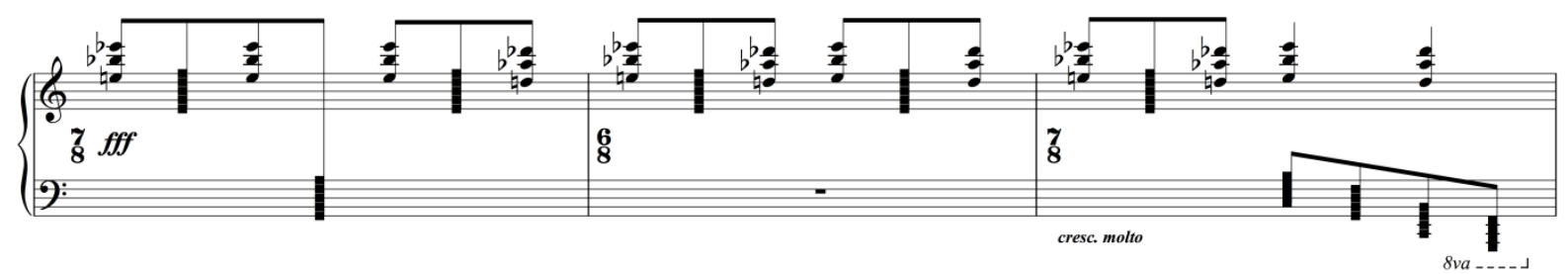

The return of the theme, andante (m. 145), uses pedal for glissando and also uses one long sustain pedal, like the introduction. In the lento, m. 157, del Aguila indicated the following in his score: (add ped. gradually). The performer should therefore play with deeper sustain pedals for the ten-time repetition of chords in order to accentuate the fff and create intensity; especially for the left hand long trill. 


\section{Rhythm and Tempo}

Rhythmic confusion can happen because of the alternation between $7 / 8$ and 6/8. It is better to practice very slowly in order to secure the memory and gradually speed up to the fast tempo. In the presto, pacing the tempo conservatively is a good strategy to increase the speed in the poco più mosso in m. 135.

\section{Dynamics}

The most important factor to create drama in this toccata is the dynamics. Wide ranges of dynamics appear from ppp to fff. In mm. 109-145, del Aguila wrote crescendo at the beginning of each line, which is a miniature version of the dynamic concept of the entire presto section, which reaches its climax at the end.

Another interesting point appears in $\mathrm{m} .157$ at the beginning of page 8 . The chords range in dynamics from $p$ crescendo to fff. The performer has to consider carefully how louds each chord should be played in order to make a smooth crescendo.

\section{Technique}

There are many technical challenges in this toccata. This toccata contains perpetual motion in series of intervals in both hands, which can cause wrist and arm fatigue. Therefore, relaxation of the arm and wrist while playing can help the performer avoid wrist and arm fatigue. For the climactic part in mm. 143-145, the performer can play the chromatic clusters by using his/her left lower arm. Performers who have big hands will find it easier to play this toccata because the piece requires a hand whose span can reach at least ninth. The left hand plays 
octaves with added ninths in mm. 119 and 121 (Figure 3.1.7). Another example is both hands playing tenths in mm. 147, 149, 151, 153 and 155 and ninths in m. 157 (Figure 3.1.8).

Figure 3.1.7: Octave with adding ninth in the left hand, m. 119

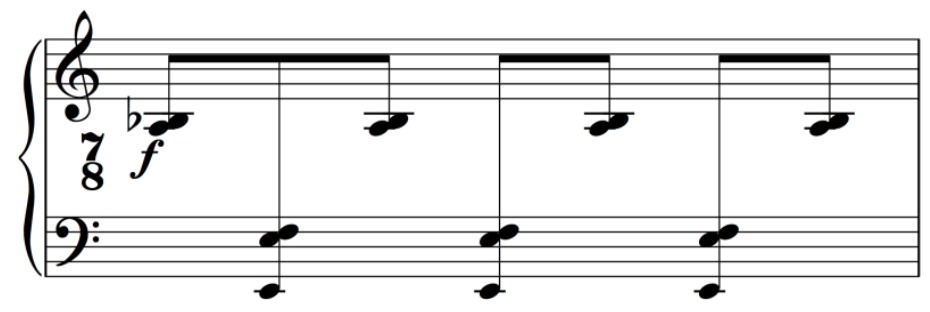

Figure 3.1.8: Tenth in both hand m. 147

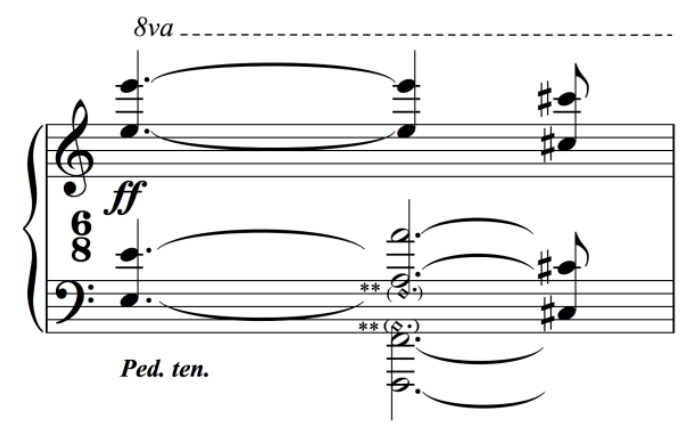

\section{Miscellaneous}

Finding the theme in the right hand, dividing it into many phrases and playing only the melody are vital strategies for memorizing this piece. Many of Del Aguila's piano pieces deal with wide registers and sometimes with high or low registers. Practicing for a long time in an unusual sitting position, such as twisting to the left or right side, can cause back pain and arm fatigue. For example, in mm. 62-118, both hands have to play in low register. To avoid injuries, moving the sitting position to the left side will reduce tension in the back and arm. 


\section{ii) Piano Sonata No. 2, Op. 29}

\section{Overview and General Characteristic}

Piano Sonata No. 2, Op. 29 was composed in 1988. Miguel del Aguila premiered this sonata at Carnegie Recital Hall in New York in $1989 .{ }^{40}$ The Piano Sonata No. 2 was dedicated to Jorge Basurto, del Aguila's friend who is a historian at National Autonomous University of Mexico (UNAM) ${ }^{41}$ This piano sonata was recorded by James Miltenberger, professor of piano at West Virginia University, on the CD album Piano Music of the Americas. ${ }^{42}$ The performance time is around fifteen minutes. ${ }^{43}$

The second sonata has three movements; I. Allegro, poco ritenuto, II. Lento, and III. Presto. The first movement relies on an irregular ostinato rhythm (11/16) in the left hand over which a gaucho song is played in the right hand ${ }^{44}$ Nicolas Slonimsky explained gaucho as "the wandering minstrel of the pampas, who roves the plains on horseback with his faithful guitar slung over his shoulder. The subject of the gaucho song is usually romantic love, but often these songs are ballades and narratives of personal adventure, similar to the cowboy songs of the North American West." ${ }^{45}$ The second movement was written in the style of slow blues. The second movement continues to the third movement without stopping. The third movement was written in the style of 1920s jazz, ragtime, and Caribbean dance. A sense of humor is presented with irregular rhythms which get faster and end with the unexpected fff forearm cluster. These themes

\footnotetext{
${ }^{40}$ Miguel del Aguila, "Program Notes", accessed September 22, 2016, http://www.migueldelaguila.com/programnotes.html.

${ }^{41}$ Miguel del Aguila, interview by Sornsuang Tangsinmonkong, , January 12, 2017, Camarillo, CA.

42 James Miltenberger, Piano Music of the Americas, ACA Digital Recording CM 20021, 1993, CD.

${ }^{43}$ Miguel del Aguila, "Work by Instrumentation, Buy/Rent Music," accessed September 22, 2016, http://www.migueldelaguila.com/works-buy-rent.html.

$\frac{{ }_{44}}{E}$ E-mail correspondence with Miguel del Aguila, March 23, 2016.

${ }^{45}$ Slonimsky, op. cit., 282.
} 
became material for other compositions of del Aguila, such as his String Quartet no. 2 (1988) and his Presto $I I .{ }^{46}$

The style of Sonata No. 2 presents a wonderful mixture between classical and popular music. This sonata, with its combination of a classical music genre and popular music idioms from jazz, ragtime, and Uruguayan and Caribbean dance, can appeal to a wide audience.

\section{$\underline{\text { Form }}$}

\section{First movement}

This sonata follows a nineteenth-century trend in sonata composition which brings apotheosis to the last movement. The first movement is in irregular sonata-allegro form. Unlike the traditional sonata-allegro form, which has two themes, this sonata has only one theme. Other monothematic piano sonatas include some of Franz Joseph Haydn’s (1732-1809) piano sonatas; for instance, Piano Sonata in C Major, Hob. XVI: 50, L. 60.

The character of the first movement of del Aguila's sonata is very unusual due to the fact that the whole movement is based on an ostinato pattern (Figure 3.2.1). From m. 43, the ostinato is altered its variation in sixteenth notes (Figure 3.2.2).

Figure 3.2.1 : Left-hand ostinato mm. 1-2

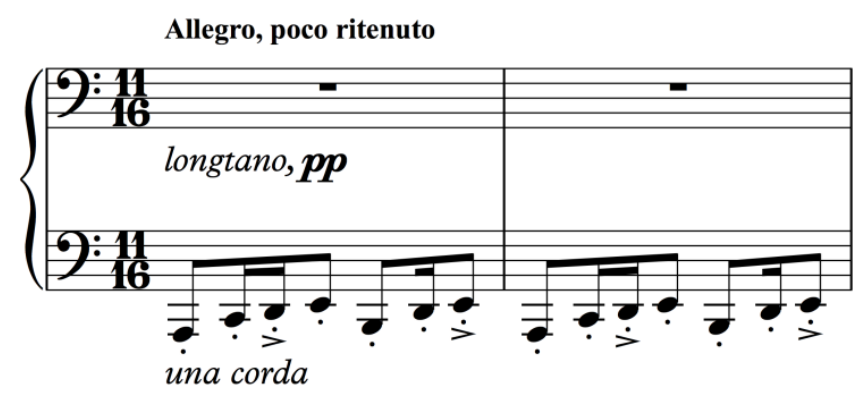

\footnotetext{
${ }^{46}$ Miguel del Aguila, "Program Notes," accessed December 5, 2016, http://www.migueldelaguila.com/otherworks.html.
} 
Figure 3.2.2: Variation of left-hand ostinato, m. 43

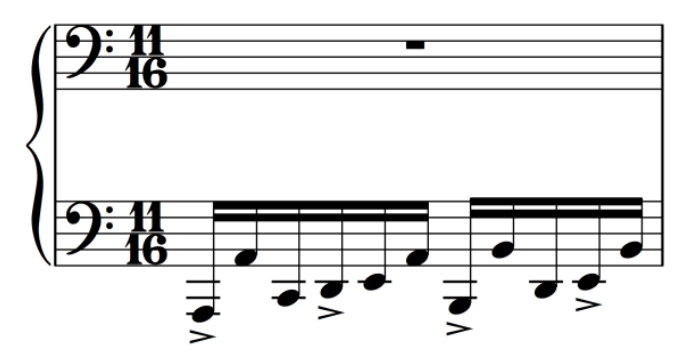

The exposition, mm. 1-66 (66 bars), has one theme which consists of two different ideas:

a1 and a2. The a1 idea is a series of augmented chords in mm. 3-6 which creates a sense of uncertainty and mystery (Figure 3.2.3) before a fragment of the a2 theme appears in the lower register in mm. 10, 15 and 18-19 (Figure 3.2.4). The complete a2 is presented in mm. 21-24, which is the gaucho song (Figure 3.2.5). The entire opening is in A minor which was established by the ostinato.

Figure 3.2.3: a1 idea: series of augmented chords, mm. 3-6

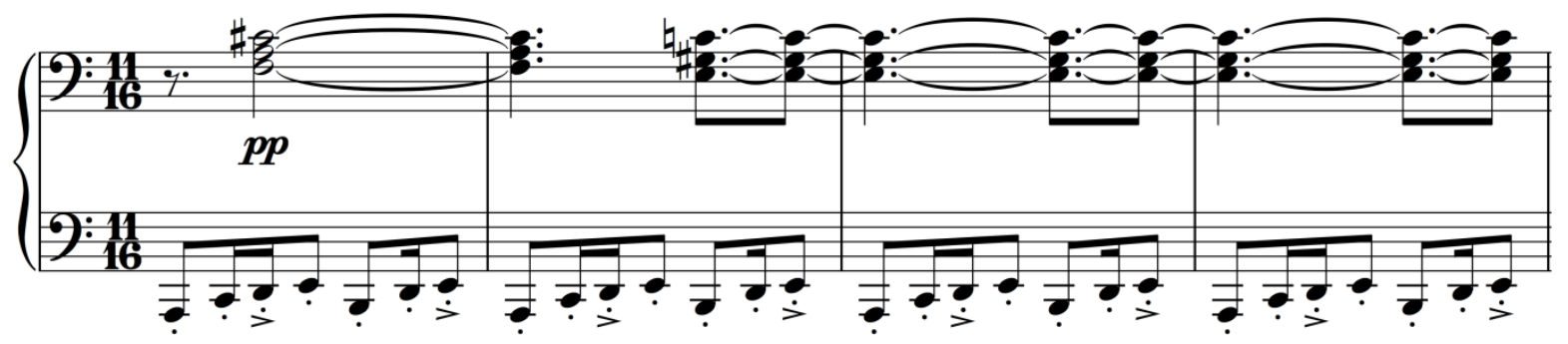

Figure 3.2.4: Fragment of a2, mm. 10

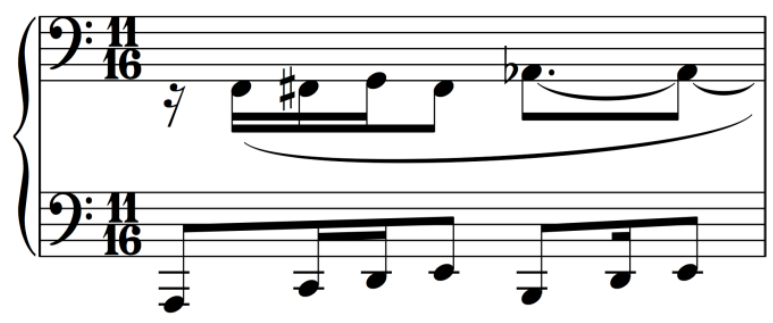


Figure 3.2.5: Complete a2 idea, mm. 21-24

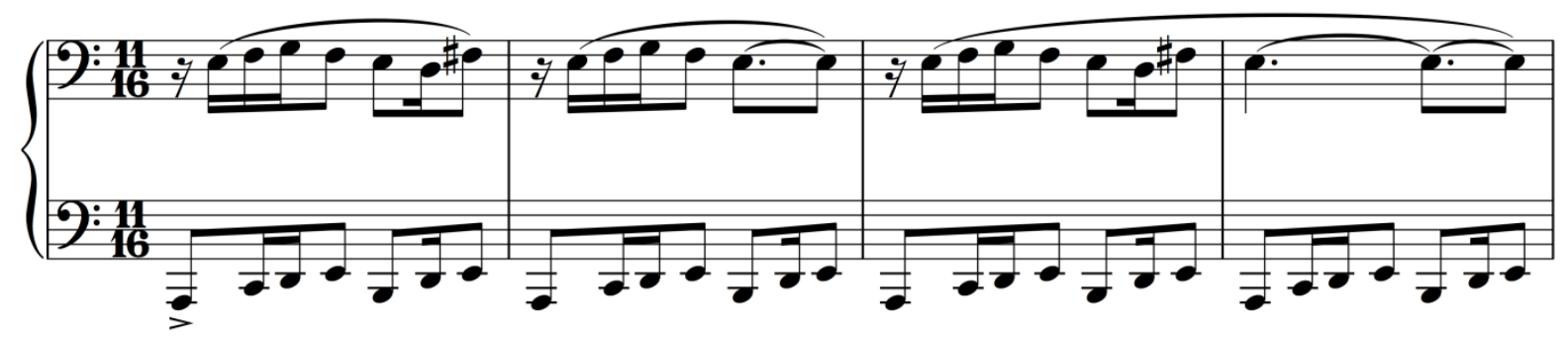

The sequence of the ostinato and its inversion in mm. 55-66 act as a transition starting in A minor and modulating to D minor (Figure 3.2.6).

Figure 3.2.6: Transition, mm. 55-57

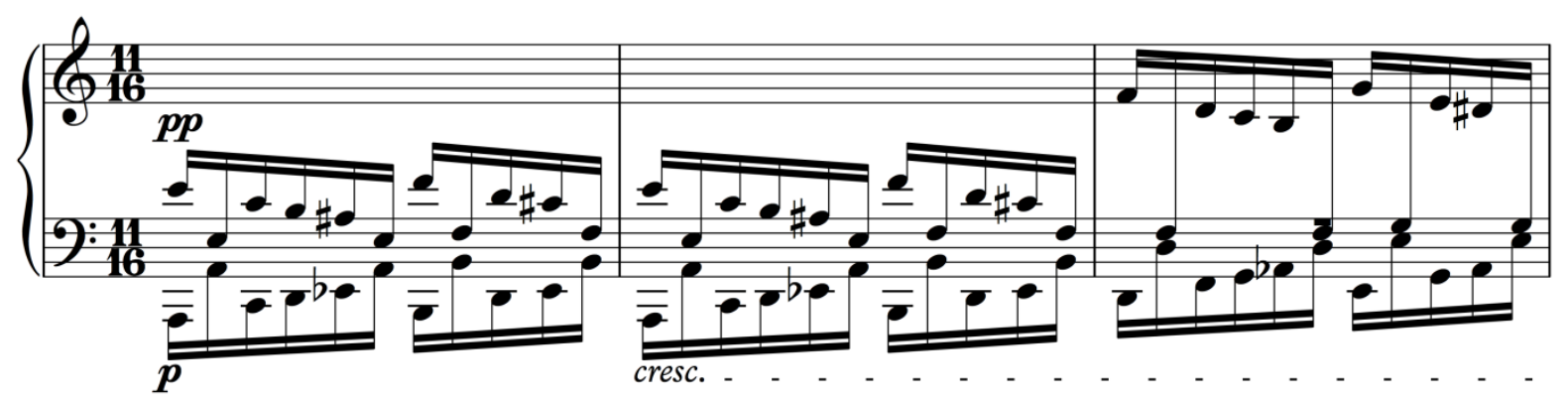

The development section is found in mm. 67-143 (77 bars). It starts with the a2 idea in D minor (Figure 3.2.7). In mm. 73-74, 86-87 and 90-91, the left hand presents the opening ostinato in octaves in E-flat major and A-flat minor while the right hand becomes the accompaniment which presents the new Figure 3.2. (Figure 3.2.8). Later, the material from the transition comes back at the end of the development section (Figure 3.2.9).

Figure 3.2.7: Development section starting with a2, mm. 67-68

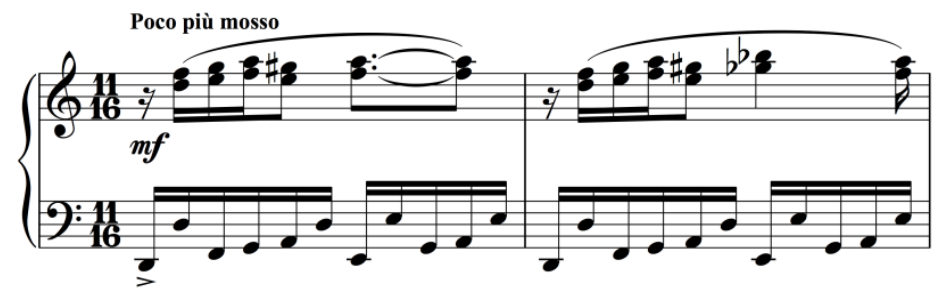


Figure 3.2.8: New figure in the right hand as accompaniment, mm. 73-74

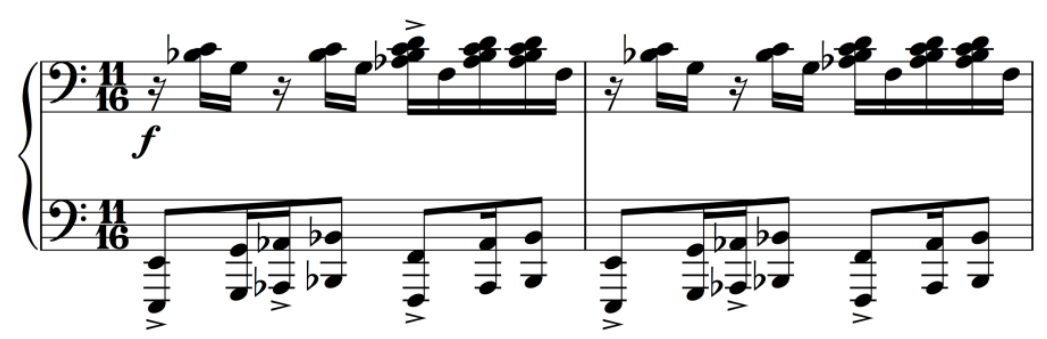

Figure 3.2.9: Material from transition in development section, mm. 95-96

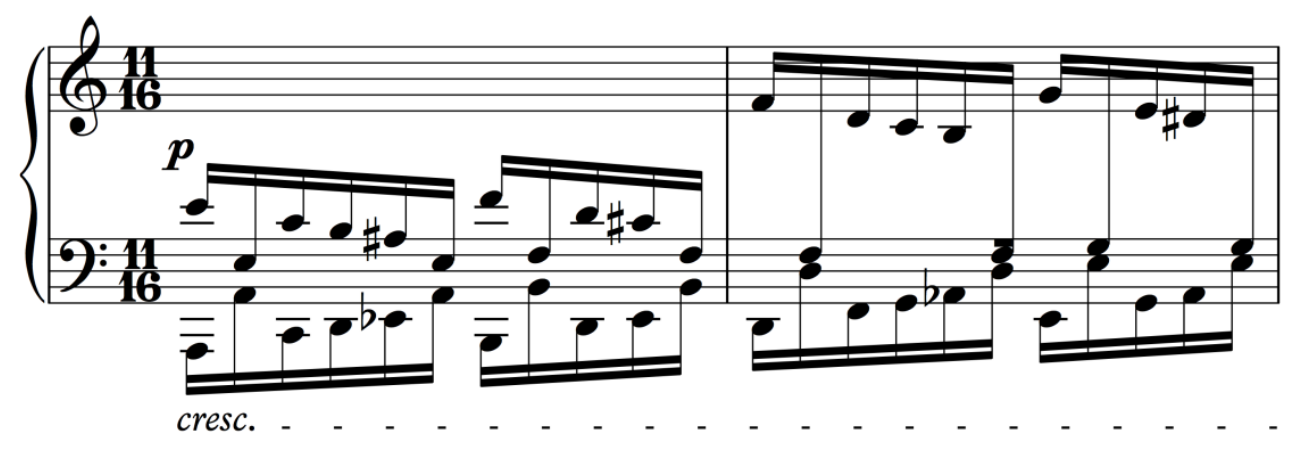

The recapitulation starts with a1 from m. 144 to m. 213 (70 bars) in D minor. This seems to be a false recapitulation because it is not in the tonic key (Figure 3.2.10). However, upon closer examination one finds that it is the real recapitulation because the a1 idea does not appear again.

Figure 3.2.10: Recapitulation in D, m. 145-147

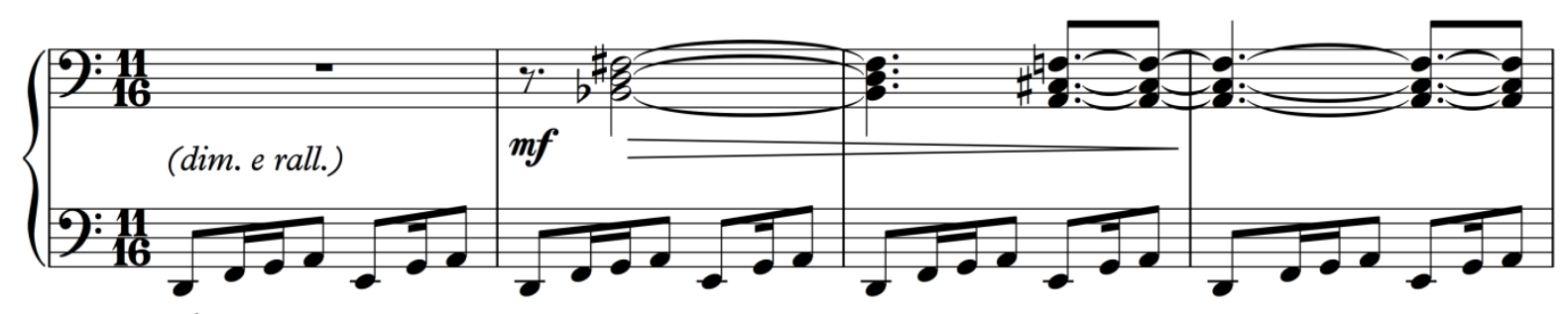

$8 v b$

The transition reappears in mm. 160-167 and uses the sequence of the ostinato and its inversion (Figure 3.2.11). 
Figure 3.2.11: Transition mm. 160-161

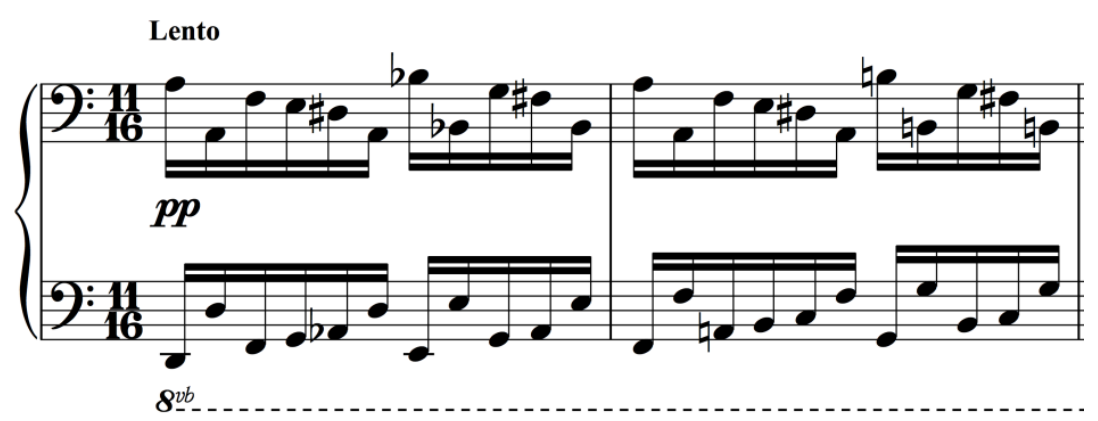

The closing theme consists of two ideas; a fanfare-like idea and the a2 idea. The fanfarelike idea is presented with a thick, blocked chord (Figure 3.2.12). The a2 idea is presented in a lower register below the left-hand ostinato (Figure 3.2.13). Both ideas interact as a dialogue.

Figure 3.2.12: Fanfare-like chords in the closing theme, m. 168

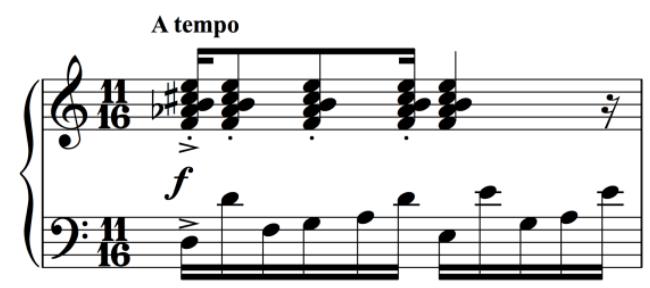

Figure 3.2.13: a2 in the closing theme, mm. 170-171

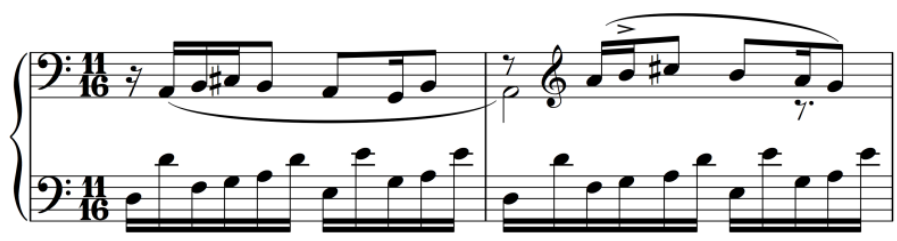

The coda, mm. 182-213 (31 bars), starts with a variation of the ostinato's inversion

(Figure 3.2.14) and continues with fanfare-like chords from the closing theme and a2.

Figure 3.2.14: Starting of coda, mm. 182-213

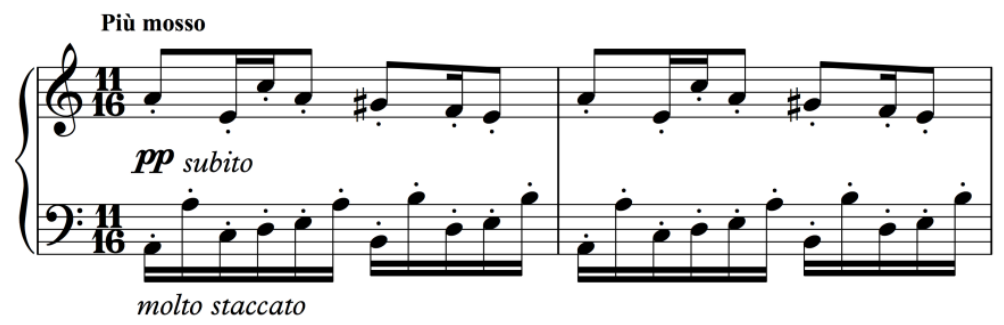


The climax of this movement occurs at the end of the movement. The proportions of each section are almost equal; the exposition has 66 bars, development section has 77 bars and recapitulation has 70 bars. A summary of the first movement structure is presented in Table 3.2.1.

Table 3.2.1: First movement structure

\begin{tabular}{|l|l|l|l|}
\hline Sections & $\begin{array}{l}\text { Tonal } \\
\text { Center }\end{array}$ & \\
\hline \multirow{2}{*}{ Exposition } & a1 and a2 & A minor & $1-54$ \\
\cline { 2 - 2 } & Transition & & $52-66$ \\
\hline \multirow{3}{*}{ Development } & a1 & D minor & $67-72$ \\
\cline { 2 - 2 } & New theme in E-flat major and A-flat major & & $73-94$ \\
\cline { 2 - 2 } & Transition & & $95-143$ \\
\hline \multirow{2}{*}{ Recapitulation } & a1 & & $144-159$ \\
\cline { 2 - 2 } & Transition & & $160-167$ \\
\cline { 2 - 2 } & Closing theme; fanfare-like chords and a2 & & $168-181$ \\
\hline \multirow{2}{*}{ Coda } & $\begin{array}{l}\text { The variation of ostinato's inversion, fanfare-like } \\
\text { chords and a2 }\end{array}$ & A minor & $182-213$ \\
\hline
\end{tabular}

\section{Second movement}

The form of the second movement is ternary, or ABA', which is similar to the traditional form of the second movement of a sonata (Table 3.2.2): A, mm. 1-51; B, mm. 52-86; and A', mm. 87-115. The second movement begins with a guitar-like melody and open-string texture which is very similar to the third movement of Ginastera's Sonata No. 1 (Figure 3.2.15). ${ }^{47}$ The melody of the main theme is built on a tritone.

Table 3.2.2: Second movement structure

\begin{tabular}{|l|l|l|}
\hline A & B & A' $^{\prime}$ \\
\hline mm. 1-51 & mm. 52-86 & mm. 87-115 \\
\hline
\end{tabular}

\footnotetext{
${ }^{47}$ Cheong, op. cit., 51.
} 
Figure 3.2.15: (1) guitar-like melody and open-string texture in del Aguila's second movement, Sonata No. 2, mm. 1-8; (2) third movement of Ginastera’s Sonata No. 1, mm. 1-7

(1) del Aguila’s second movement from Sonata No. 2
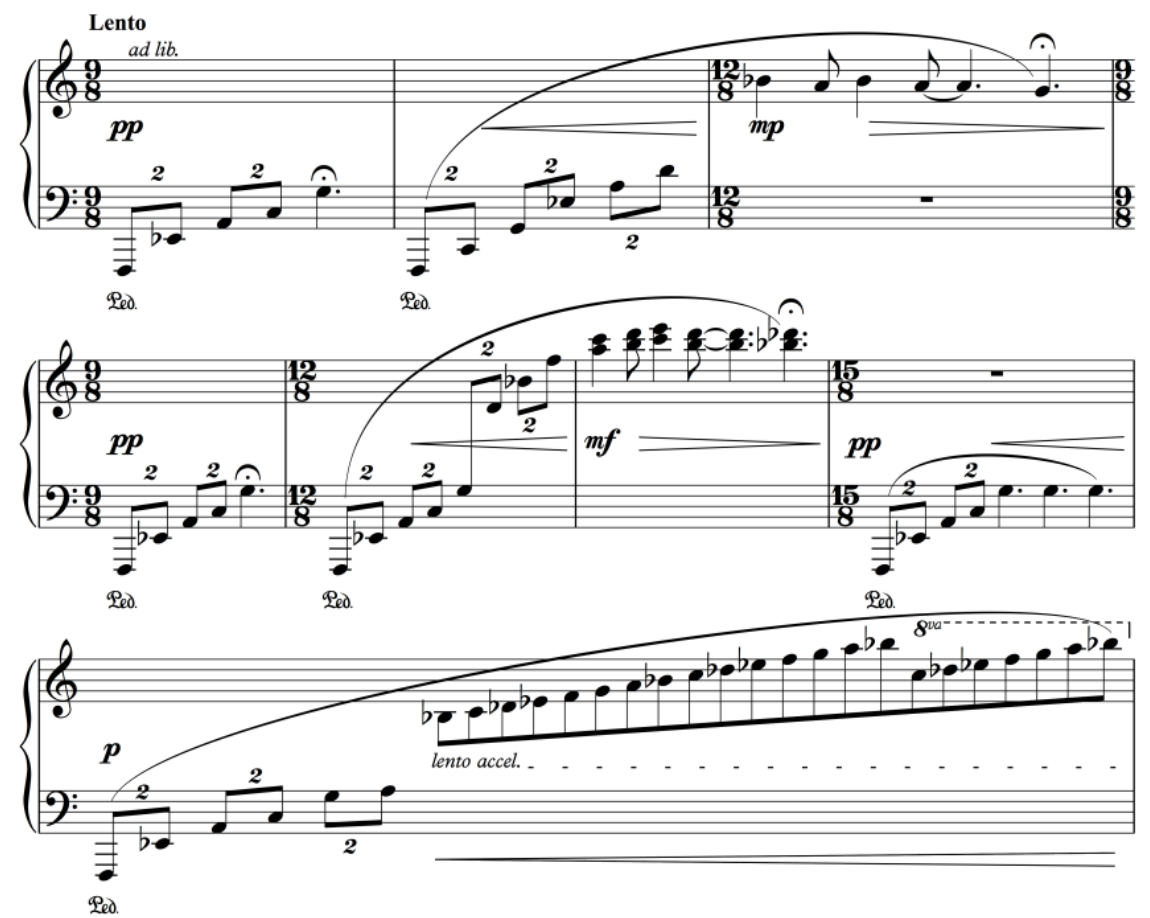

(2) The third movement from Ginastera’s Piano Sonata No. 1, Op. 22

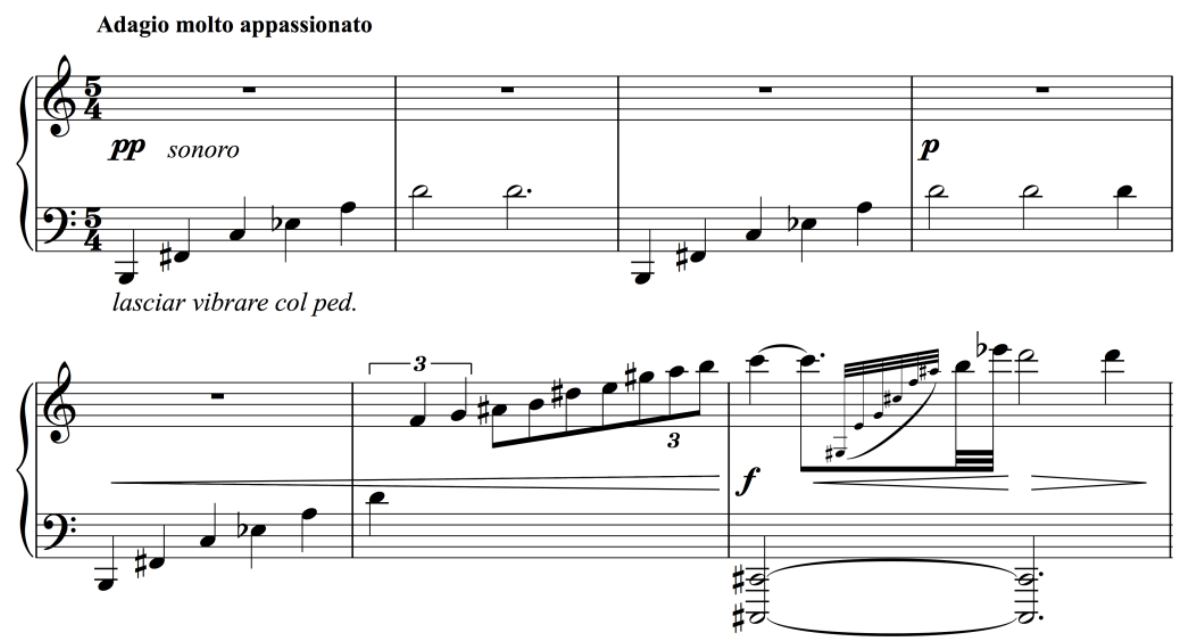

Piano Sonata No. 1, Op. 22 by Alberto Ginastera

(C) 1954, 1982 by Boosey \& Hawkes, Inc., Copyright Renewed.

Reprinted by Permission of Boosey \& Hawkes, Inc. 
The B-flat melodic scale passage is similar to the opening scale passage in the clarinet of George Gershwin’s (1898-1937) Rhapsody in Blue, m. 1-2 (Figure 3.2.16).

Figure 3.2.16: B-flat melodic scale passage of del Aguila’s second movement, Sonata No. 2, m 8

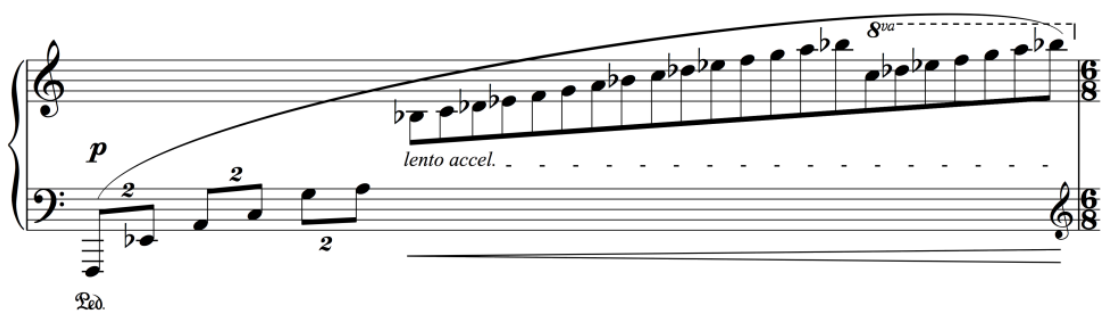

The main theme is similar to the melodic line in the opening of Gershwin's Prelude No.

2, mm. 4-8 (Figure 3.2.17).

Figure 3.2.17: Main theme of del Aguila’s second movement, Sonata No. 2, mm. 22-29
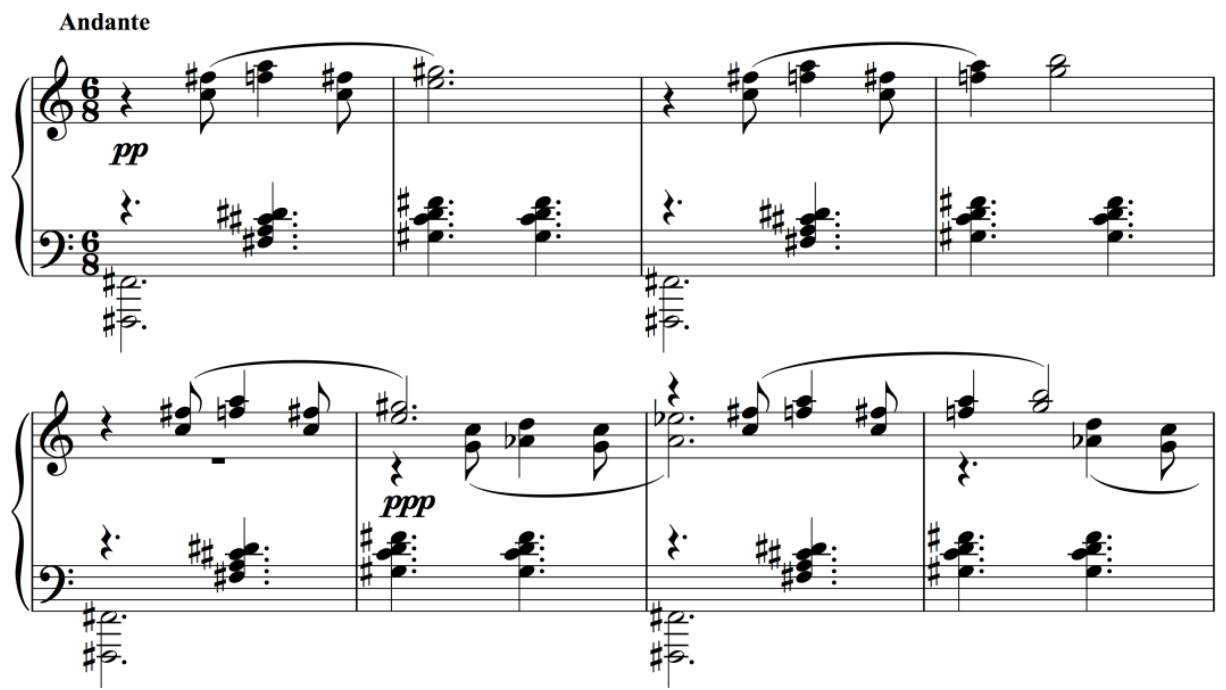

The series of tritone intervals in the melodies create a dark sonority. The melodies reveal a significant influence from Gershwin’s “Prelude No. 2”. However, unlike Gershwin, del Aguila employed a two-voice texture as a conversation between the soprano and alto lines in mm. 26-40 (Figure 3.2.18). 
Figure 3.2.18: Conversation between soprano and alto, mm. 26-29

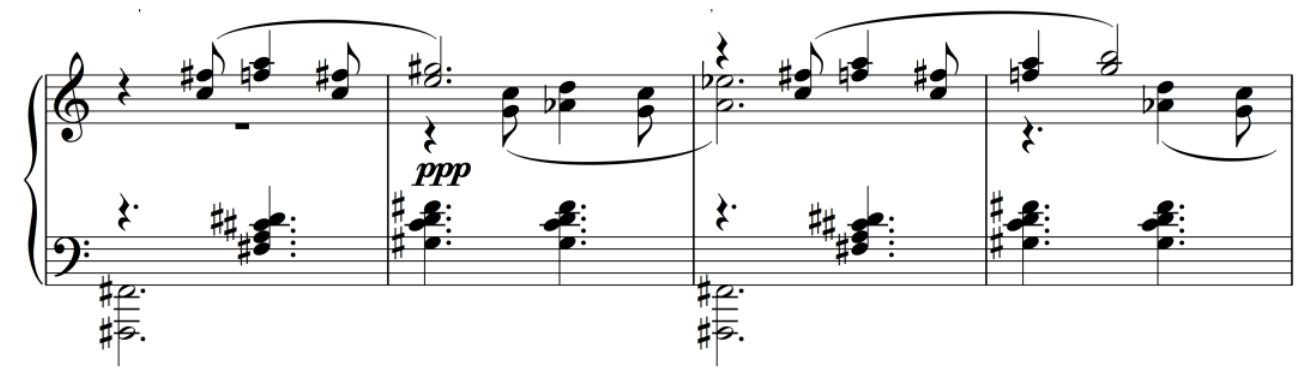

In the B section, mm. 52-86, there is a three-line conversation with a block chord accompaniment. In this conversation, the soprano continues the main melody and engages in a discussion with the alto and the bass (Figure 3.2.19). The conversation gradually builds up in intensity to the climax at the end of B section in m. 86 (Figure 3.2.20).

Figure 3.2.19: B section, mm. 52-56

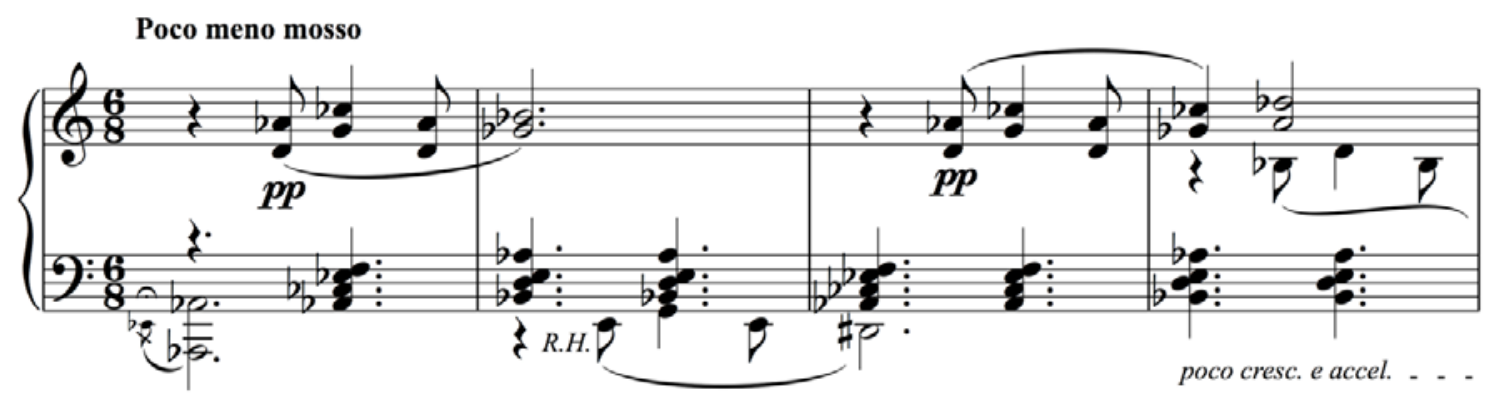

Figure 3.2.20: The climax at the end of B section, mm. 84-86

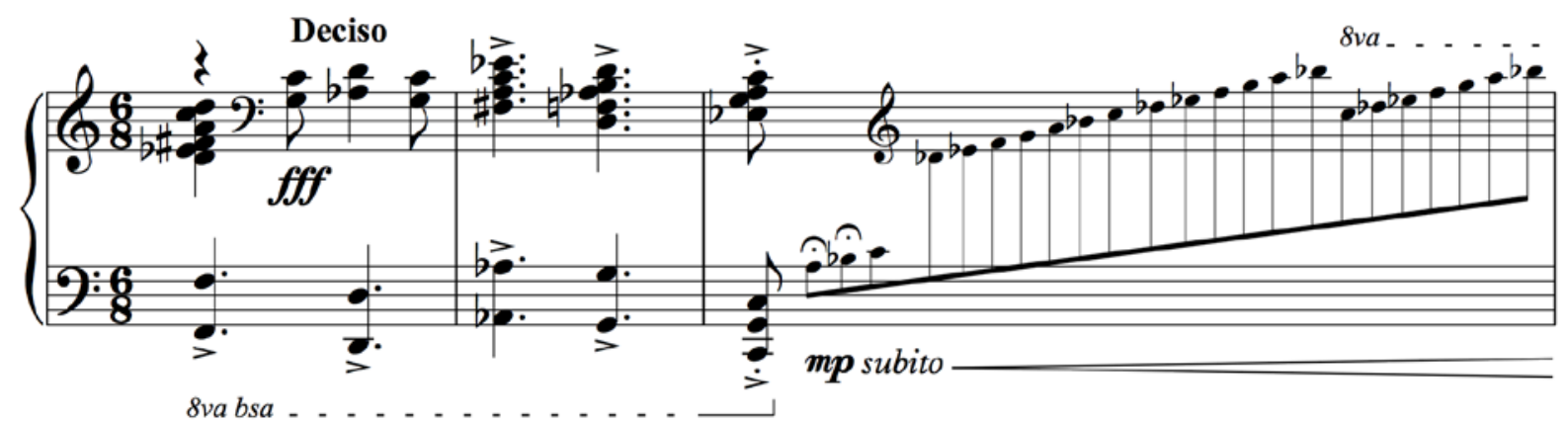

The A' section returns in mm. 87-115 with a thinner texture and ends the second movement quietly. There is an attacca at the end which connects this movement to the energetic third movement without stopping. 


\section{Third movement}

The form of the third movement is unusual. When one considers the form through the lens of tonality, this movement can be divided into two sections: AB and coda (Table 3.2.3). In the A section, there are two main themes which have their tonal center in $\mathrm{C}$ major; the first theme (mm. 1-7) in 4/4 is in style of 1920s jazz and ragtime, while the second theme (mm. 8-36) has irregular time signatures of 13/16, 15/16, 17/16, and 18/16 characteristic of Caribbean dance (Figure 3.2.21 and 3.3.22). The transition continues using material from the second theme. The first transition (mm. 29-38) modulates back to the first theme, which is in C major (Figure 3.2.23). The second transition (mm. 76-87) modulates to the B section in A minor (Figure 3.2.24). In the B section (mm. 88-127) with the repeat sign, the tonal center moves to A minor. Most of the B section is dominated by the $2^{\text {nd }}$ theme except mm. 116-119 and mm. 126-127, where there is a variation of the first theme in chords. The coda in mm. 128-145 serves as the climax of the piece and the movement ends with chromatic forearm clusters.

Table 3.2.3: Structure of the third movement

\begin{tabular}{|c|c|c|c|}
\hline \multicolumn{2}{|c|}{ Sections } & Tonal & mm. \\
\hline \multirow[t]{6}{*}{ A } & $1^{\text {st }}$ theme $(4 / 4)$ & \multirow[t]{6}{*}{ C major } & $1-7$ \\
\hline & $2^{\text {nd }}$ theme $(13 / 16,15 / 16,17 / 16$ and $18 / 16)$ & & $8-36$ \\
\hline & Transition & & $29-38$ \\
\hline & $1^{\mathrm{st}}$ theme & & $39-54$ \\
\hline & $2^{\text {nd }}$ theme & & $55-81$ \\
\hline & Transition & & $76-87$ \\
\hline B & $\begin{array}{l}\text { Material from } 2^{\text {nd }} \text { theme and variation form the } 1^{\text {st }} \text { theme } \\
\text { (with repeats) }\end{array}$ & A minor & $88-127$ \\
\hline Coda & & & $128-145$ \\
\hline
\end{tabular}


Figure 3.2.21: First theme, mm. 1-2

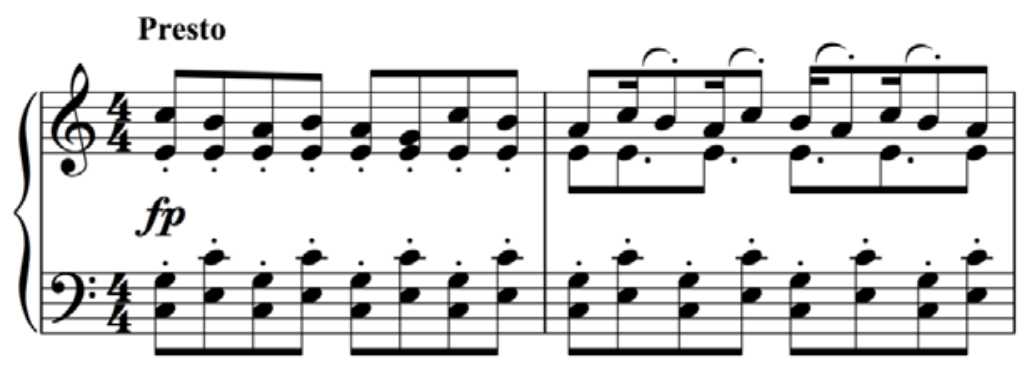

Figure 3.2.22: Second theme, the Caribbean dance rhythm mm. 8-12
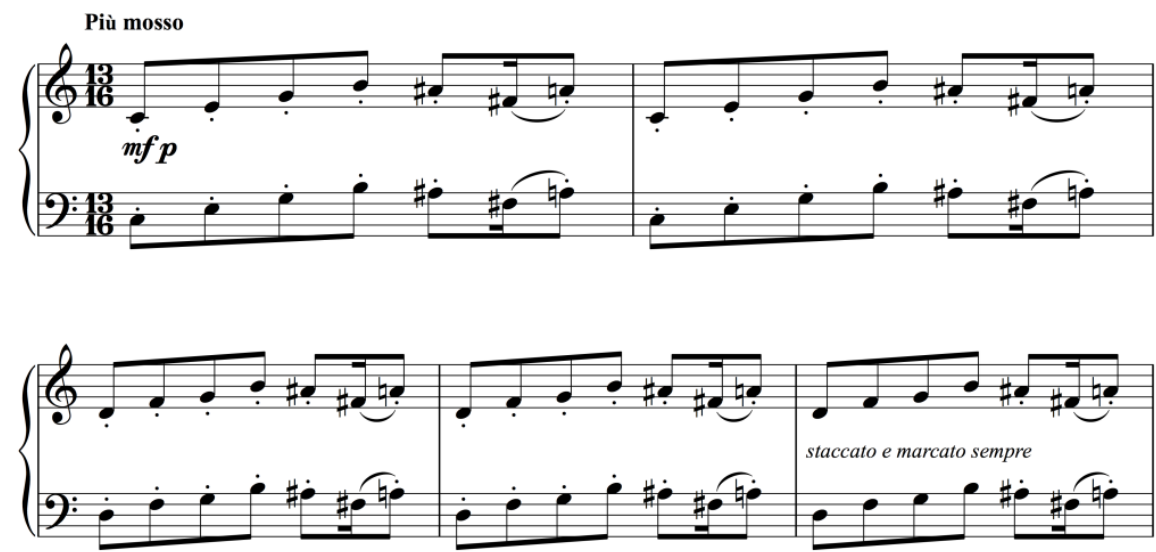

Figure 3.2.23: The first transition, mm. 29-38
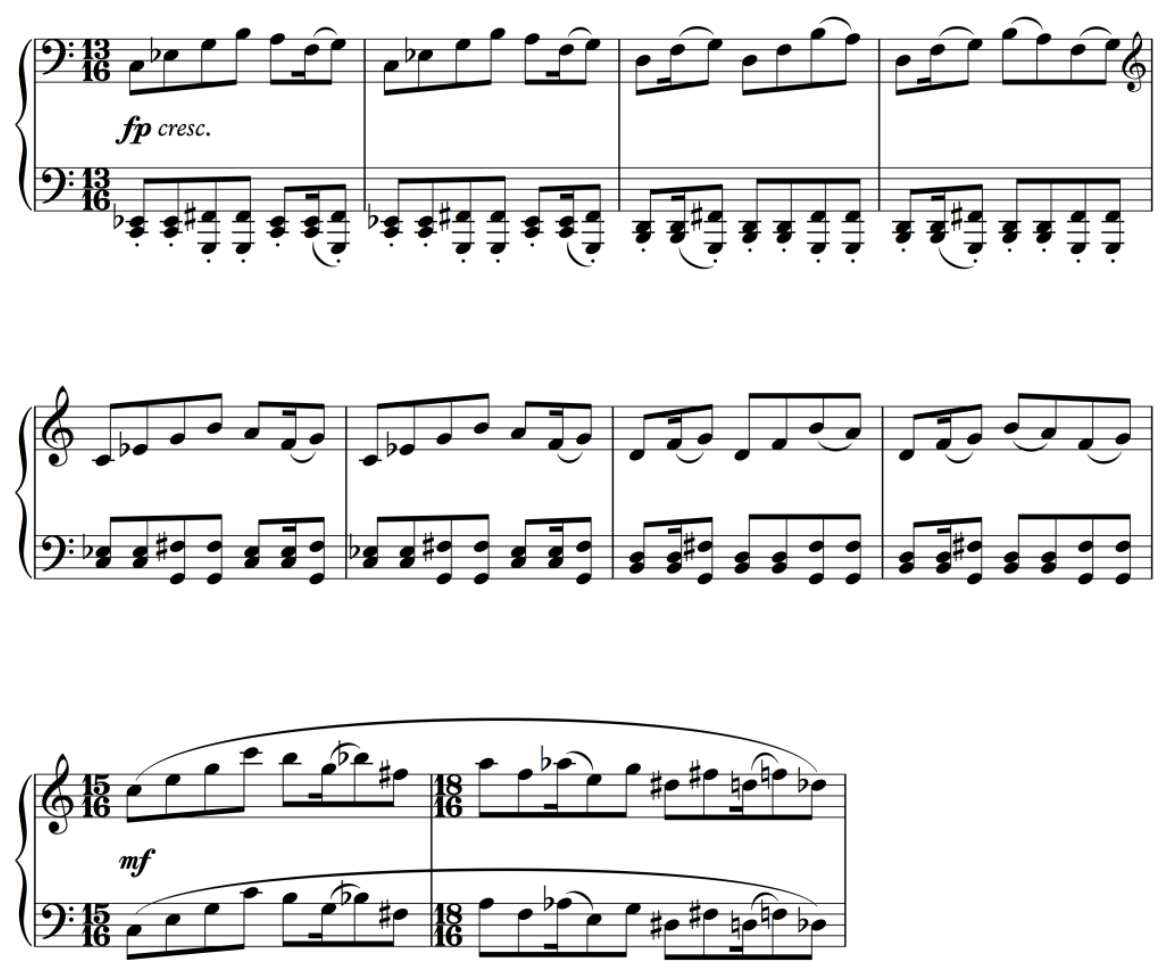
Figure 3.2.24: The second transition, mm. 76-87
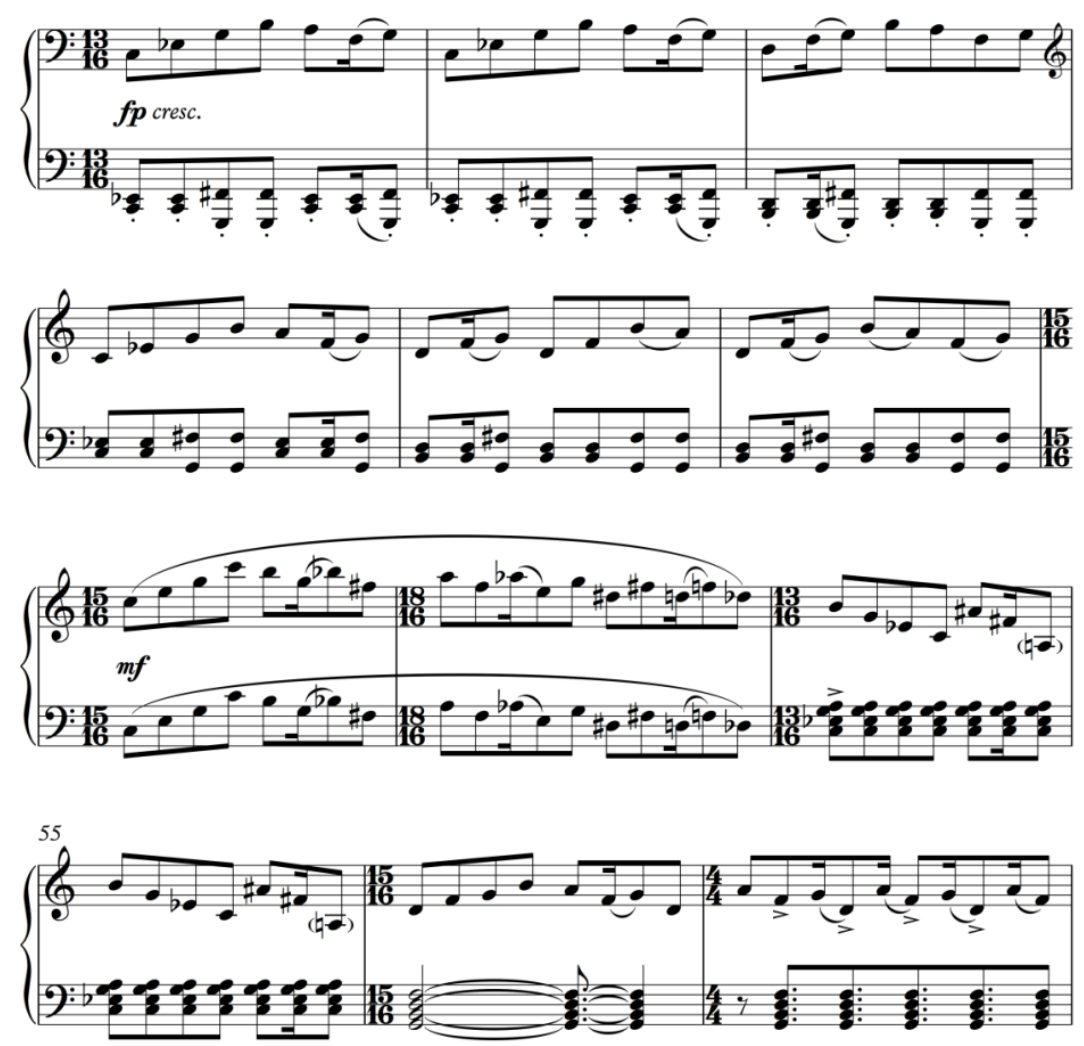

\section{$\underline{\text { Pedagogical Concerns }}$}

When compared to other sonatas of the twentieth century, the notation of Piano Sonata No.2 is straight forward and easy to read. Nevertheless, this piece is only suitable for advanced students, rather than intermediate students, due to the frequent motive repetitions and the gradual change of the melodic lines, which are difficult to memorize. In addition, students can get confused from irregular rhythms and frequent rhythmic changes. The pedagogical aspects of each movement of Sonata No. 2 will be discussed separately. There are also some notation errors which will be presented in the Appendix I of this document. 


\section{First Movement}

\section{Melody, Texture and Range}

The melodies of the first movement consist of short motives and conjunct series of major thirds which are based on five notes: E-F-G-E-D-F\# (Figure 3.2.25). Variations of these melodies can be found throughout this movement. Conversations between two counter melodies appear in some sections. The melodies start from a low register in the bass clef, which may show the darkness in the gaucho song, and climbs up to the middle range in the development section. The drama of this movement is built up by a thicker texture in the left hand in the development section. In the coda, the left-hand tremolo (mm. 202-209) in the lower register leads to a decisive ending (Figure 3.2.26).

Figure 3.2.25: Five-note melodies in the first movement melody, mm. 21-24

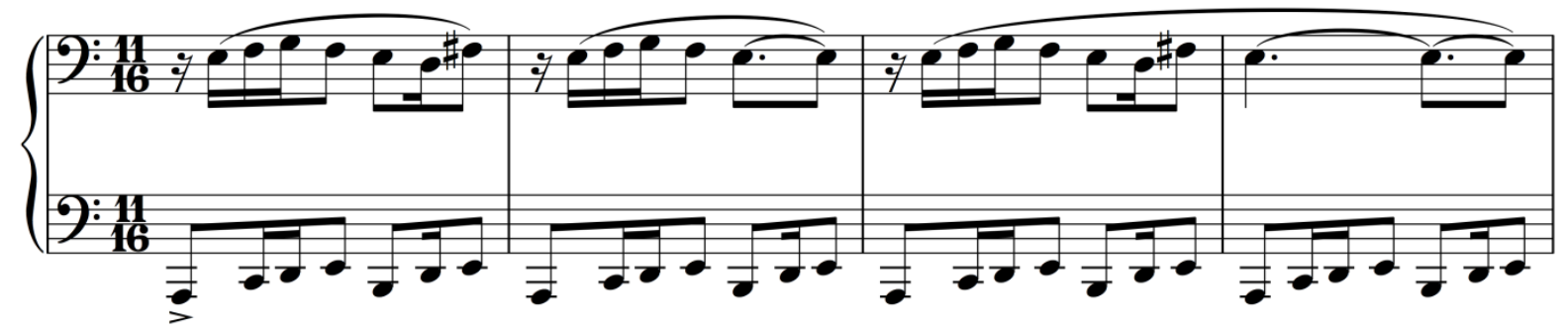

Figure 3.2.26: Changing texture in the left hand from sixteen-note accompaniment to tremolo

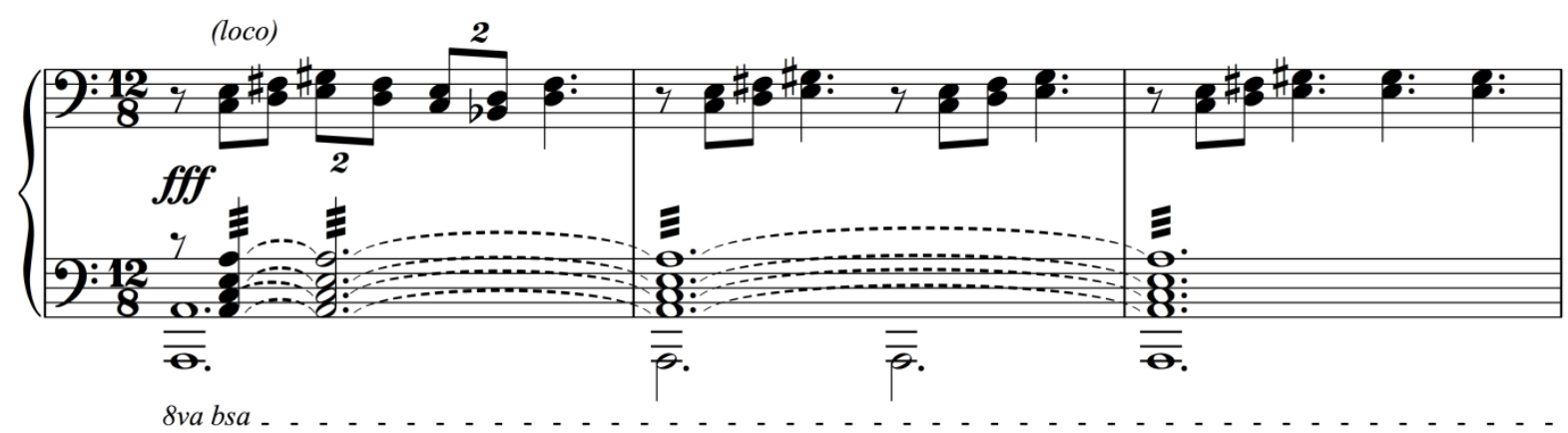




\section{Articulation}

In general, articulations are rarely specified in the first movement. Thus, the performer has the freedom to add articulations in many places where they are not indicated. For example, the variation of the left-hand ostinato figures can be played all legato, all staccato, or slur at the first two sixteenth notes in beats 1-2 and 7-8, while the others play staccato (Figure 3.2.27). However, del Aguila preferred the performer to play with shorter articulations. ${ }^{48}$

Figure 3.2.27: Variation of the left hand ostinato figures (1) legato, (2) staccato and (3) slur and staccato

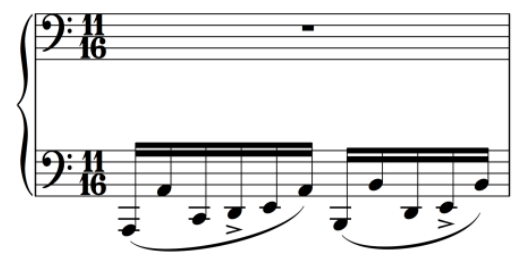

(2)

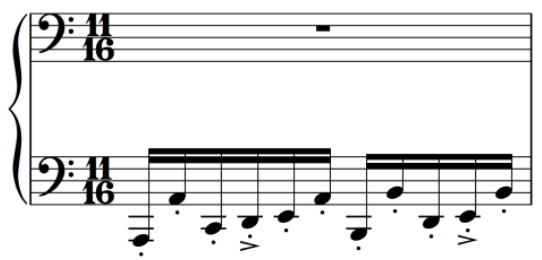

(3)

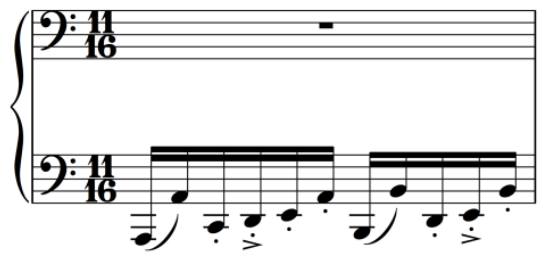

\section{Rhythm and Tempo}

It is easy for students to get confused when they are counting 11/16 while practicing, especially when playing both hands together. To fix this problem, the performer should divide the rhythm into 6+5 and practice slowly until he/she can play correctly. The tempo indication at the beginning of the first movement is allegro, poco ritenuto. There are many places that change to faster and slower tempos in the latter part. Markings such as più mosso, poco più mosso, accelerando, rallentando and lento appear. Therefore, choosing the right tempo is very important for a successful performance of this piece. The performer will struggle if he/she starts too

\footnotetext{
${ }^{48}$ Miguel del Aguila, interview by Sornsuang Tangsinmonkong, January 12, 2017, Camarillo, CA.
} 
quickly, because there is no room to speed up and it is very difficult to make clear articulations in the latter parts.

\section{Direction, Phrasing, Shaping and Dynamics}

Due to the fact that the first movement is dominated by the left hand ostinato, good plans of direction, phrasing, and shaping will control the musical flow and create momentum and expression. In some sections, the direction is guided by the musical terms, like dim. e rall. in mm. 137-159 and molto cresc. e accel. in mm. 160-166.

\section{Pedaling}

To create a crisp, active character for the left-hand ostinato, the pedal should be used only rarely. Exception might nr for forte dynamics, big chords, accents, and climactic sections. There are many places where a pianist should use the sostenuto pedal; for example, in mm. 38, 42, 171, and $174-175$, the right hand has to play the melody in both the soprano and alto lines together. The best way to accomplish this is by using sostenuto pedal to hold the melodies of the soprano line while playing the alto line. This will not blur the articulation of left-hand ostinato (Figure 3.2.28). In case the sostenuto pedal does not work on some pianos, using a very shallow sustain pedal can hold the sound without too much blurring in the left hand. ${ }^{49}$

\footnotetext{
${ }^{49}$ In a masterclass with Miguel del Aguila on January 12, 2017, he said that he preferred using sustain pedal.
} 
Figure 3.2.28: Using sostenuto pedal after the first beat of $\mathrm{m}$. 39 to catch the melody in soprano line while jumping to alto line, mm. 38-39

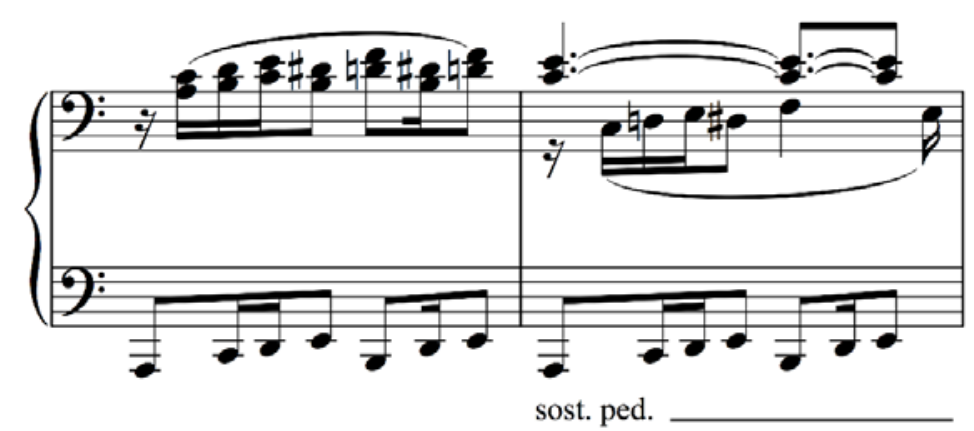

\section{Techniques}

The first movement relies on left-hand piano techniques such as bass melody, left-hand ostinato, chords, and octaves. However, playing long staccato ostinato passages use can cause stiffness or injury. To avoid arm stiffness and soreness from playing the left-hand ostinato, students should sit in lower position, relax their arms and play close to the key to control the sound. This will train the muscles to play with less tension.

There are many places where hand crossings are required (Figure 3.2.29). Practicing right hand alone to enhance connection of the melody and listening to its smoothness will make these tricky places easier to play.

Figure 3.2.29: Right-hand crossing between the low and middle range, mm. 170-171

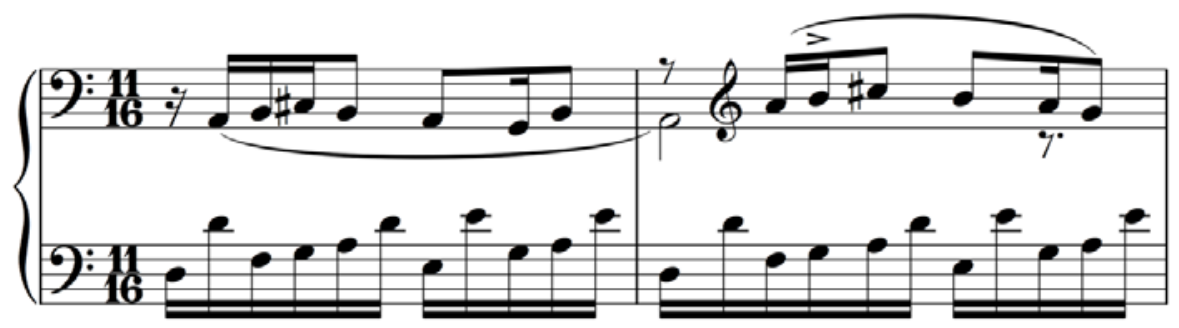




\section{Miscellaneous}

Much of the first movement is concentrated on the left-hand side of the piano. Playing the accompaniment in a lower register for a long time can cause back pain, if the performer is leaning or twisting in order to reach the low notes. This can be alleviated if the performer moves their sitting position towards the left side of the piano in order to release tension on the back.

In a personal interview with del Aguila, he suggested an alternative way of playing in m. 200 by using a left-hand palm cluster at the lowest end of the keyboard in the first beat. In m. 205-210, he also suggested that the performer must listen to E and F in the left hand chords.

\section{Second Movement}

\section{Style, Phrasing and Shaping}

The second movement was written in a Spanish guitar-like texture in mm. 1-8 and jazz swing style blues in the latter part. The rhythms of swing style blues are written out in the time signature 6/8. In addition, the musical influence of Ginastera and Gershwin can be heard in this movement, as discussed earlier. The introduction in mm. 1-8 starts with a guitar-like texture which shows a hint of Latin American music, and it also indicates that it should be played ad lib. The performer should play like as if improvising. Compared to the first movement, this movement has longer phrases. The direction of each phrase should be carefully planned out in order to unify the whole section. 


\section{Dynamics}

The range of dynamics of this piece is $p p$ to fff. The climax is at the end of the B section. The performer should pay attention to the dynamics and details in order to create drama for this movement. The A section (mm. 22-40) includes the melody of both soprano and alto lines. Playing the soprano louder than the alto will make this section more interesting, like a dialogue between a melody and its echo in mm. 27-32 and mm. 37-40 (Figure 3.2.30).

Figure 3.2.30: The melody in soprano and its echo in alto, mm. 27-32

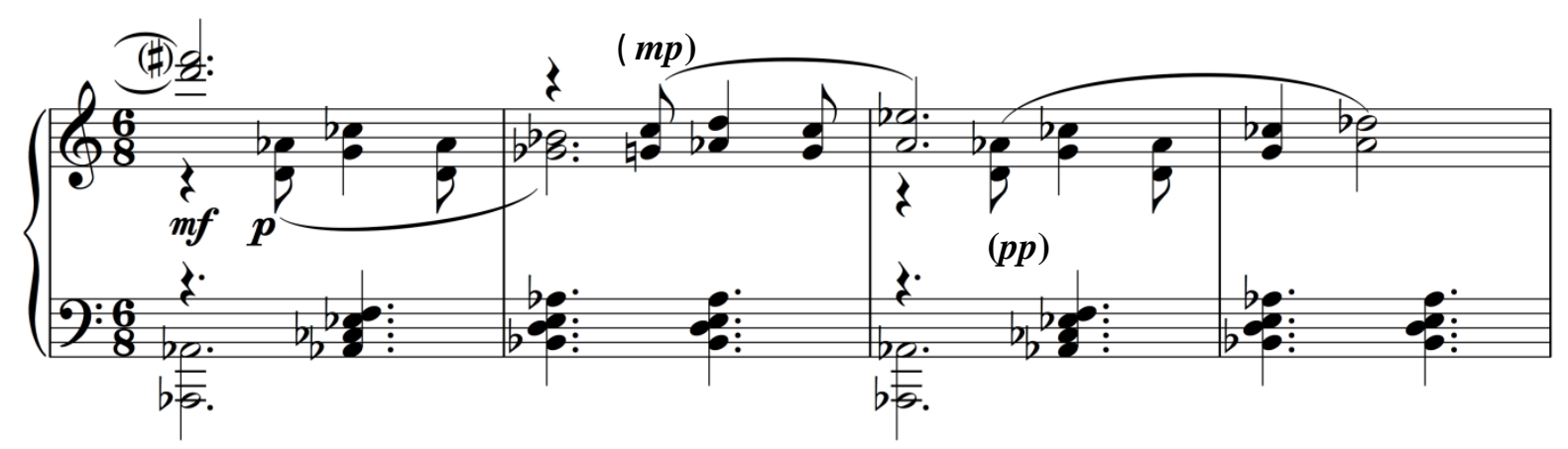

A long phrase starts from m. 61 ( $\mathrm{mp}$ ) and gradually climbs to the climax (fff) in mm. 84-86. The performer has to plan the crescendo to reach its climax in m. 86.

\section{Technique and fingering}

Hand crossing in the B section, mm. 52-61, poco meno mosso, is very important in this section because the right hand brings out the melody in soprano, alto, and bass. The balance between the melody and accompaniment must be distinct (Figure 3.2.31). It is necessary to relax the whole arm while playing the melodies in order to bring out nice, singing tones from the top notes.

Figure 3.2.31: The melody in soprano, alto and bass, mm. 52-56 


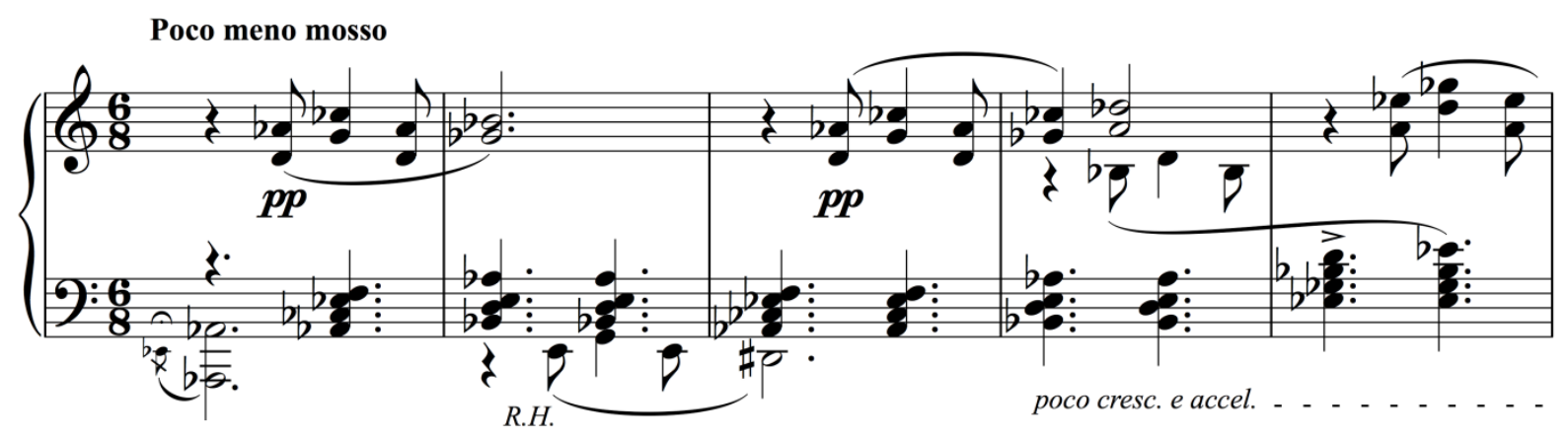

In order to play the five-note chord (D-Eb-F\#-A-C-D) in the right hand (mm. 77-83), students can use the thumb to hold both the D and E-flat while the other fingers play the other notes (Figure 3.2.32).

Figure 3.2.32: Fingerings in five-note chord in the right hand, mm. 77-78

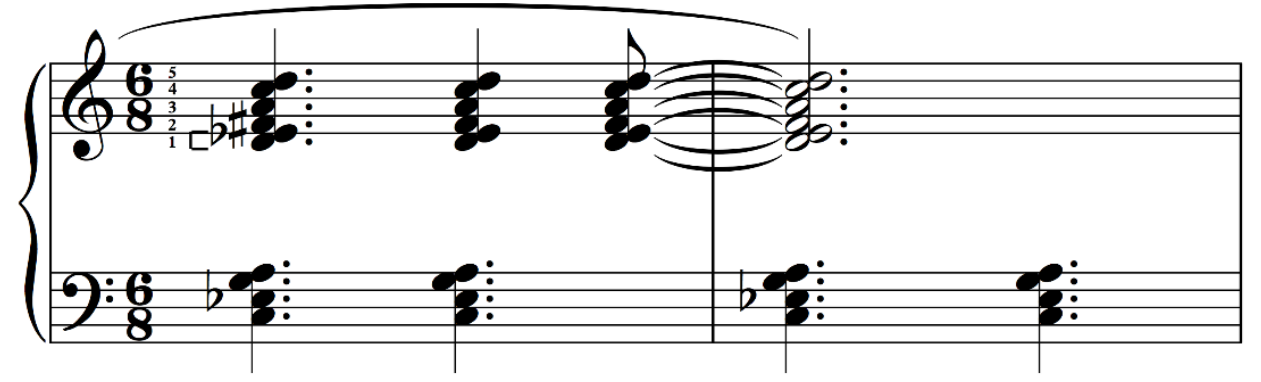

\section{Pedaling}

Compared to the first movement, the second movement uses more pedal and longer pedals to connect the long melodic lines and to resemble the style of the blues. The opening of the second movement uses a long sustain pedal to create sonority from the open strings of a guitar. In the swing style blues section, the pedal mostly changes when the left hand changes in the first and fourth beats. Some places can use the sostenuto pedal to capture the melody and avoid blurring the accompaniment (Figure 3.2.33). 
Figure 3.2.33: Using sostenuto pedal after the first beat to hold the right hand melody while playing the melody in bass line

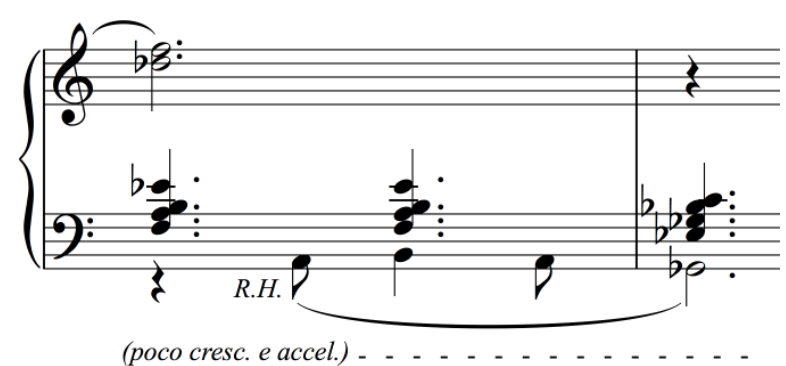

\section{Miscellaneous}

The second movement connects to the third movement immediately. It is necessary to prepare the performer's mind to be ready to change the mood from slow blues to fast, fun jazz and ragtime in the third movement.

\section{Third movement}

\section{Style, Tempo and Rhythms}

The style of this movement shows the combination of jazz and ragtime. A bright, cheerful, and festive atmosphere is created as the tempo starts with presto and gets faster until the end. The performer has to plan wisely how fast to start. My suggestion is not to start too fast, preferably around $J=72$, to provide space in order to push the tempo in the latter part of the movement.

When practicing this movement, there is a tendency to push the tempo faster until it is uncontrollable because of the frequent rhythmic changes. The rhythm travels from $4 / 4$ in the first theme to $13 / 16,15 / 16,17 / 16,12 / 16,16 / 16,7 / 16$ in the second theme, creating an unstable 
feeling. Thus, it is better to practice by setting the metronome to the smallest unit, which is the sixteenth-note.

\section{Pedaling}

The use of the pedal for the third movement is quite similar to the first movement. To enhance the active and crisp sonority, the pedal is rarely used in this section, except for the accent notes, chords and climactic parts (Figure 3.2.34).

Figure 3.2.34: Pedal for chords, mm. 116-117

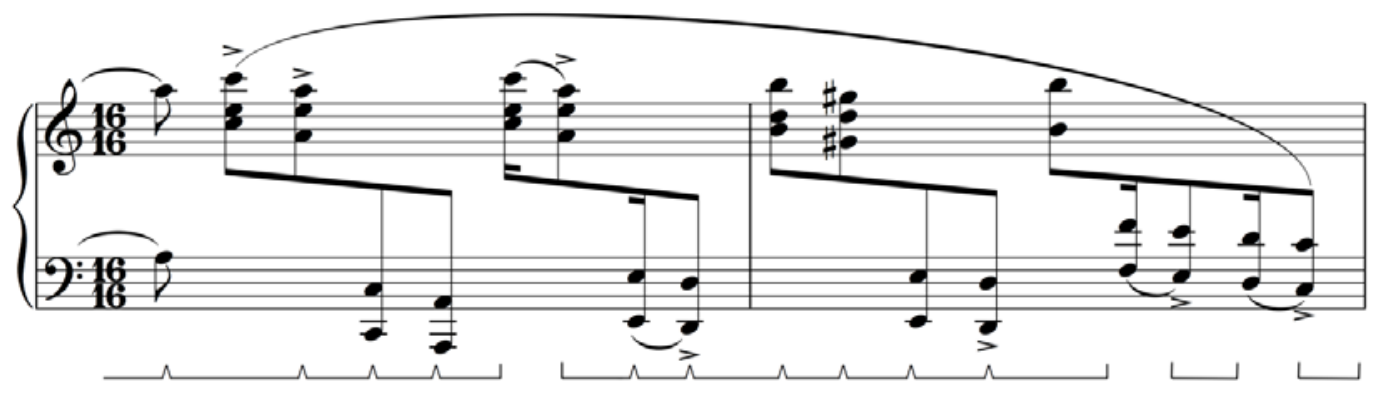

\section{Dynamics and Phrasing}

The dynamic range for this movement is $p p$ to ffff. There is a repeat sign for the B section (mm. 88-127). To make it interesting, the performer should play differently the second time different, compare to the first time, perhaps by changing the dynamics to softer or louder, or by playing longer or shorter phrases.

\section{Techniques}

Relaxation is the most important aspect of this movement, especially for the lower arm, because this movement is based on staccato. Using the whole arm, wrist and shoulder movements to play staccato instead of using only fingers will release unnecessary tension and 
make it easier to play. Moreover, sitting in a higher position is very helpful for playing chords and octaves, and it reduces stiffness on wrists and entire arms. When practicing slowly, the performer should pay attention to whether the entire body is relaxed in order to help it learn the correct way to play without any tension.

The length of the performer's fingers plays a vital role in this movement. The left-hand accompaniment in mm. 88-91 requires the performer to play ninths (E-F). In this case, it will be better if the performer can reach ninths and play both notes together (Figure 3.2.35). If not, the sound will be a bit bumpy for this section. The end of this movement requires the use of both lower arms to play chromatic clusters as loudly as possible. It is vital to lift the cluster decisively in order to create a dramatic ending (Figure 3.2.36).

Figure 3.2.35: Ninth in the left hand, mm. 88

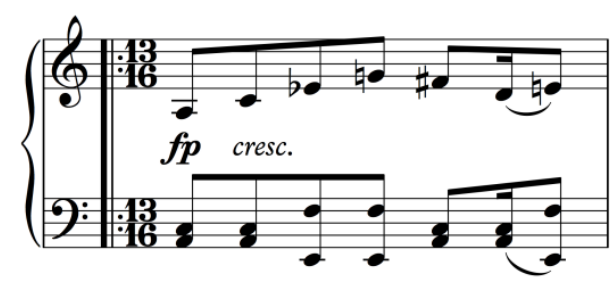

Figure 3.2.36: Chromatic clusters at the end of the third movement

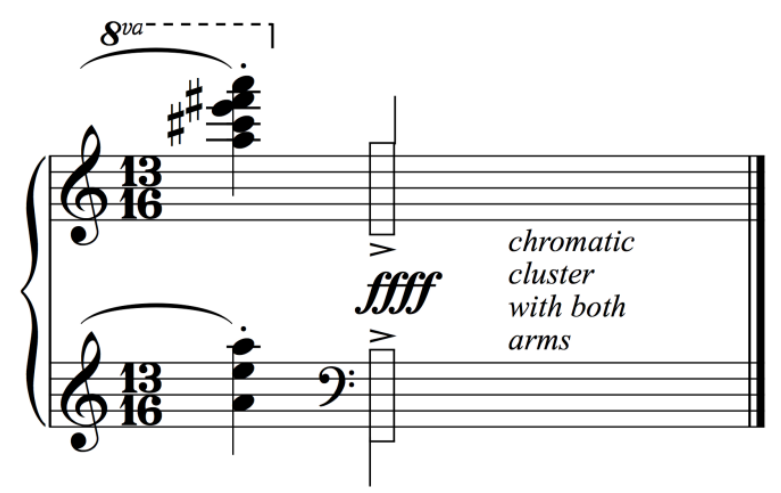




\section{Miscellaneous}

Concentration is the most important part of performing the third movement. The effectiveness of this movement can give the right character to the entire sonata, because the apotheosis of the sonata appears at the end of this movement.

In a personal interview with del Aguila, he recommended an alternative ending for the third movement. Instead of ending with chromatic clusters with both arms, he suggested playing a left-hand palm cluster staccato and ffff at the lowest end of the keyboard, while the right hand plays the long A major $6^{\text {th }}$ chord (A-C\#-E-F\#-A) in $p$. 


\section{iii) Conga, Op. 39}

\section{Overview and General Characteristics}

Conga, Op. 39 is one of the most famous compositions of del Aguila. Conga was first composed in 1993 as the last movement of Organ Fantasy. Del Aguila expanded this piece to eleven minutes for solo piano. There are five versions of Conga. The first version (Conga) is for solo piano. This version was premiered in January 1994 by Eileen Huang in Winterthur, Switzerland. The second version (Conga-Line in Hell) is for flute, two clarinets, harp, piano, percussion, and eight cellos. It was premiered in Los Angeles by the Lo-Cal Composers Ensemble in September 1993. The third version (Conga-Line in Hell) is for sixteen players: wind, brass, and string quartets including harp, piano and percussion. This version was commissioned and premiered in September 1994 by The New Juilliard Ensemble in New York City. The fourth version (Conga) is for full orchestra and was commissioned by the Ventura Symphony Orchestra in October 1994 in Ventura, California. The last version is for six pianos, arranged by David Appleton and premiered by Piano Circus in 2000. The first four versions have the same piano part. ${ }^{50}$

The solo piano version was dedicated to Boris Brott (b. 1944), the Canadian conductor. The story behind this piece related to del Aguila's best friend in Vienna who had mental disorder and died after del Aguila went back to the United States. Del Aguila was so depressed after he read the letter, his friend sent in which he described his life in hell and mentioned that there was fire in it. ${ }^{51}$ Del Aguila fell asleep and dreamt that he composed music for his friend and people in

\footnotetext{
${ }^{50}$ Miguel Del Aguila, "Program Notes." in Miguel del Aguila Conga for Solo Piano (Peer International Corporation: New York, Hamburg, 1995).

${ }^{51}$ Schulslaper, op. cit., 166.
} 
hell to make them happy. He also conducted this music for them to dance a conga line. ${ }^{52} \mathrm{He}$ remembered the tune from his dream and started writing Conga after he woke up. ${ }^{53}$

Conga is a large-scale character piece. Its mood is cheerful, which makes sense given that it was del Aguila's purpose to relieve pain for his friend and people in hell. The piece starts with a dreamy atmosphere in the very high register in both hands. Many kinds of dance appear in this piece, such as conga, salsa, and tango. ${ }^{54}$ However, this piece is dominated by a conga dance which is presented in its typical rhythmic pattern of 4/4 and its distortion in 13/16 (see Figure 3.3.1). The rhythm of Conga relies on repeated ostinato dance patterns. Thus, its style can be seen as minimalist. Del Aguila illustrates pictures and a variety of colors in Conga. Each section of the piece represents distinct characters: ironic, eccentric, emotional, lighthearted, and frightening. ${ }^{55}$

\section{Form}

According to Tse Wei Chai, the structure of Conga is divided into ten sections within ternary form, as shown in Table 3.3.1. ${ }^{56}$

\footnotetext{
52 Ibid.

${ }^{53}$ Ibid.

${ }^{54}$ Tse Wei Chai, "Pedagogical and Performance Aspects of Three American Compositions for Solo Piano: John Corigliano's Fantasia on an Ostinato, Miguel del Aguila’s Conga for Piano, and William Bolcom's Nine New Bagatelles,” (DMA diss., West Virginia University, 2016), 30-40.

55 Miguel del Aguila, "Program Notes", accessed December 20, 2016, http://www.migueldelaguila.com/programnotes.html.

${ }^{56}$ Chai, op. cit., $30-40$.
} 
Table 3.3.1: Structure of del Aguila’s Conga

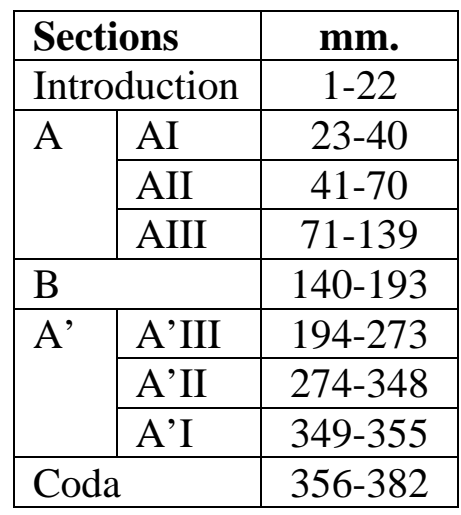

The introduction starts with soft sound in a very high register to illustrate a dreamy atmosphere. Both A and A' sections are dominated by fast Latin dances, the conga and salsa (Figure 3.3.1 and 3.3.2). ${ }^{57}$ The contrasting B section is presented by a sudden change from a fast tempo to a slow tango dance (Figure 3.3.3).

Figure 3.3.1: (1) AI, m. 23 as typical conga clave (4/4) and (2) AII, m. 41 as distorted conga clave $(13 / 16)$

(1)

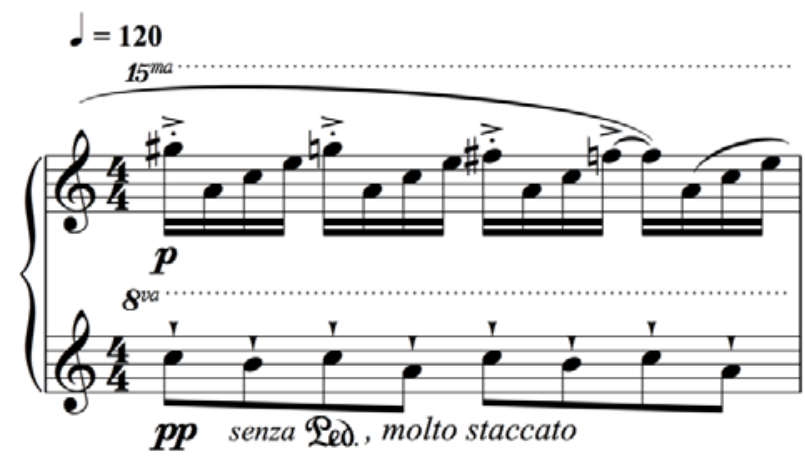

(2)

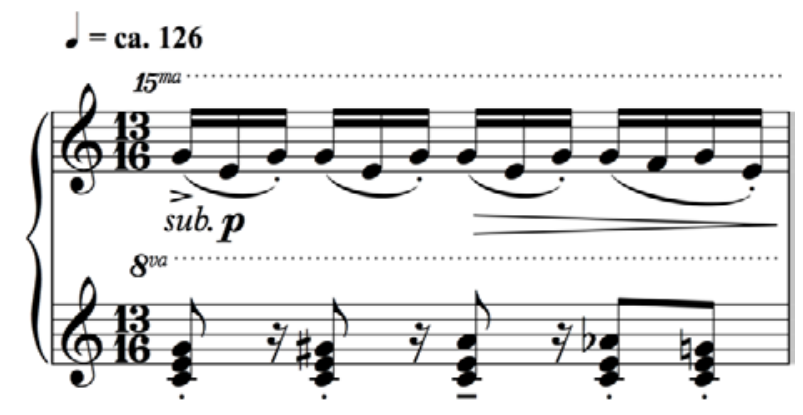

${ }^{57}$ Ibid. 
Figure 3.3.2: AIII section based on salsa, mm. 71-74

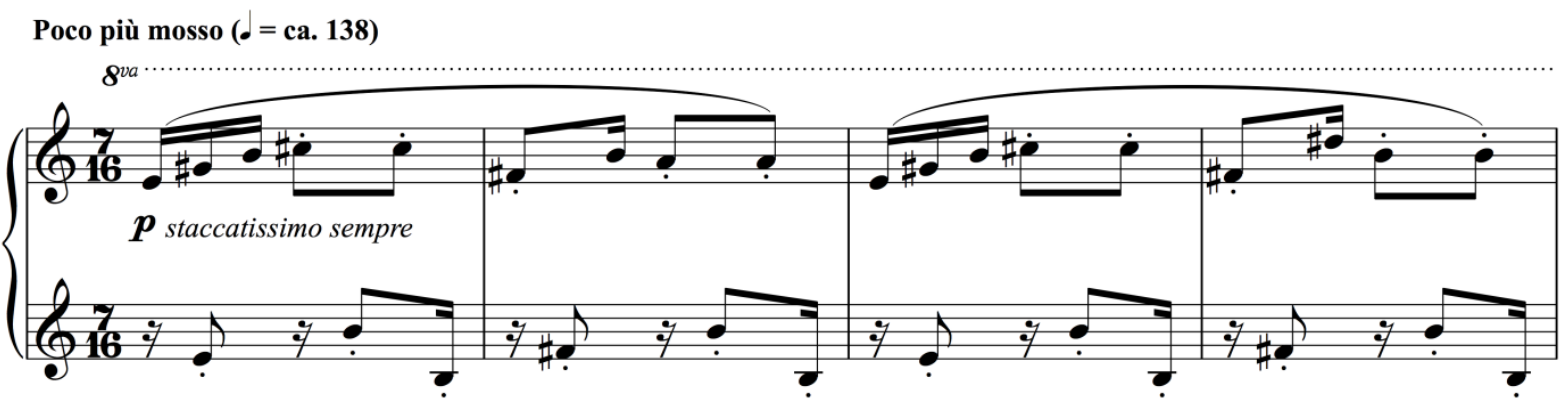

Figure 3.3.3: B section in tango mm. 142-146
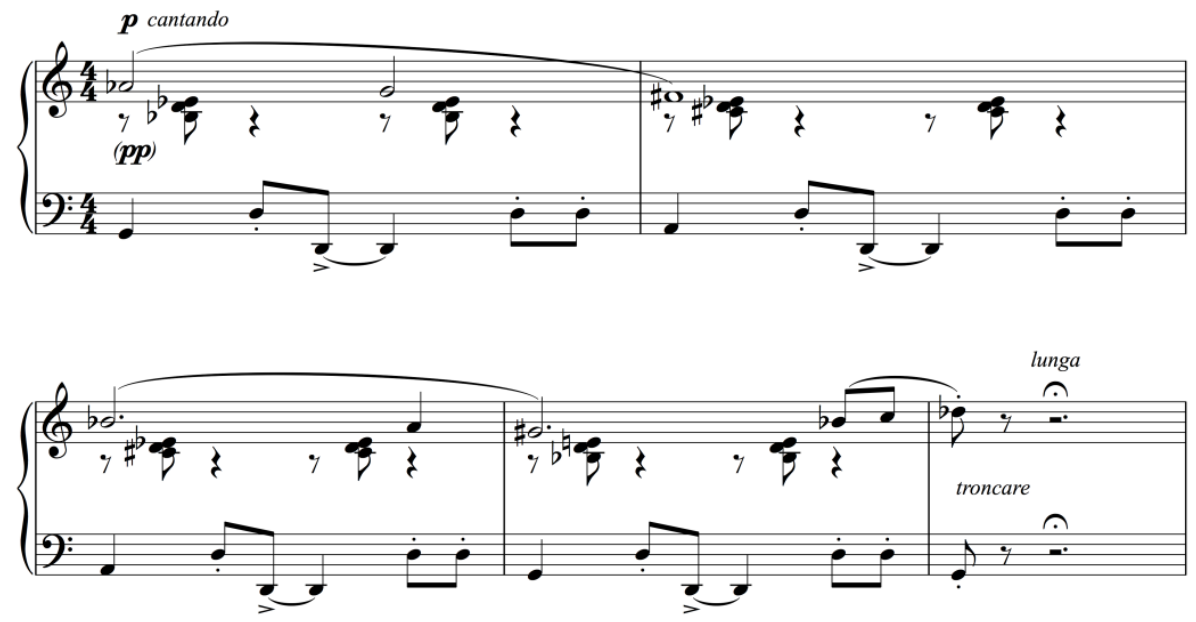

In the A'II section (mm. 274-348), Uruguayan candombe dance dominates the section in mm. 274-317; the staccato pattern in both hands imitate candombe drum (Figure 3.3.4).

Figure 3.3.4: Uruguayan candombe dance, m. 274-275

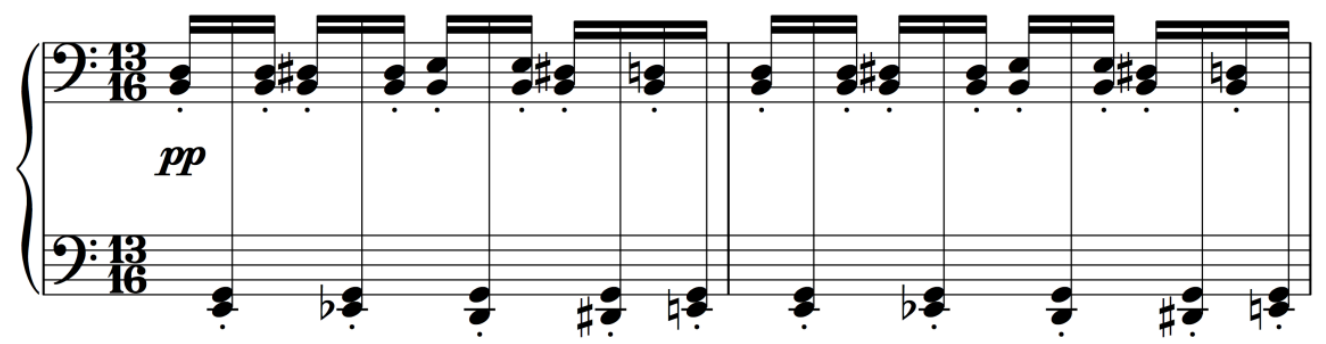

In the A'III section, there is a cadenza which consists of two descending tetrachords starting from Bb (Bb-Ab-Gb-F and E-D-C-B) (Figure 3.3.5). 
Figure 3.3.5: Two tetrachord scale of del Aguila, mm. 335

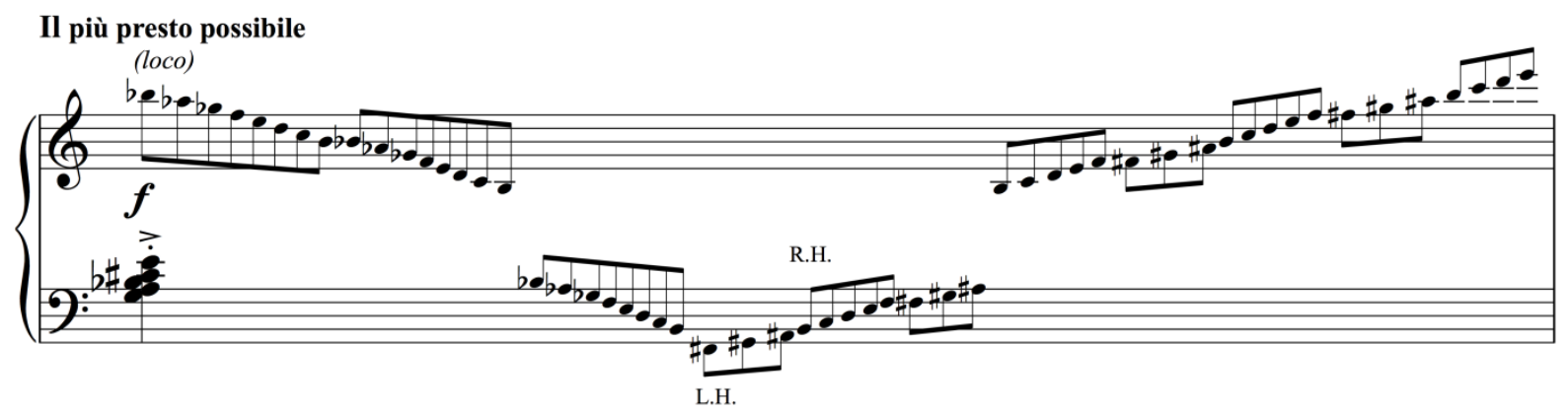

\section{Pedagogical Concerns}

Conga is suitable as an advanced-level piece. It requires great technical command.

Scales, glissandi, repeated notes, quick-changing position, and an extreme range of dynamics appear in this piece. Moreover, this piece consists of a variety of characteristics which always relate to varied tempo and changing time signatures.

\section{Fingering}

The repetitive pattern in the right hand can cause stiffness, especially in mm. 41-45, 5260 and 302-307. The tension in the right hand can be released by using the groups of fingering (3-1-2)-(3-1-2)-(3-1-2)-(3-2-3-1) or (3-1-3)-(2-1-3)-(2-1-3)-(3-2-3-1) and moving the wrist down and up in each group (Figure 3.3.6). 
Figure 3.3.6: Right hand fingering (3-1-2)-(3-1-2)-(3-1-2)-(3-2-3-1) or (3-1-3)-(2-1-3)-(2-1-3)(3-2-3-1) in mm. 41

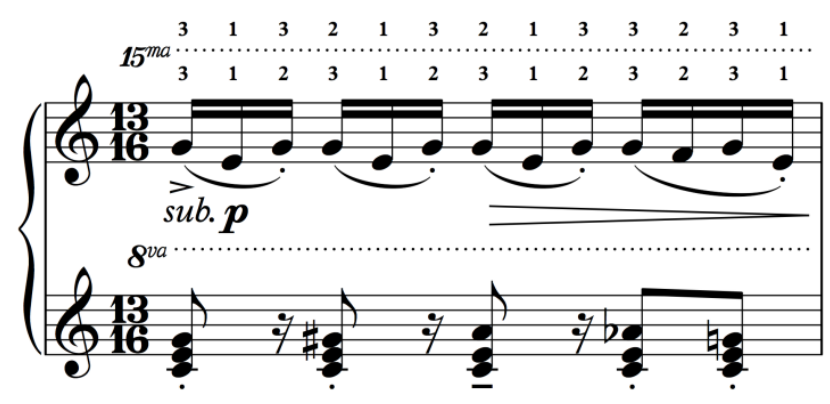

For the scale that consists of two tetrachords; F-Gb-Ab-Bb and B-C-D-E, in mm. 318322, using the fingering 1-2-3-4 and 1-2-3-4 for each group will fit these patterns (Figure 3.3.7).

Figure 3.3.7: Right hand scale using 1-2-3-4 and 1-2-3-4, m. 318

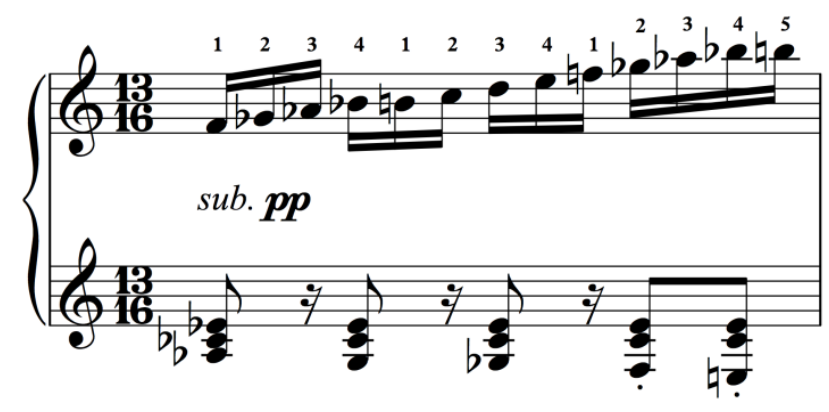

Tempo

Tempo indications appear throughout the piece. The tempo gets faster, adding excitement. However, the B section is expressive, less exciting, and steady compared to the other sections.

\section{Voicing and Movement}

The left hand plays the melody in its top notes while the right hand plays sixteenth notes in mm. 41-60. It is necessary to bring out the chromatic line in the left hand chords, for example, 
the top notes of the left hand chords in mm. 41-45 (Figure 3.3.8), the lowest notes in the left hand mm. 52-59 (Figure 3.3.9).

Figure 3.3.8: The melody in the left hand in the upper notes (G-G\#-A-Ab-G), m. 41

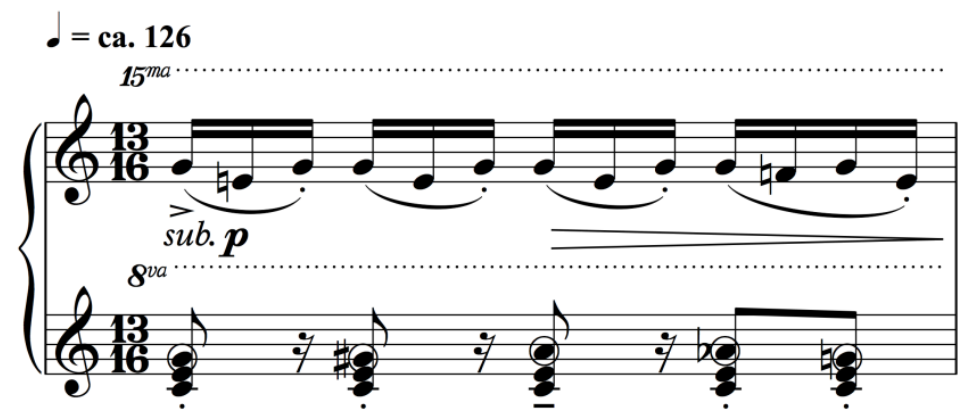

Figure 3.3.9: The melody in the left hand in the lowest notes (A-Ab-G-Gb-F), m. 52

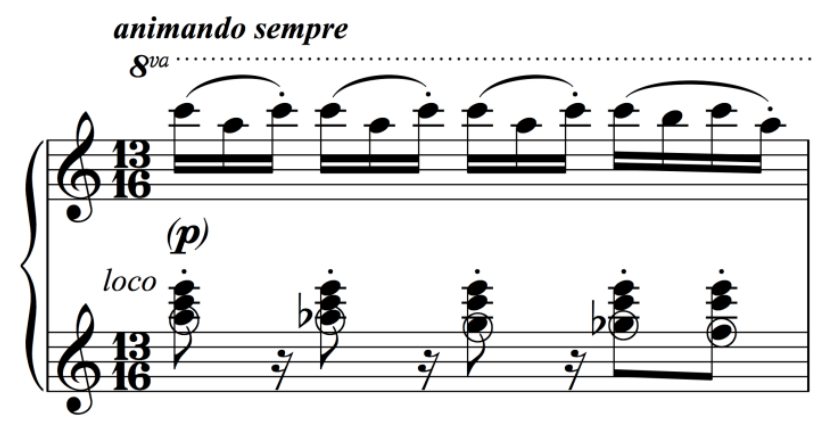

In the tango section or B section (mm. 140-185), the balance between melody and accompaniment is very important. The right hand plays both melody and block-chord accompaniment. In this case, the chords should be played softly so they do not overpower the melody in the top notes (Figure 3.3.10).

Figure 3.3.10: Right-hand chords should not overpower the melodic line, mm. 142-143

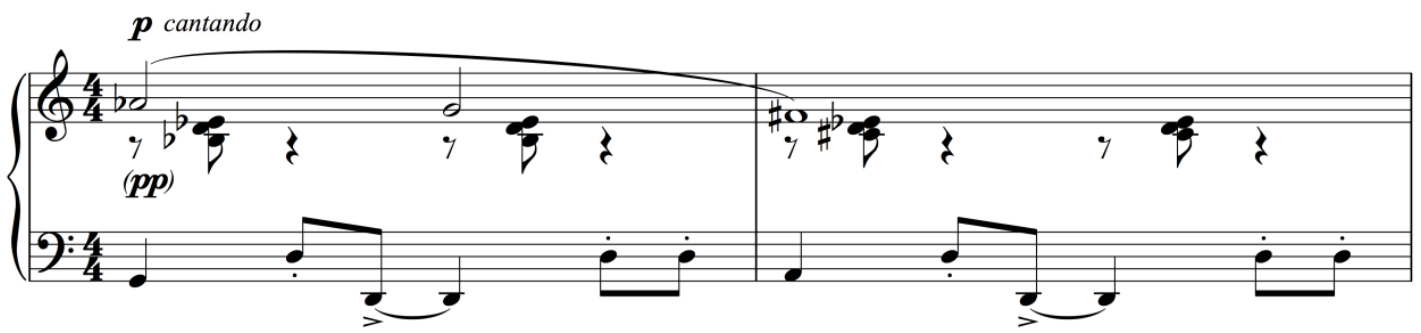




\section{Dynamics}

The extreme dynamic range and abruptly changing dynamics are important characteristics of this piece. Carefully preparing dynamic changes will make the piece more dramatic and create unique colors for each section.

\section{Pedaling}

Pedal is necessary for creating varied atmosphere and character. In mm. 1-23, del Aguila indicated ped. tenuto until bar 23, which means using one long sustain pedal until m. 23. The effect is to blur all the sound from both hands together to create a dreamy atmosphere. For the other places, the short sustain pedal is mainly used for accent notes, glissandi, and catching some resonances, for example, the B section in mm.140-193 (Figure 3.3.11).

Figure 3.3.11: Pedal in B section, mm. 140-143

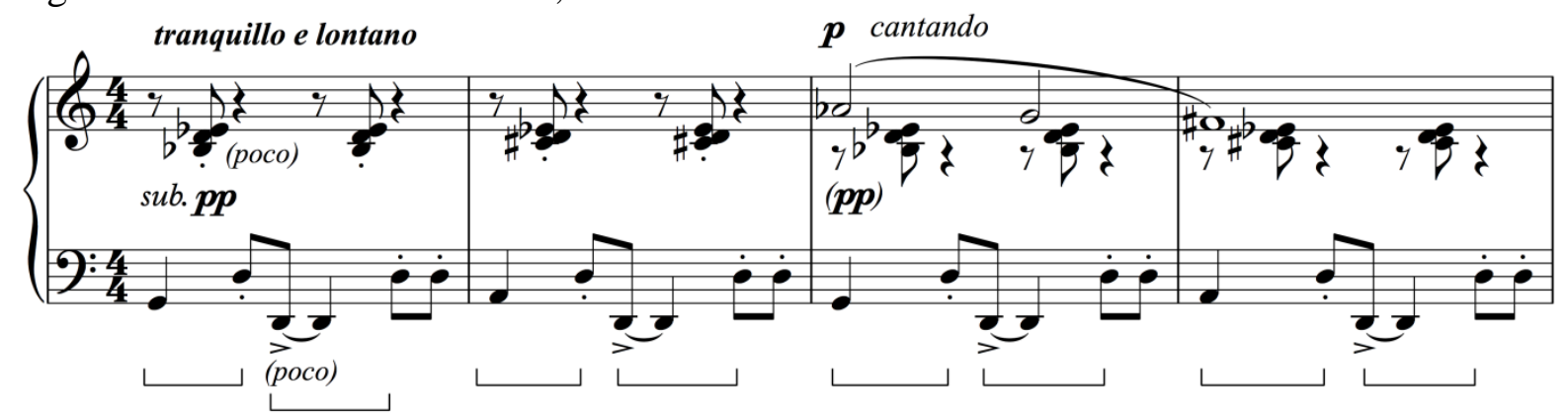

\section{Techniques}

Using only fingers to play all sixteenth notes in mm. 20-40 can cause fatigue in the fingers and lower arm. To avoid fatigue, using wrist and forearm rotation will make this section easier to play. This section is necessary to bring out the right-hand melody (Figure 3.3.12). 
Figure 3.3.12: Pointing out the right-hand melody by using forearm and wrist rotation, m. 20

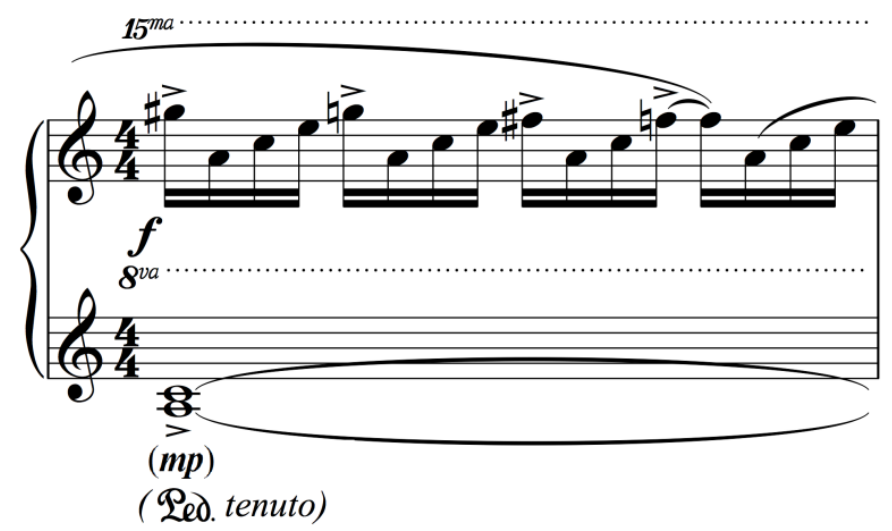

Playing glissando is an important technique in this piece. In m. 185, the performer should play using half of the nail in the third finger of the right hand while using the first finger to support the third finger (Figure 3.3.13). The left hand glissando in $\mathrm{m}$. 284 is played by using the nail of the first finger (Figure 3.3.14). The trick to playing a quick glissando is playing the note on the surface of the keys with half of the nail and moving quickly.

Figure 3.3.13: Right hand glissando, m. 185

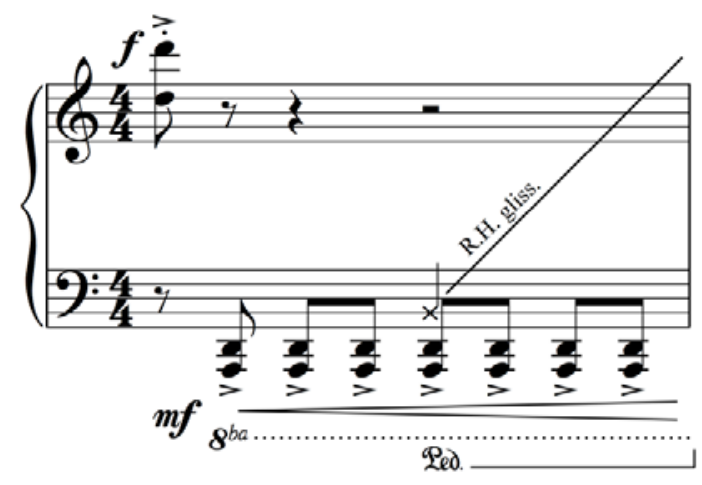

Figure 3.3.14: Left hand glissando, m. 284

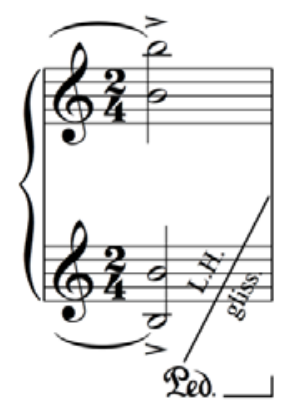


There are many places the performer has to move his/her body to change register between high and low registers to create an echo effect, for example, mm. 93-131. To practice this part, playing each hand separately, and playing the first note of each position and moving quickly to the new position will train the performer's body to recognize the new position. After that, practicing both hands together will prepare the performer to play in each position as quickly as possible.

In mm. 336-348, the left hand plays broken chords moving from low to high register. Practicing only left hand in block chords instead of broken chords and jumping to the higher position as quickly as possible are efficient ways to practice this section (Figure 3.3.15). Figure 3.3.15: Left hand broken chords in different registers, m. 336

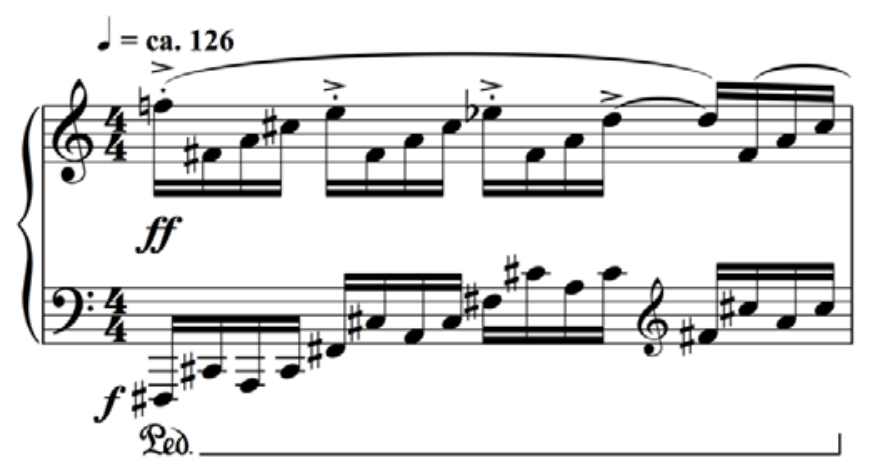

In mm. 274-275, the performer should play as if using a Uruguayan Candombe drum (Figure 3.3.16). This technique can also be seen in del Aguila’s “Toccata”. The performer should relax the wrists and arms when playing to avoid stiffness. The hidden melodies in the lowest note in the left hand and highest notes in the right hand should be emphasized. 
Figure 3.3.16: Uruguayan Candombe dance, mm. 274-275

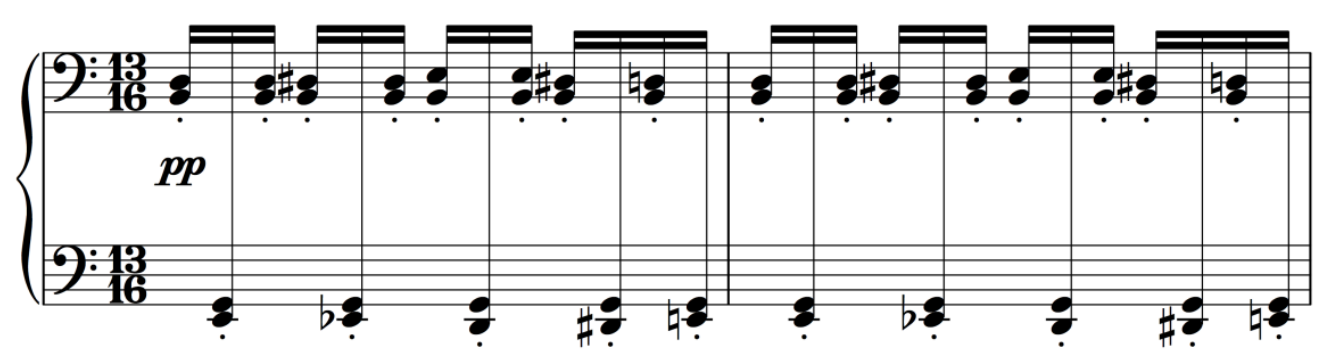

\section{Miscellaneous}

The fermata plays a significant role in this piece. It separates the sections and surprises the audience. For example, the fermata in m. 40 ends the AI section while the fermata in mm. 146 must surprise the audience by leading them to think the performer played the wrong note. To achieve this effect in m. 146, the performer should act like he/she is shocked and pause before continuing to play the next passage.

To achieve a higher level of performance, the performer should pay attention to physical appearance, which can convince the audiences that he/she is dancing while performing this piece; for example, in the B section in tango, rotating both arms while playing gives the impression of dancing. 


\section{iv) Piano Concerto, Op. 57}

\section{$\underline{\text { Overview and General Characteristics }}$}

This piano concerto has two versions. The first version was written in 1997. It was premiered by the composer in Ventura, California with the New West Symphony Orchestra (Ventura Symphony), conducted by Boris Brott. Del Aguila revised this piano concerto in summer 2001 in Chautauqua, New York. The length of performance is 26 minutes. ${ }^{58}$ This concerto consists of three movements; I Andante, II Adagio Recitando, and III Finale Allegro.

This concerto is programmatic and del Aguila has characterized it as autobiographical. ${ }^{59}$

Del Aguila described each movement in his program notes,

"The first movement is a dramatic account of desolation, depression and sorrow. Something beautiful happens in the second movement which slowly transforms the mood of the piece to a more positive one. This simple second movement is an intimate dialogue between pianist and orchestra where the piano part is often emotional, introverted, direct and simple. The movement ends in an introspective and reflective mood. The third movement is light, uplifting and often humorous and mocking. The character of the music often hints elements from Latin music and from Jazz. The theme of the "beautiful event" of the second movement returns now with full power and sweeping determination leaving behind all doubts that the drama of the first movement will ever return."60

In short, the style of this piano concerto shows the combination of Latin dance, romantic, and jazz. Del Aguila wrote the piano part to sound percussive in the first and third movements. In contrast, the piano part in the second movement is lyrical and full of dramatic quality.

There are some differences between the earlier version in 1997 and the revised version in 2001. In the 2001 version, del Aguila cut off and added some sections. The texture of the 2001 version is thicker and the techniques are more elaborate and more difficult. This research will consider the 2001 version. The orchestration for this concerto is unique, especially percussion

\footnotetext{
${ }^{58}$ http://www.peermusicclassical.com/classical-us-catalog/9210/versions/304, accessed November 24, 2016.

${ }_{59}$ E-mail correspondence with Miguel del Aguila, March 13, 2016

${ }^{60}$ Ibid.
} 
part. There is atypical instrumentation in the percussion, such as thunder sheet, bird whistle, and police whistle. Del Aguila also suggested amplifying the piano lightly if the available piano cannot give enough bright and loud sound. ${ }^{61}$ The detailed instrumentation is presented in Appendix II.

\section{Form}

This piano concerto is highly cyclic. The motives and sections in the first movement, mm. 124-160 reappear in the third movement. According to del Aguila, the form of this piano concerto relies on the story or message of the music. ${ }^{62} \mathrm{He}$ also explained the structure of each movement as follows,

"Movement 1 in this case has three themes which I use throughout and they function as introduction, development and some sort of recapitulation at the end as well as during the cadenza. Theme 1 is dramatic and starts the piece. Theme 2 starts in 37. It's just a transition theme takes us back to theme 1 . In the meantime we keep hearing excerpts of Theme 3 which is the theme that opens Movement 3. Movement two draws a lot from blues, Jazz and 1940-50's Latin pop song idioms. It has two themes and two sections. Third movement starts with the Theme 3 already heard on Movement 1 as fragments. It's inspired on the typical trumpets calls as used on the Latin Bands. Theme 2, Jazz inspired, begins on B16. The piano accompanies the theme on B. 53 on a rhythm derived from Uruguayan Candombe dance. Bar 48 a new, sort of humorous waltz theme begins. I wanted to create the feel of the typical Rondo form of piano concertos by adding this and the treatment on letter J. Even though themes are the same it sounds like a different variation. The movement ends with I believe themes 1 and 2 of Movement 1. In this case the entire piece is cyclical." ${ }^{63}$

\section{First movement}

The first movement seems to fit in sonata-allegro form. The exposition, which includes the introduction, spans mm. 1-36

\footnotetext{
${ }^{61}$ Miguel Del Aguila, "Program Notes." in Miguel del Aguila Piano Concerto, Op. 57, (Peer International Corporation: New York, Hamburg, 2001).

${ }^{62}$ E-mail correspondence with Miguel del Aguila, December 6, 2016.

${ }^{63}$ Ibid.
} 
There are three themes in the first movement which appear through the movement and serve as introduction, development, some part of recapitulation, and cadenza. The first theme, which is dramatic, starts the movement in mm. 1-36 (Figure 3.4.1 and 3.4.2).

Figure 3.4.1: The first theme of the first movement in orchestral part (oboe), mm. 5-6

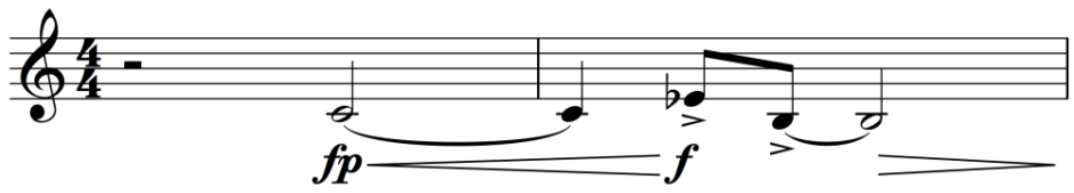

Figure 3.4.2: The first theme in piano part, m. 1

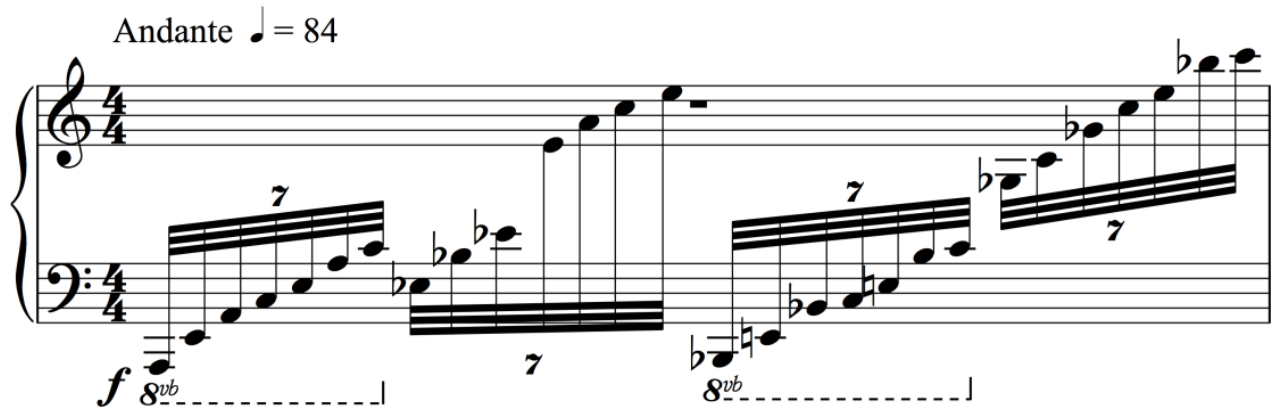

The second theme begins in $\mathrm{m}$. 37-48 as a transition back to the first theme (Figure 3.4.

3). The third theme appears within the first theme in mm. 23, 28, 29 which is a part of the opening theme of the third movement (Figure 3.4.4).

Figure 3.4.3: Second theme in piano part mm. 37-38

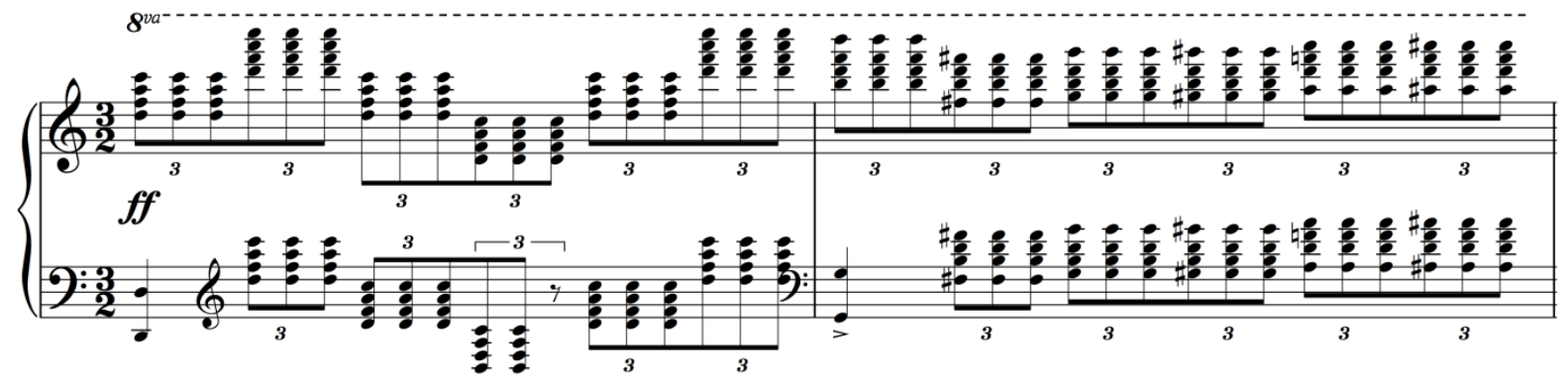


Figure 3.4.4: The third theme in orchestral part (flute), mm. 23

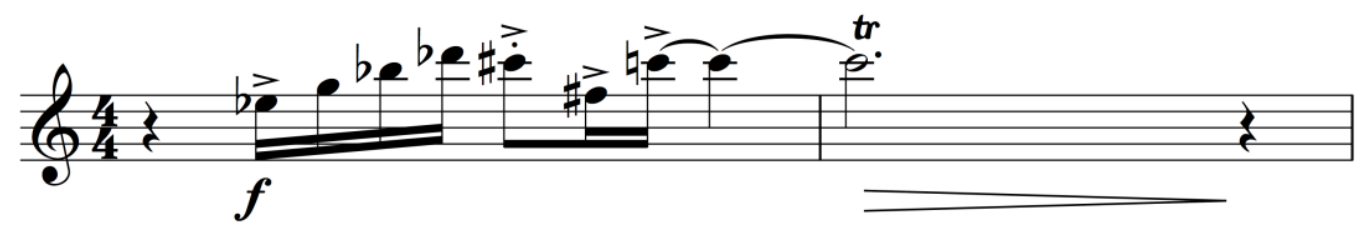

The cadenza is in mm. 70-123. This section is highly challenging technically. The right hand plays fast running figures and a two-tetrachord scale (F-Gb-Ab-Bb,B-C-D-E) while the left hand plays arpeggios with the melody in the top notes (Figure 3.4.5). In mm. 107-123, the theme in the left hand became the B section of "Half of Me" for solo piano left hand, Op. 70 in mm. 7894, which was composed three years later in 2000.(Figure 3.4.6).

Figure 3.4.5: Cadenza, m. 87

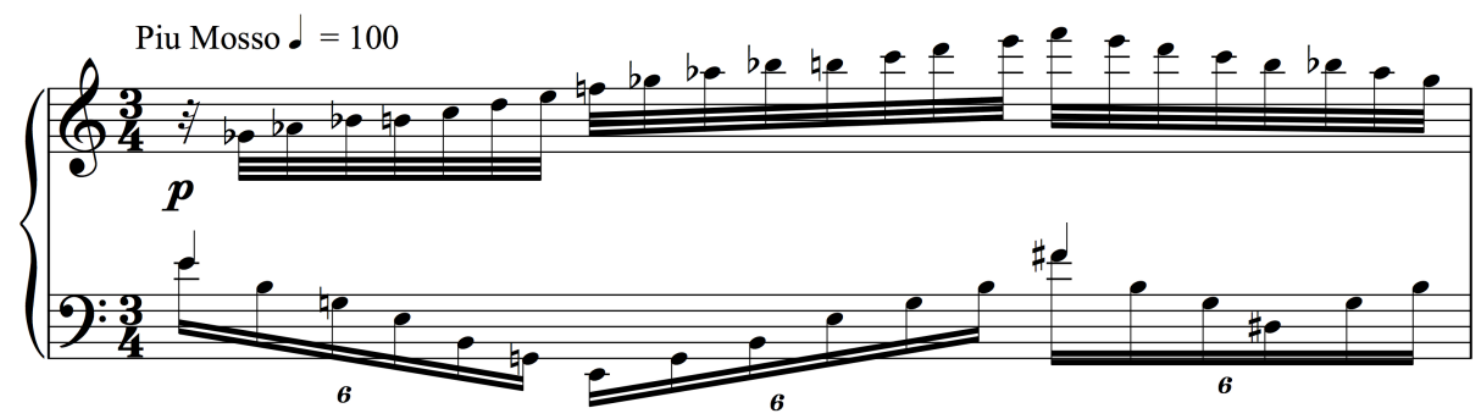

Figure 3.4.6: 1) The first-movement cadenza, mm. 107 2) B section of “Half of Me”, Op. 70 1)

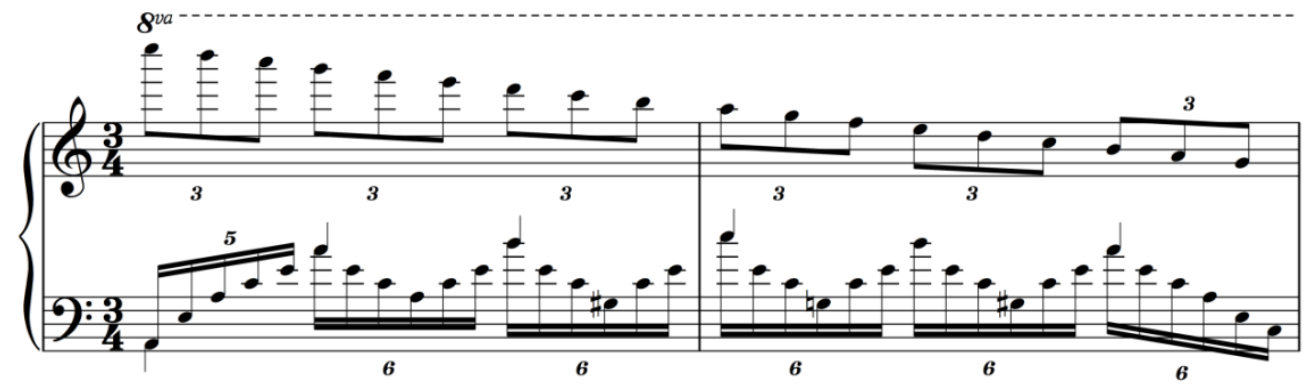


2) “Half of Me”, Op. 70, mm. 78-79

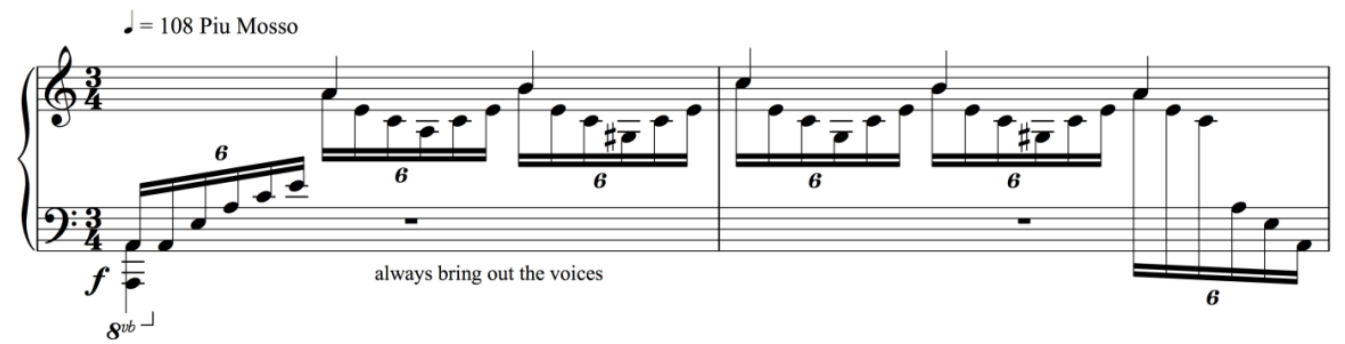

The coda is in mm. 124-160. The section in mm. 128-160 reappears in the third movement. This movement ends dramatically with a glissando and chromatic cluster with both forearms (Figure 3.4.7).

Figure 3.4.7: Ending of the first movement (mm. 159-160)

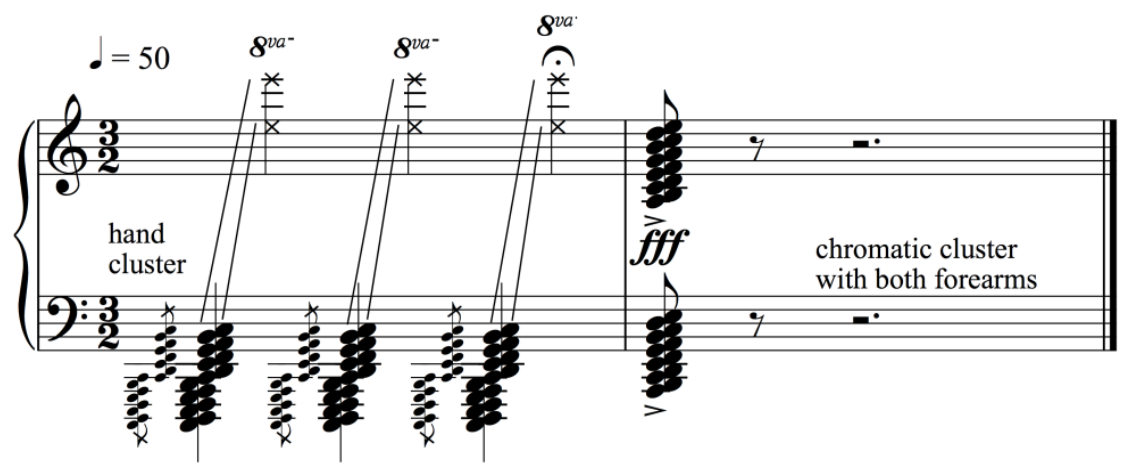

\section{Second movement}

The second movement was written in Latin and jazz style. In the orchestral part, there is unusual instrumentation, such as singing in mm. 59-61 and bird whistle from the back stage in mm. 79-81. There are two themes and two sections. This movement shares the same themes as "Nocturne”, Op. 62 (both nocturne themes will be presented in the fourth chapter). The first section is in mm. 1-38 and the second section is in mm. 39-81(Figure 3.4.8 and 9).

Figure 3.4.8: The first theme of the first section, mm. 1-2 


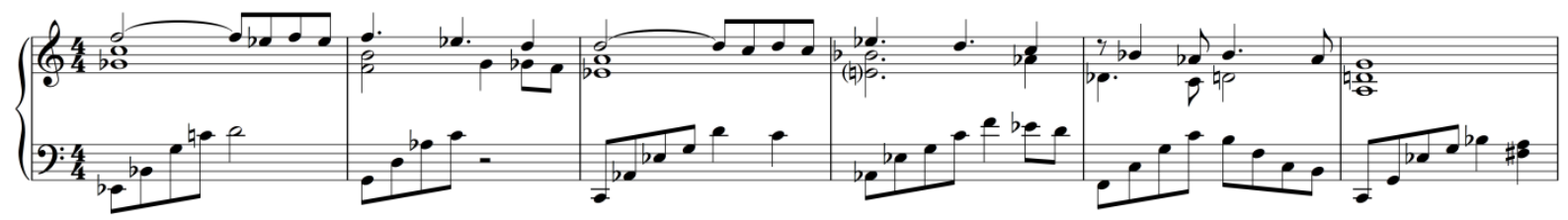

Figure 3.4.9: Theme from the second section in orchestral part (violin), mm. 41-42

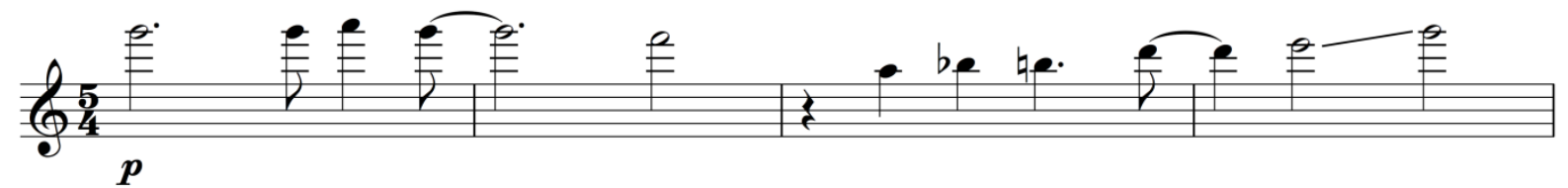

\section{Third movement}

The third movement is in typical rondo form. The third theme from the first movement, which is influenced by trumpet calls in Latin bands, becomes the first theme of the third movement played by the piano (Figure 3.4.10). This theme reappears in mm. 137-147 (rehearsal G) and is played by the orchestra.

Figure 3.4.10: First theme, mm. 1-2

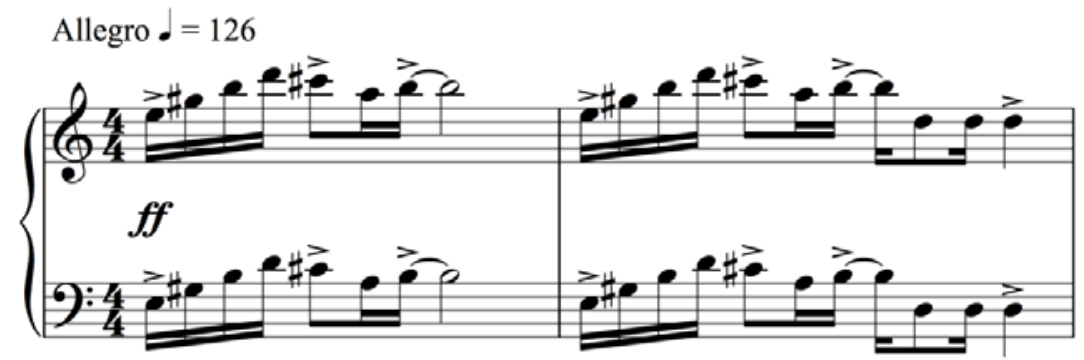

The second theme is jazz-inspired. It is presented in the orchestral part in 5/4 in m. 16-25 (rehearsal A) and B mm. 42-47 (rehearsal B) and has similar rhythms to the second movement's second theme (Figure 3.4.11). Later, this rhythm appears in mm. 71-96, 115-136, 159-164, 191212 (rehearsal D, F, H and K) in very fast tempo (Figure 3.4.12) 
Figure 3.4.11: Second theme (horn), m. 16

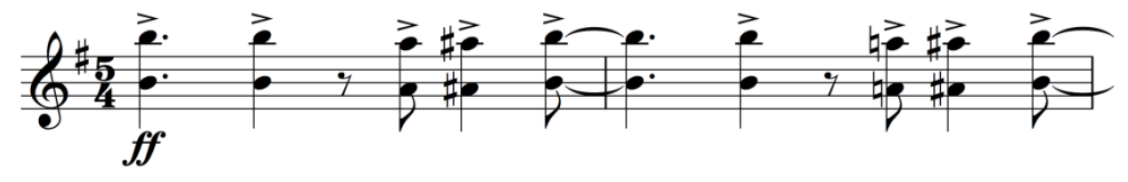

Figure 3.4.12: Reappearance of second theme, mm. 71-72

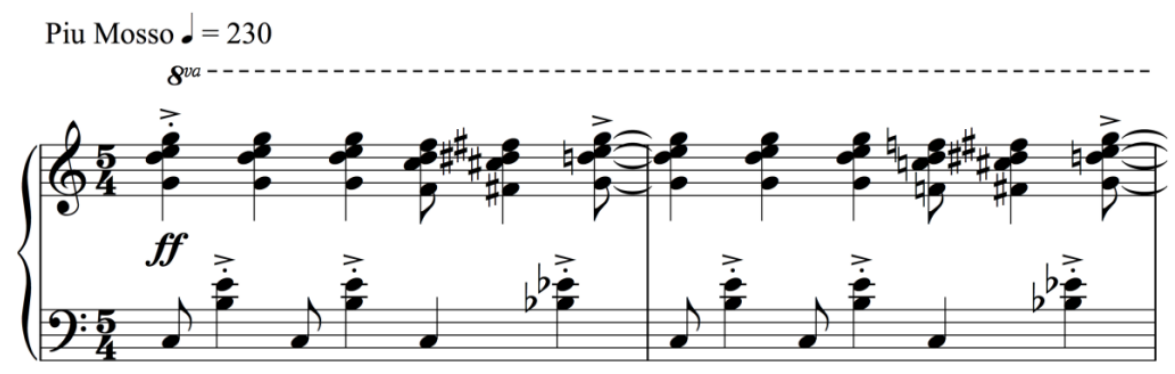

Uruguayan Candombe dance starts in m. 53-70 (Figure 3.4.13). According to the score in mm. 53-55, del Aguila indicated in the score for orchestral part, "Improvise laughter and exclamations of joy (ha ha ha!, Ah! Whistle etc)” which creates a lively atmosphere for the piece.

Figure 3.4.13: Uruguayan Candombe dance, m. 53

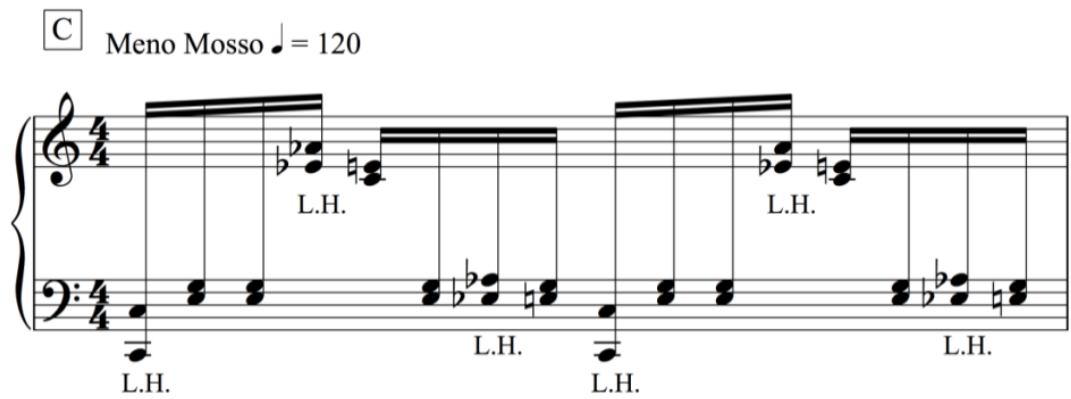

In mm. 148-158 or rehearsal $\mathrm{H}$, the piano part is technically challenging. There are running broken octaves in the right hand played with the jumping left hand (Figure 3.4.14). In mm. 175-190 (rehearsal J), the left hand pattern is similar to rehearsal H but the right hand changes to running figures. Del Aguila added this section to make this movement fit into rondo form (Figure 3.4.15). 
Figure 3.4.14: The right hand in broken octaves, m.148 (rehearsal H).

H Meno Mosso $\_=40$

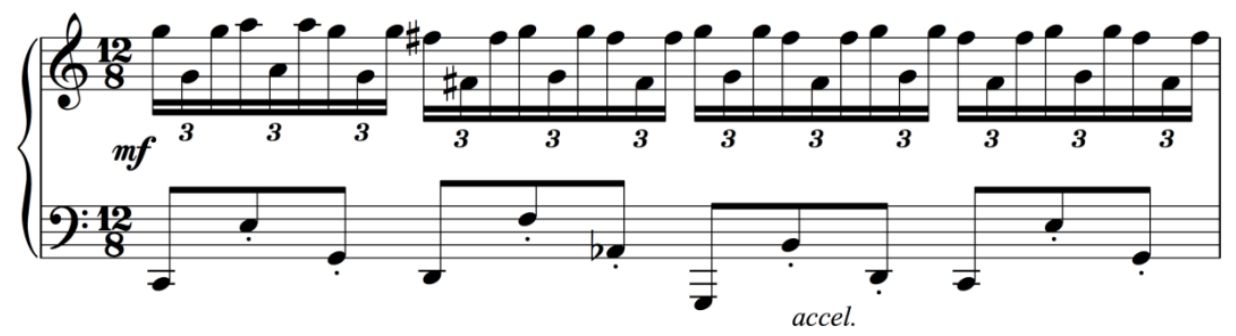

Figure 3.4.15: The right hand in running figures, m. 175

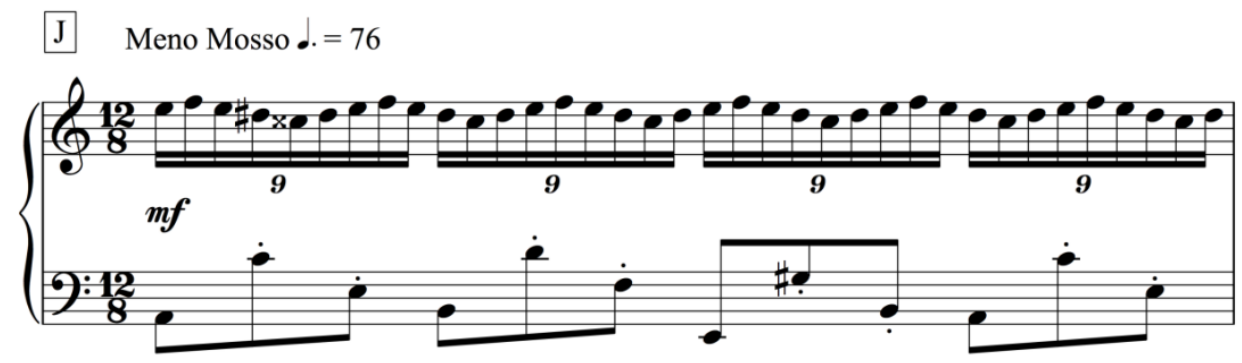

The recurrence of the first and second themes of the first movement at the end of the third movement in mm. 255-288 makes this concerto highly cyclic (Figure 3.4.16).

Figure 3.4.16: Recurrence of the first-movement theme in the third movement, mm. 255-256

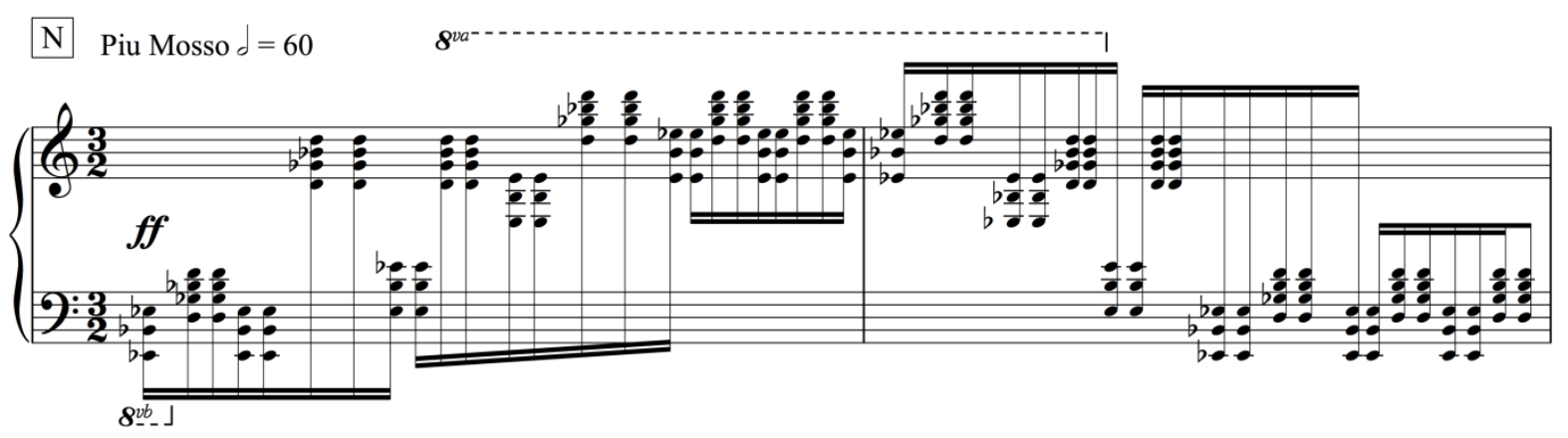




\section{$\underline{\text { Pedagogical Concerns }}$}

This piano concerto is a technically challenging composition which is suitable for an advanced level student. The piano part in the first and third movement features non-stop playing in a percussive quality, except in the cadenza. Then it changes to a lyrical quality in the second movement.

\section{First movement}

\section{Tempo and Rhythm}

The first movement starts with andante $J=84$ and gets faster in the middle section. The soloist must carefully choose the starting tempo, in order to have space to speed up tempo in the latter part. In addition, the communication with the conductor is very important because the movement frequently changes in both tempo and time signature (4/4, 3/2, 2/2 and 3/4).

\section{Technique, Melody and Direction}

The first movement is full of chords, octaves, arpeggios and scales. Effective practice techniques are necessary for this movement. In mm. 1-10, use both hands to play broken chords. Play the first three notes with the left hand and the other four notes with the right hand, changing the pedal every beat (Figure 3.4.17).

Figure 3.4.17: Playing broken chords with both hands, m. 1

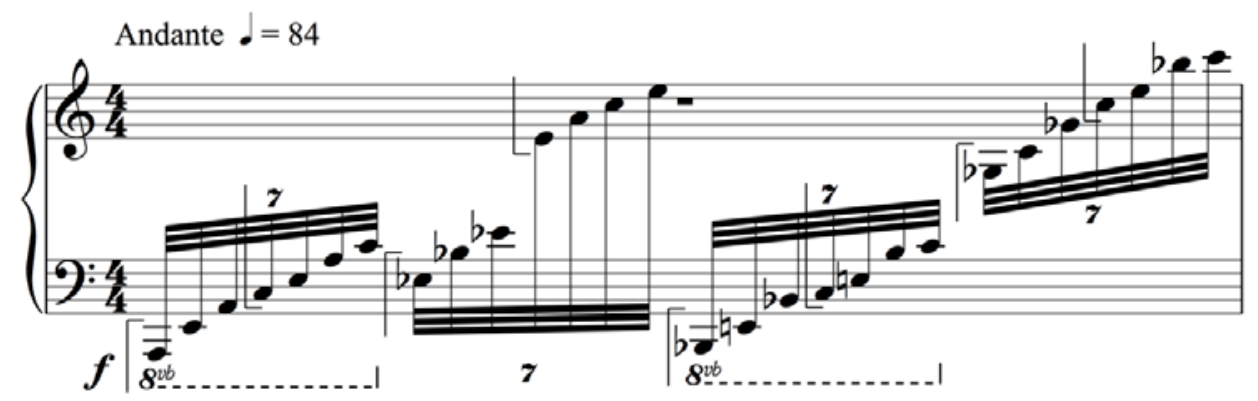


In order to play block chords, practice moving the hand(s) to the next position (chord) as quickly as possible (Figure 3.4.18). Block chords should be played to sound like percussion.

Figure 3.4.18: Block chords 1) mm. 12-13 2) mm. 128-129

1) $\mathrm{mm} .12-13$

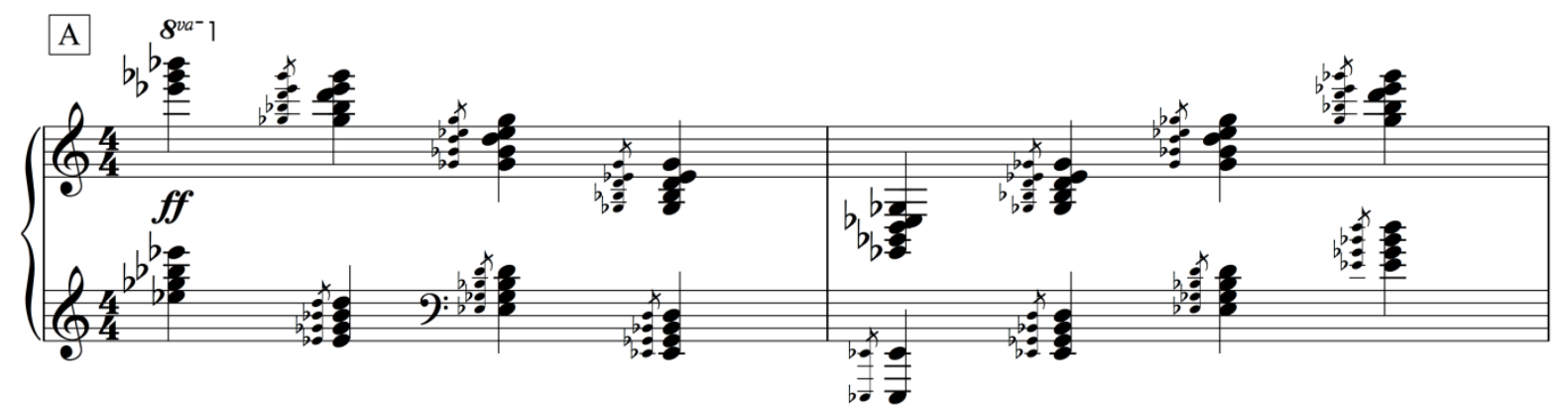

2) mm. 128-129

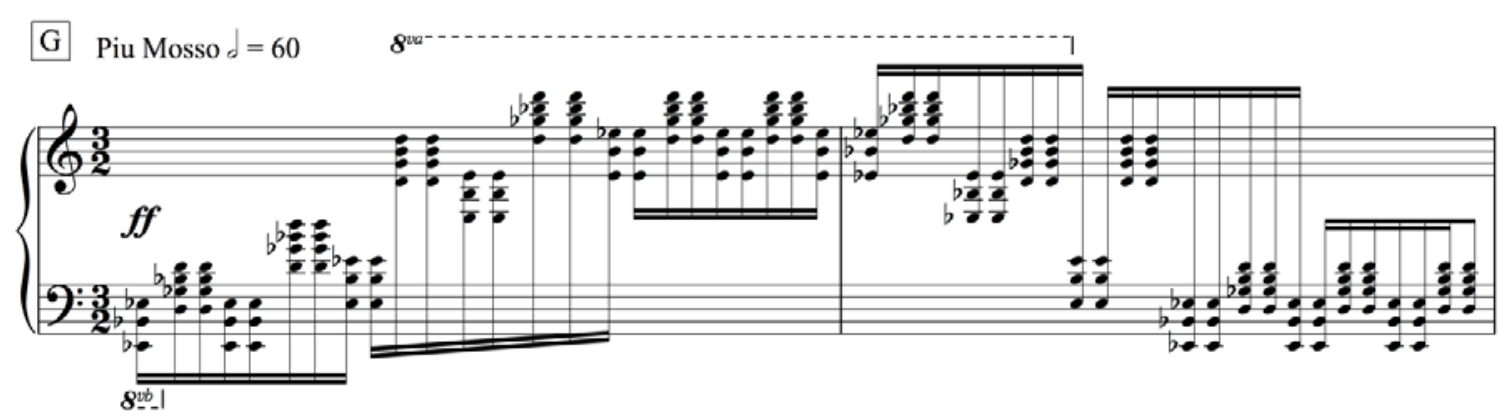

Difficult octave passages appear in m. 25-26, 40, and 45 (Figure 3.4.19). Relaxation is an important key to play these passages.

Figure 3.4.19: Series of octaves, m. 25

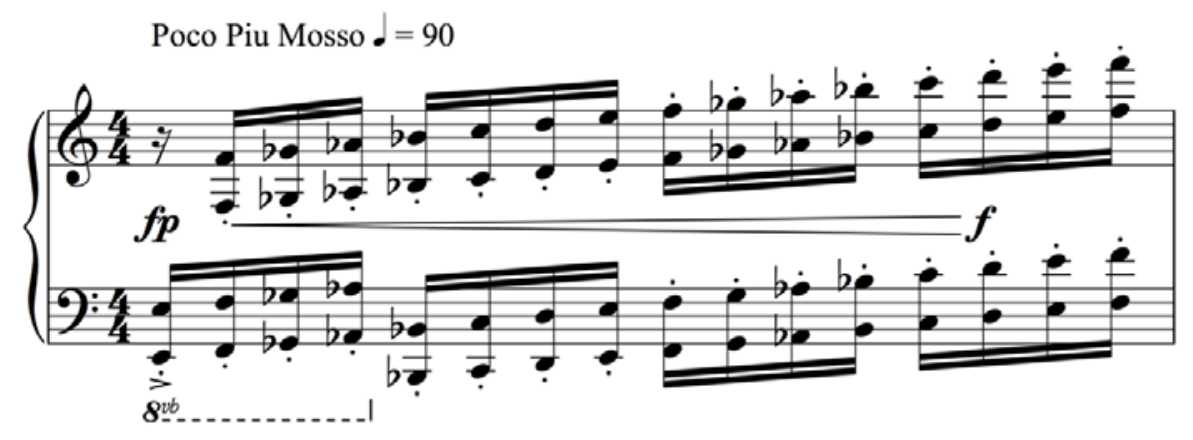


The cadenza, mm. 87-122, combines a variety of techniques, including series of arpeggios with the melodic line in the top notes in the left hand and many kinds of scales in the right hand, such as a two-tetrachord scale, ascending E-flat melodic scale, and descending chromatic scale. Dividing the cadenza into small sections with hands separated and playing slowly is an essential way to practice. In addition, playing only the melodic line in the left hand will help the performer see the direction and shape clearly (Figure 3.4.20). Rhythmic-pattern practice is necessary for increasing speed in both hands. The balance in both hands for this section is of special concern. The right-hand touch must be lighter than the left-hand melodic line.

Figure 3.4.20: Melodic line in the left hand, m. 87

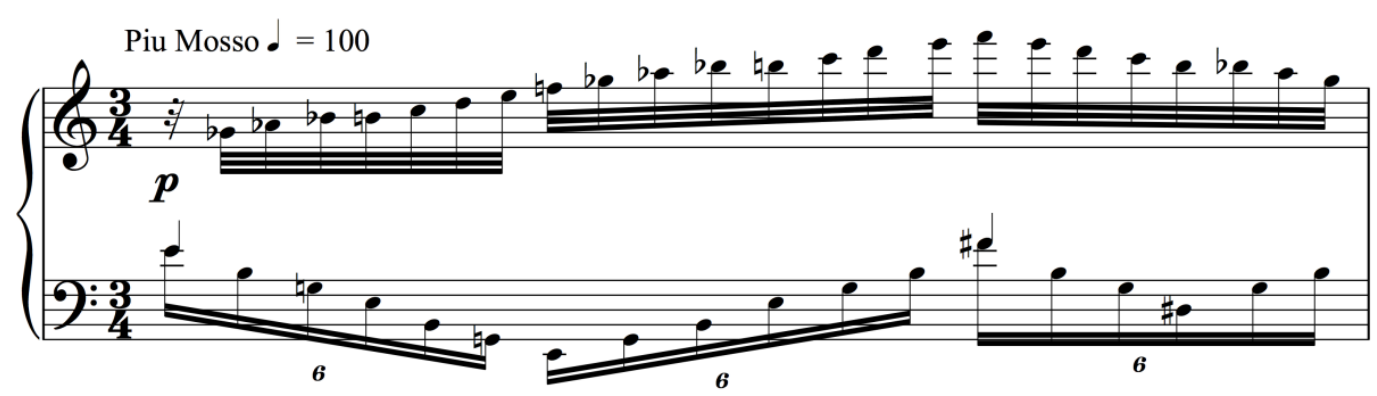

Clusters and glissandos create drama and intensity, especially at the end of the first and last movements. There are hand clusters and forearm clusters. Hand clusters appear in m. 59 and 159 (Figure 3.4.21) and the chromatic cluster at the end of the movement is in m. 160 (Figure 3.4.22). One interesting spot is in m.159, where hand clusters are followed by ascending glissando to a very high E. In order to play this passage, drop both hands to piano with sustain pedal. Then use the left-hand thumb and the right-hand third finger to sweep to the right side as fast as possible to the very high $\mathrm{E}$ with an accent. In m. 160, dropping both forearms between black and white keys as heavily as possible while using a short sustain pedal will create a dramatic effect to conclude the first movement and finish the concerto. 
Figure 3.4.21: both hand cluster, mm. 59

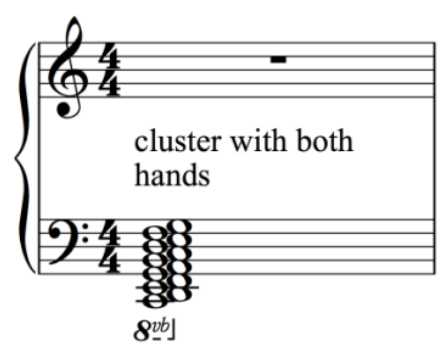

Figure 3.4.22: Hand clusters with glissando and forearm cluster mm. 159-160

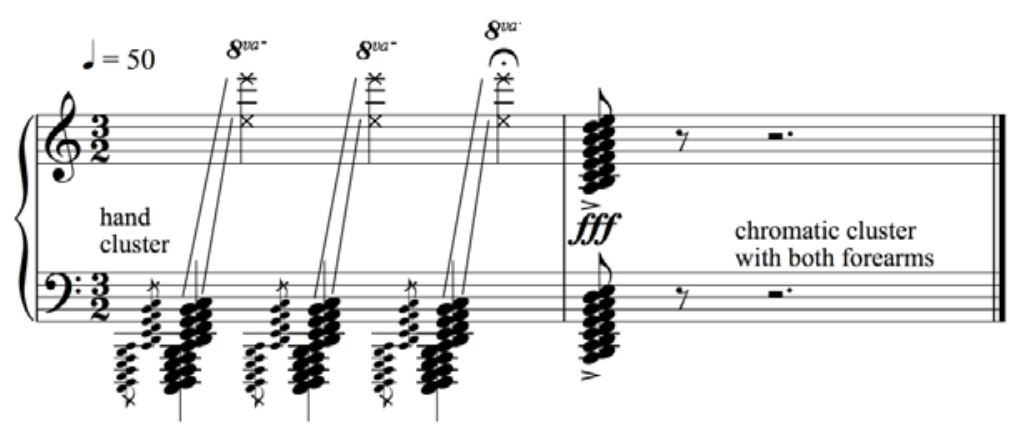

\section{Dynamics, Articulations and Pedaling}

The first movement is dominated by big, grand, and loud sound ( $f$, ff, and $f f f$, except the piano solo part in mm. 87-123. It is very interesting that del Aguila did not put any pedal marking in this score. However, the entire movement should use sustain pedal to create loud sound and resonance during chords, arpeggiated passages, scales, and clusters. If the soloist is concerned about the clarity in some musical passages, using a lighter touch and frequently changing the sustain pedal can be a good solution. 


\section{Second movement}

\section{Melody and Balance}

This movement presents long melodic lines and a dialogue between piano and orchestra. The balance between the solo part and the orchestra is significant. The soloist should emphasize the top note of the melodic line and shape it nicely.

\section{Tempo, Direction, Phrasing and Shaping}

The second movement is very lyrical and tuneful. Even though the second movement shares the same theme with "Nocturne" and "Half of Me" (these two pieces indicate rubato), the soloist should play at a steadier tempo than the other two pieces, to stay together with the orchestra. An exception to this is the cadenza at the end of this movement in mm. 80-81, where del Aguila indicates that the soloist should push and pull back the tempo (cresc e molto accel and rall e dim).

\section{Pedaling}

In general, this movement should use long pedal for long lyrical melodic lines and arpeggiated figures. However, it is necessary to change pedal when changing chords or during half-step melodic lines in order to avoid dissonance and blur. In the 5/4, or jazz waltz in mm. 4953 and 55-58, change the sustain pedal in beat 1, 21/2 and 4 (Figure 3.4.23). In the cadenza in $\mathrm{m}$. 80-81, use one long sustain pedal for the entire passage (Figure 3.4.24). 
Figure 3.4.23: Pedal for jazz waltz (5/4), m. 49

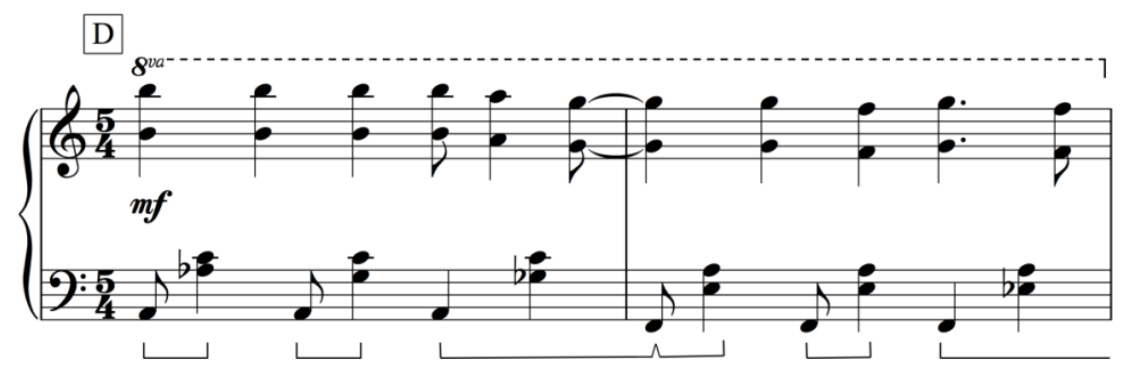

Figure 3.4.24: Long sustain pedal of cadenza, mm. 80-81
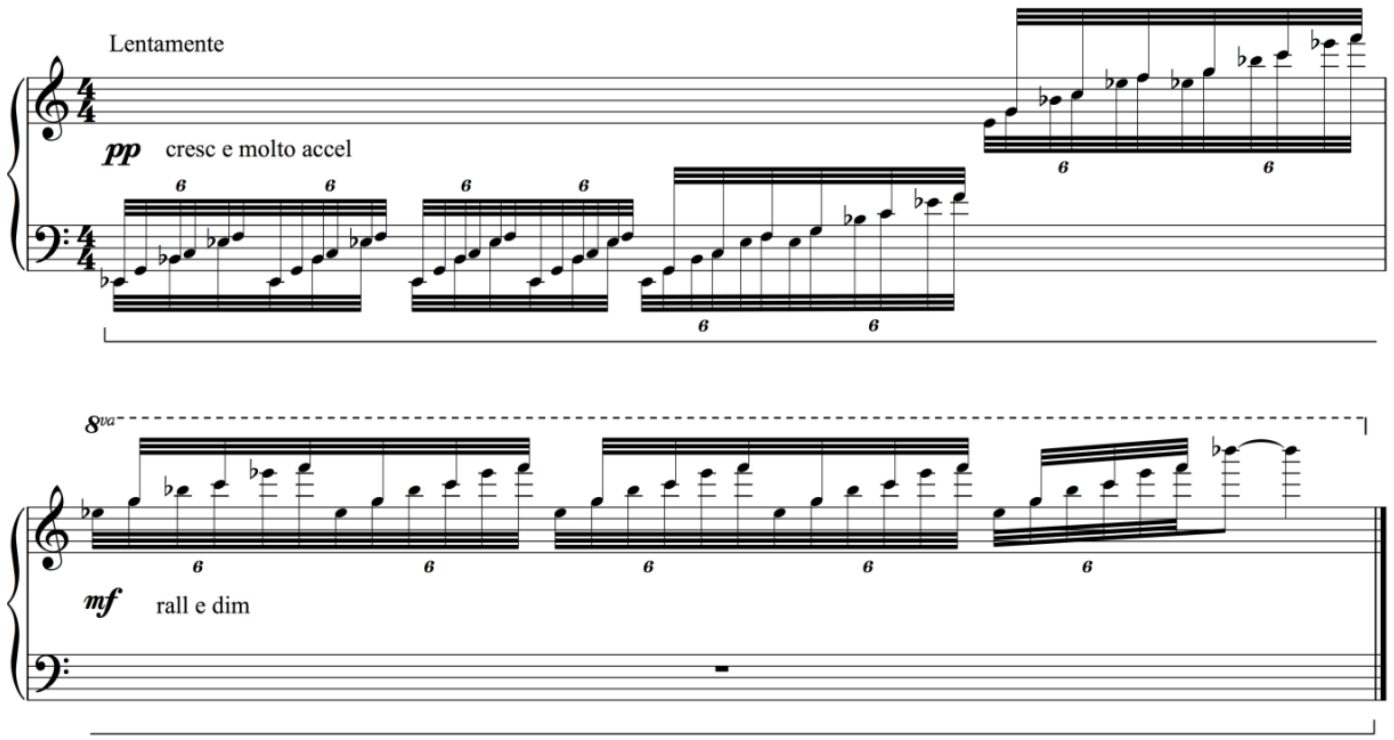

\section{Texture}

The texture of this movement is thinner than that of the first and third movements.

However, its texture is much thicker than del Aguila’s "Nocturne”, Op. 62 and "Half of Me”, Op. 70 (Figure 3.4.25) because del Aguila was concerned about the balance between the piano and orchestra. The evidence appears in his piano concerto 1997 version which has a thinner texture than the revised version in 2001. 
Figure 3.4.25: Texture in the second movement, mm. 28-29

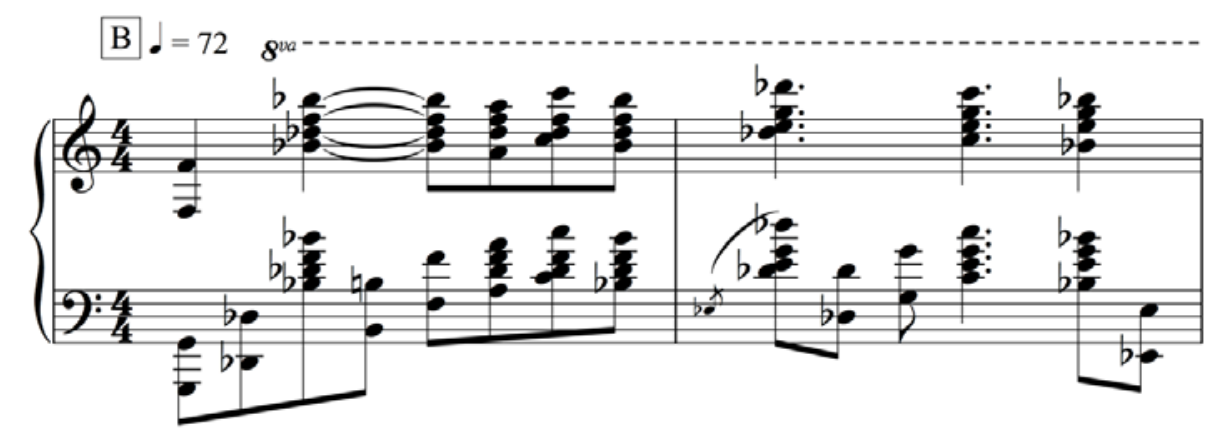

\section{Third movement}

\section{Tempo and Rhythm}

Latin dance and Uruguayan Candombe dance dominates the entire movement in 4/4 and 5/4. Different sections have different tempos. The most interesting section is in mm. 71-76, which is extremely fast at $d=230$. To speed up, it is necessary to practice slowly in order to know exactly the fingering and hand position movements.

\section{Articulation and Pedaling}

Articulation is very important in this movement. The first theme, in Latin dance character, should be played detached or staccato, using short pedal on accented notes to create a lively effect (Figure 3.4.26). The section in 5/4, which has the same rhythmic pattern as the second movement in mm. 71-96, uses the same pedal technique as the second movement in figure 3.4.23. 
Figure 3.4.26: Latin dance with short and detached articulation, mm. 1-2

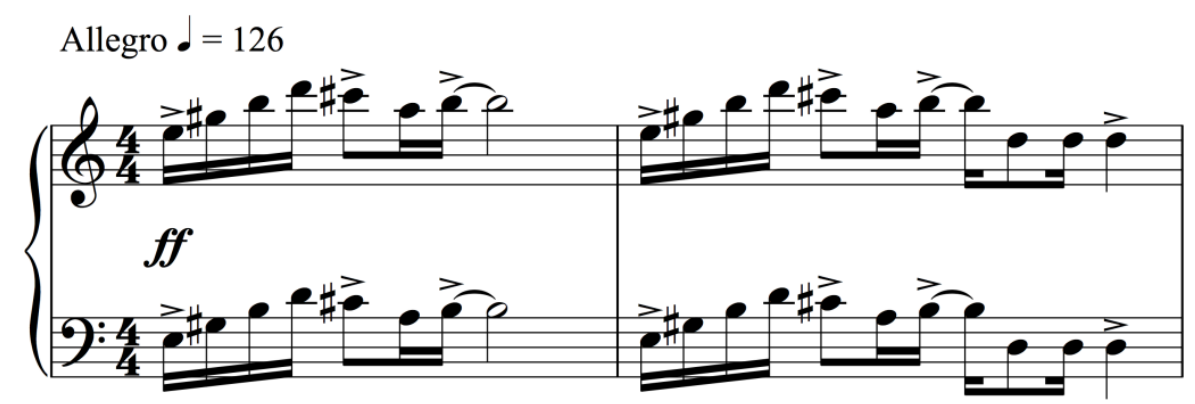

\section{Technique and Melody}

Chords, scale passages, broken octaves, and tremolo are the main techniques in this piece. However, del Aguila wrote this movement in a very pianistic style. In mm. 175-183, the right hand plays the running passages with a very light touch. Playing these passages using both wrist movement and fingers will make them easier. Writing down all fingerings and practicing slowly will help the body and brain memorize this piece. In mm. 184-190, using the fingering pattern 3-2-1 for the right hand running passages, and bringing out only the melodic line (the first note of triplet) is a good way the perform this passage (Figure 3.4.27).

Figure 3.4.27: Bringing out only the melodic line in the right hand, mm. 184

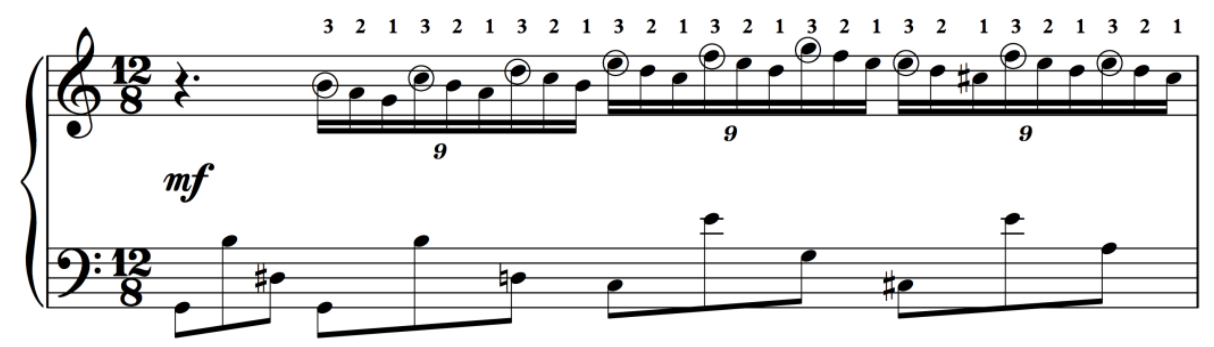

To practice the fast tetrachord scale passage (B-C-D-E, F-Gb-Ab-Bb) playing with both hands in mm. 97-114, requires dexterity of finger and relaxing the lower arm. In the rehearsal $\mathrm{H}$ mm. 148-150, the soloist should start the section in a slower tempo and gradually speed up in the 
latter part. In addition, an effective way to practice the right-hand broken octaves is by using rotation and playing them in groups. The melodic line in this passage is in the fifth finger of the right hand (Figure 3.4.28).

Figure 3.4.28: The right hand in broken octaves and melodic line in the fifth finger, m. 148

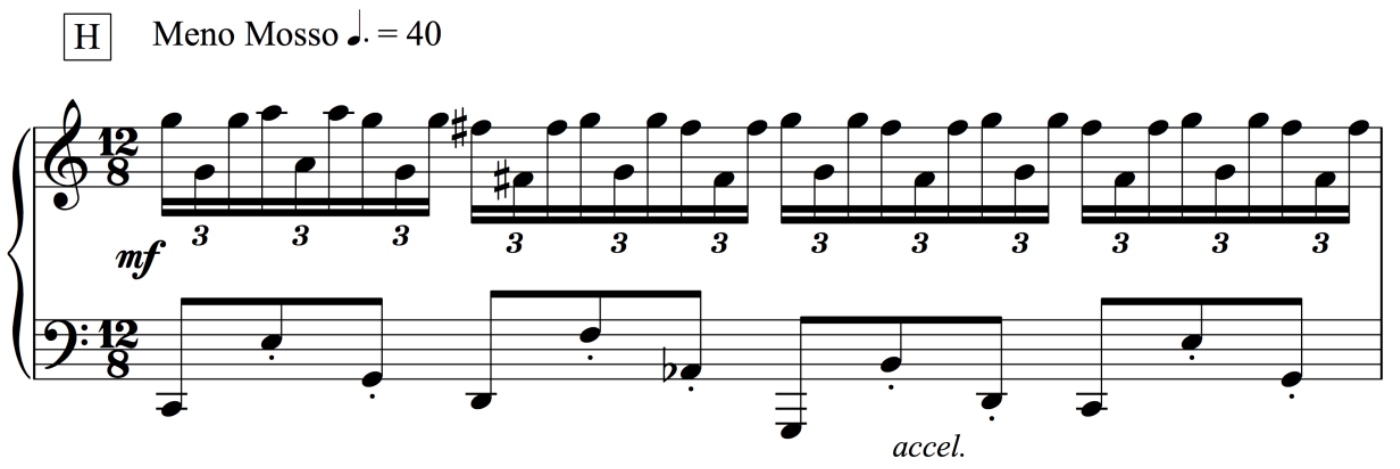

In the Uruguayan candombe dance theme in $\mathrm{mm}$. 213-254, it is necessary to practice body and hand movement to the next position as quickly as possible in order to play accurately (Figure 3.4.29).

Figure 3.4.29: Uruguayan candombe dance, mm. 213-214

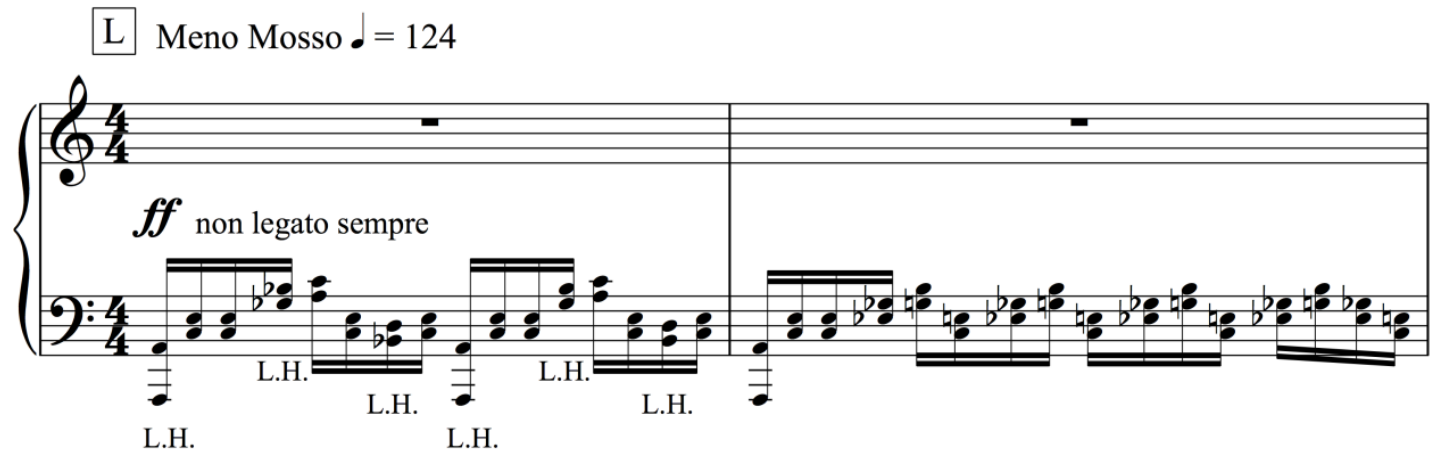

Playing a chord tremolo will easily cause arm fatique. Relaxing the wrist and entire arm but maintaining firm fingers is an important technique for playing tremolo; for example, the left hand plays the E-flat major chord (Eb-Bb-Eb) while the right hand plays the G-flat Augmented chord (D-Gb-Db-D) (Figure 3.4.30). 
Figure 3.4.30: Chord tremolo, m. 267

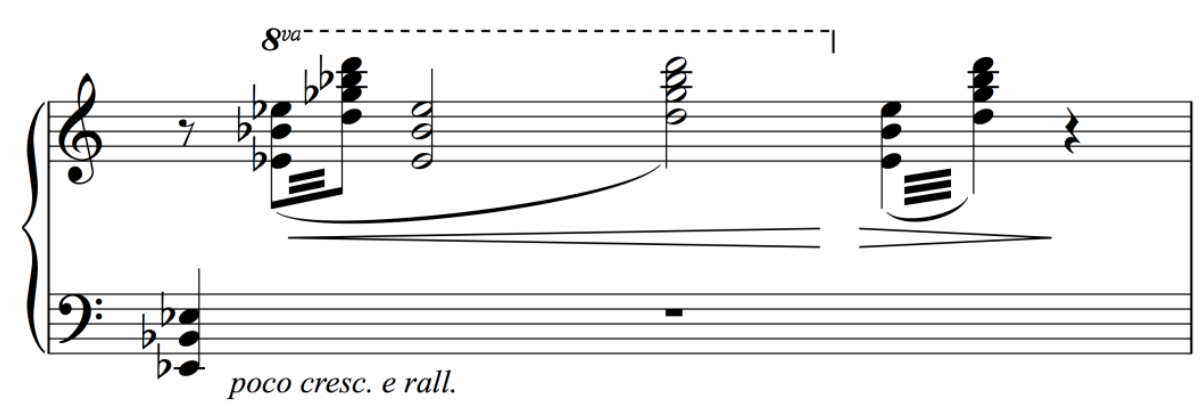




\section{CHAPTER IV}

\section{SELECTED UNPUBLISHED PIANO WORKS}

Chapter 4 consists of selected unpublished piano works by Miguel del Aguila. Four pieces are examined in this chapter: "Vals Brutal”, Op. 48; "Nocturne”, Op. 62; "Music in a Bottle”, Op. 67 ;and "Half of Me”, Op. 68. Each piece will be discussed in terms of its general characteristics, form, and pedagogical considerations.

\section{i) “Vals Brutal”, Op. 48}

\section{$\underline{\text { Overview and General Characteristics }}$}

"Vals Brutal" was written in 1995. This is a short character piece, about five minutes in length. Del Aguila premiered this piece at Bing Theater at the Los Angeles Museum of Art. This piece was inspired by a meeting del Aguila had with art patrons who had negative views of his music, and who considered most Latin classical music to be less valuable than other classical works. ${ }^{64}$ After the meeting, Del Aguila was very angry. He went home and improvised this aggressive waltz to express his emotions.

This piece is full of technical challenges such as scales, arpeggios, and continuous running passages. Both physical and mental strength are necessary in order to successfully play this piece. Extreme, violent feelings are demonstrated throughout the entire piece. The most remarkable place is at the ending of the waltz, where the pianist is instructed to drop the piano lid on the keys. ${ }^{65}$

\footnotetext{
${ }^{64}$ Email correspondence by Miguel del Aguila, March 13, 2016

${ }^{65}$ Ibid.
} 


\section{Form}

This waltz has an introduction, an ABA’ body, and a coda (Table 4.1).

Table 4.1: Structure of "Vals Brutal”

\begin{tabular}{|c|c|c|c|c|}
\hline Introduction & A & B & A' & Coda \\
\hline mm. 1-7 & $\mathrm{mm} .8-59$ & $\mathrm{~mm} .60-112$ & $\mathrm{~mm} .113-177$ & $\mathrm{~mm} .178-191$ \\
\hline
\end{tabular}

The introduction starts in mm. 1-7 (Figure 4.1.1). In the A section in m. 8-59, the right hand is playing the melody and other elaborate figures, including two-tetrachord scale (B-C-DE,F-Gb-Ab-Bb), while the left hand plays a waltz bass figure (Figure 4.1.2).

Figure 4.1.1: Introduction, mm. 1-7

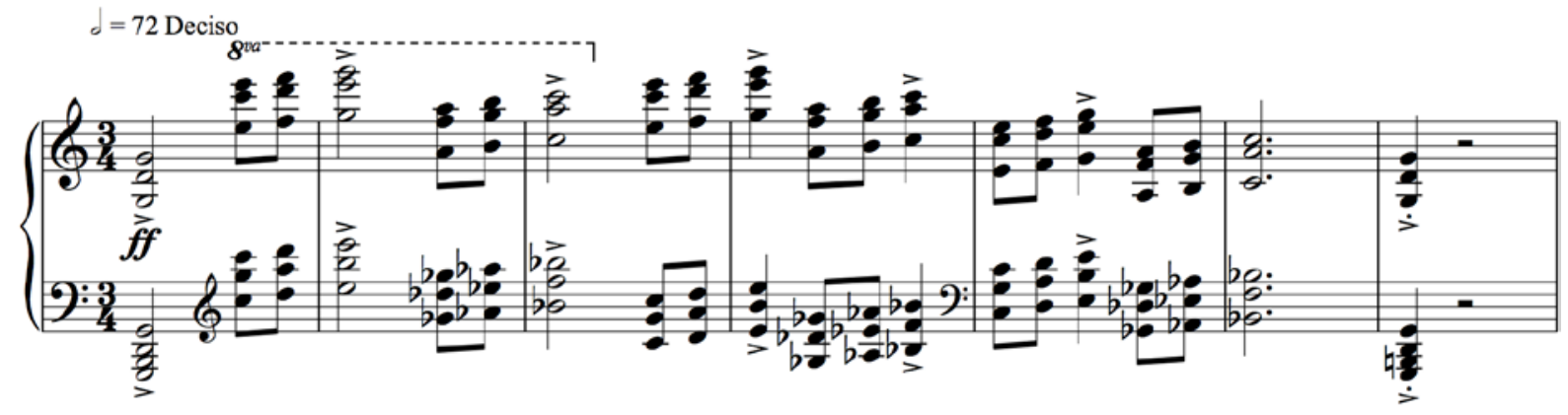

Figure 4.1.2: A section, mm. 8-11

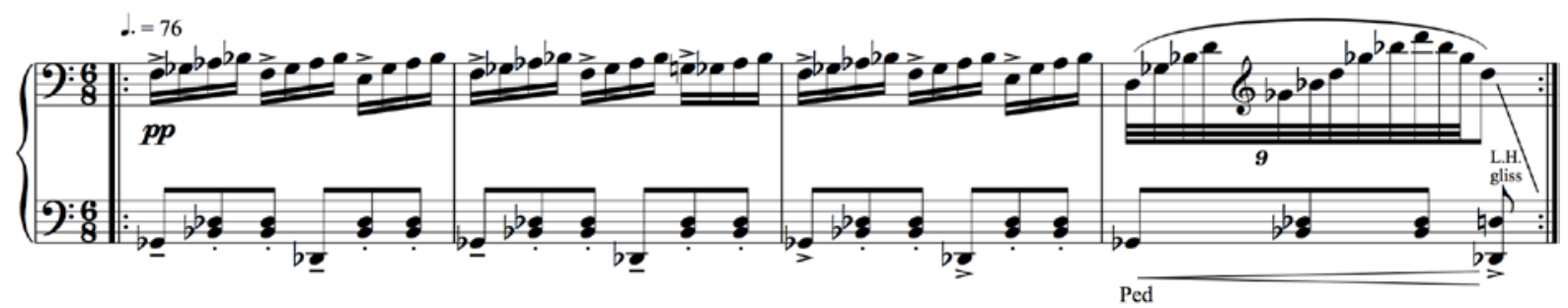

The B section, mm. 60-112, uses material from the A section. It starts with a more elaborate left-hand accompaniment in sixteenth-note broken chords, and later changes to twotetrachord scales, mm. 86-89 and 94-97 (Figure 4.1.3). In mm. 102-112, the right hand changes 
to octaves with the emphasis on the first and fourth beats (Figure 4.1.4). The B section ends with left-hand cluster.

Figure 4.1.3: B section, mm.60-61

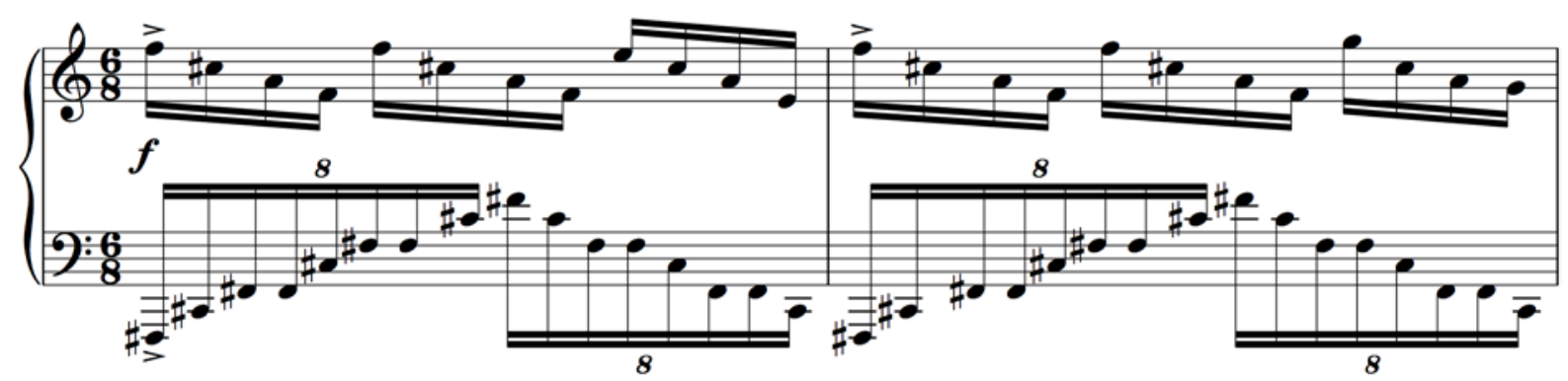

Figure 4.1.4: Right hand changing to octave, m. 102

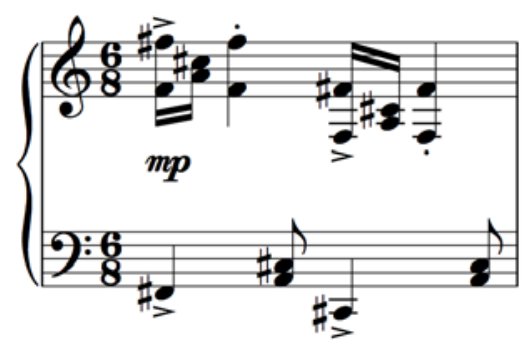

The A’ section, mm. 113-177, comes back in the high register and changes to left hand chords (Figure 4.1.5). Material from the B section in mm. 102-112 reappears in mm. 156-165, but it is made more complicated by changing the left-hand figure to two-tetrachord scales in the left hand.

Figure 4.1.5: A' section, mm. 113-114, the right hand one octave higher than the A section

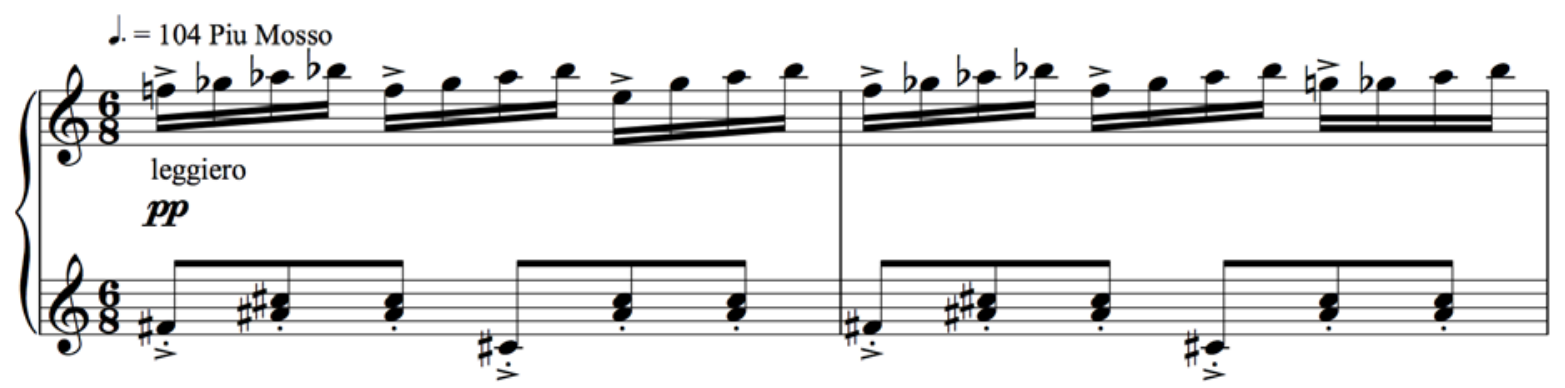


The coda in Lento, mm. 178-191, begins with the left-hand “um-pah-pah” figure, establishing the waltz pattern with the right-hand broken chords. The tempo increases at the cres. e accel. and the piece concludes with a right-hand glissando and double hand clusters (Figure 4.1.6 and 4.1.7).

Figure 4.1.6: Coda, mm. 178-180

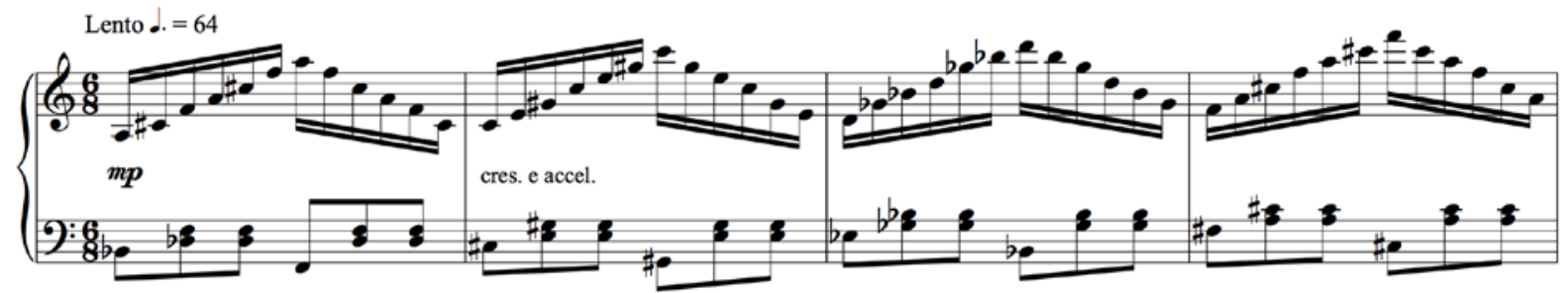

Figure 4.1.7: Ending of "Vals Brutal” with glissando and clusters in both hands, mm. 188-191

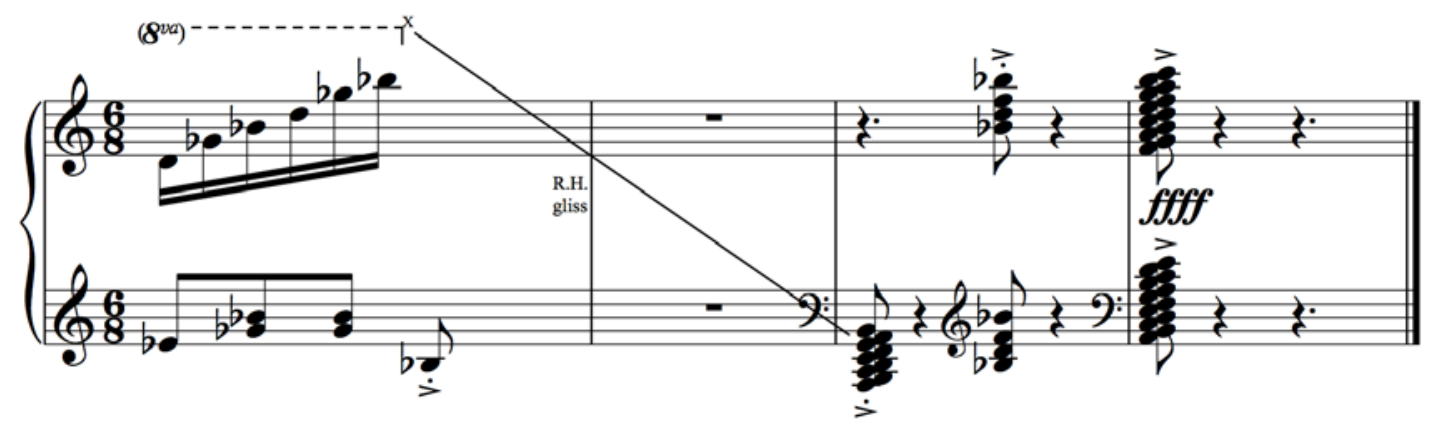

\section{$\underline{\text { Pedagogical Concerns }}$}

"Vals Brutal” is one of del Aguila’s most technically demanding piano works. The level of this piece is suitable for advanced students such as undergraduate students and upper level players. Its difficulty could be compared to an étude of Liszt or Chopin. The section of this chapter which addresses pedagogical considerations will cover the fingering, techniques, melody, voicing, direction, phrasing, tempo, time signature, pedal, dynamics, and miscellaneous considerations. 


\section{Fingering}

When playing the two-tetrachord scales, pianists should use 1-2-3-4 and 1-2-3-4 for the right hand and 4-3-2-1 and 1-2-3-4 for the left hand in the ascending scale (B-C-D-E and F-GbAb-Bb) (Figure 4.1.8 and 4.1.9).

Figure 4.1.8: Fingering for two-tetrachord scale in the right hand, m. 53

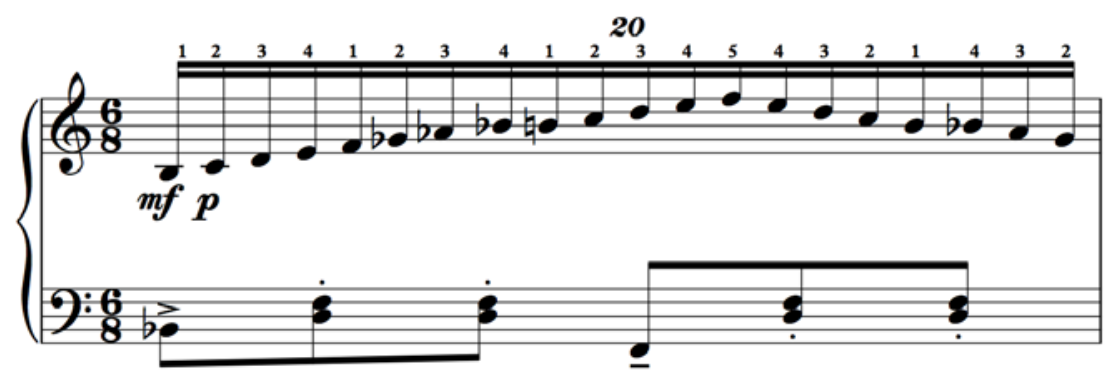

Figure 4.1.9: Fingering for two-tetrachord scale in the left hand, m. 94

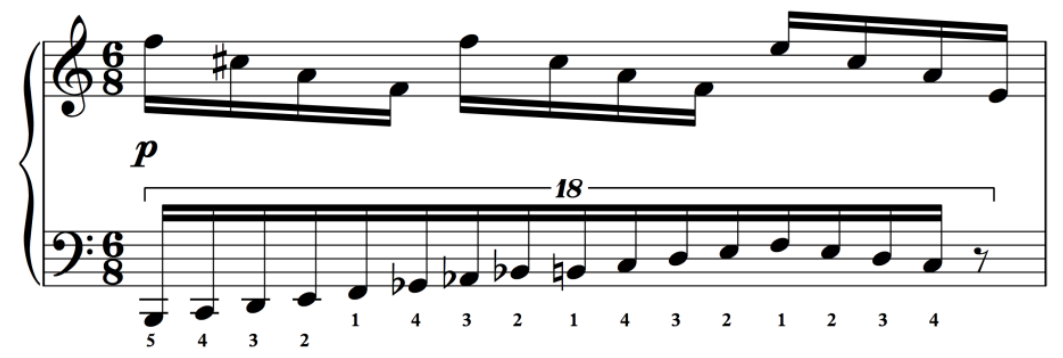

In mm. 170-172, the performer should use both hands to play the arpeggiated passages

(Figure 4.1.10).

Figure 4.1.10: Using both hands to play arpeggiated passages, m. 170

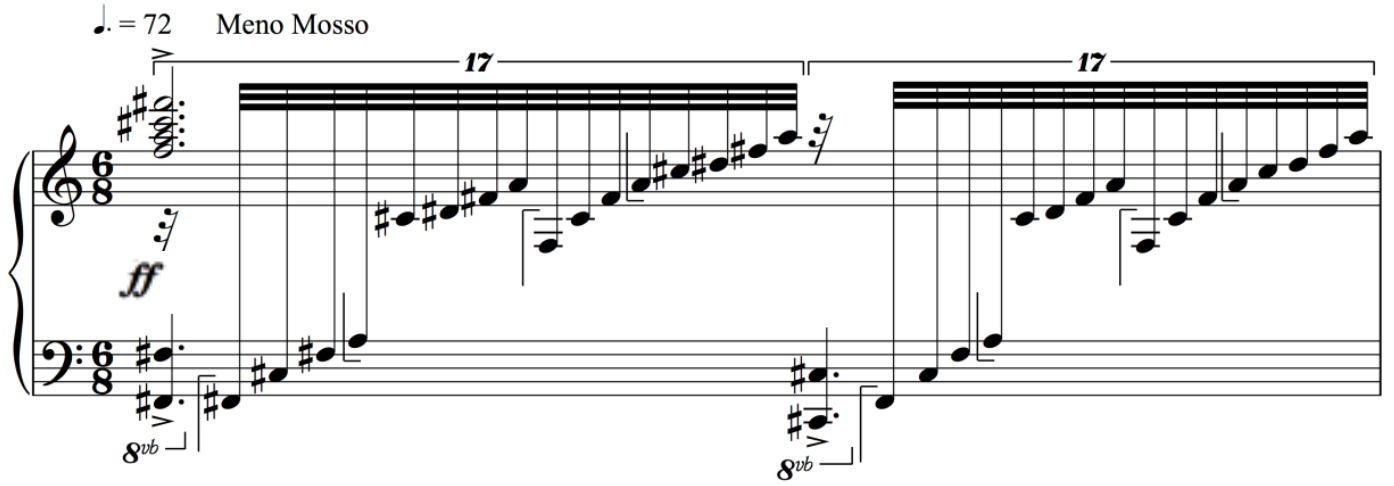




\section{Technique}

A variety of pianistic techniques can be found in "Vals Brutal”: scales, arpeggios in both hands, glissandi, chords and clusters. The glissandi appear in both hands. To play the glissandi, use the third finger's nail for the right hand ascending or the left hand descending, and the thumb’s nail for the right hand descending or the left hand ascending sweep. The glissandi should be played on the surface of the keyboard as fast as possible with the sustain pedal.

The two-tetrachord scales 1-2-3-4 and 1-2-3-4 should be practiced by blocking 1-2-3-4 and playing the rhythmic pattern with a relaxed wrist, in order to train the body to memorize the fingering and execute the passage without any tension.

As with all fast-tempo pieces, it is necessary to practice this piece slowly and with careful attention to details and accuracy. The performer must prepare his/her mind to play this piece with an aggressive character and without any hesitation. However, relaxation of the whole body, especially the arms and wrists, is the key to performing this piece successfully. Physical and mental strength and control are essential for a successful performance of this piece.

\section{Notation}

In mm. 175-177, there are “ $x$ ” markings in the score (Figure 4.1. 11). Del Aguila said in his email that there is no specific note referenced for the x markings. He also gave the following suggestion for how to play these three measures: "Let the speed and the other hand getting in the way give you the limit of how wide the glis(sando) is." 66

\footnotetext{
${ }^{66}$ Email correspondence by Miguel del Aguila, November 18, 2016
} 
Figure 4.1.11: x markings, mm. 175-177

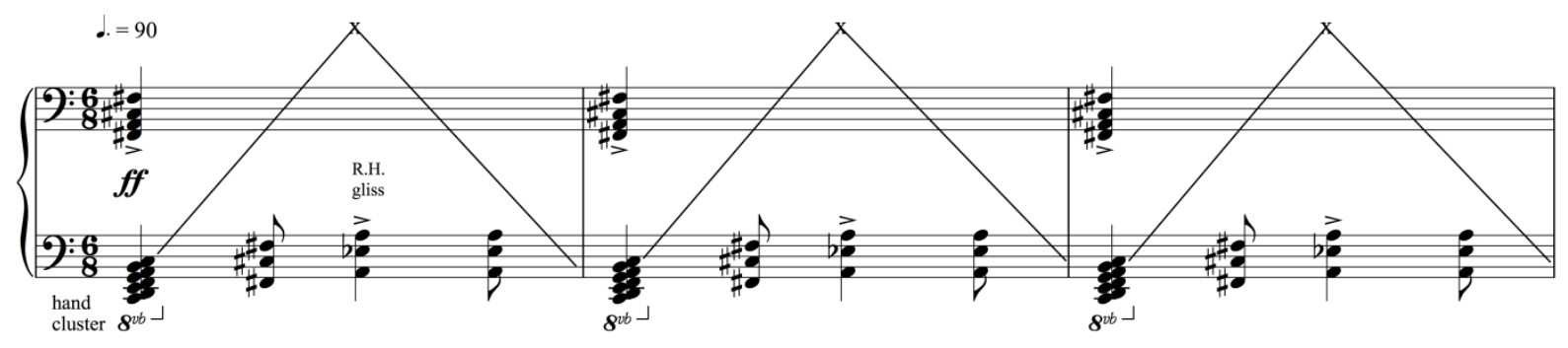

\section{Melody, Voicing, Direction and Phrasing}

The melody of this waltz uses accented notes in the right hand, which is conjunct and appears in short motives. Voicing is an important aspect to consider, because there are several notes in both hands. The important notes and motives shown in the score should be played in such a way as to distinguish them from the other notes. For example, the melody in m. 8-10 is FF-E, F-F-G and F-F-E in the right hand, found in the sixteenth notes in the first, third, and fifth beats. All the other notes in both hands should be played softly (Figure 4.1. 12).

Figure 4.1.12: Melody in right hand F-F-E, F-F-G and F-F-E

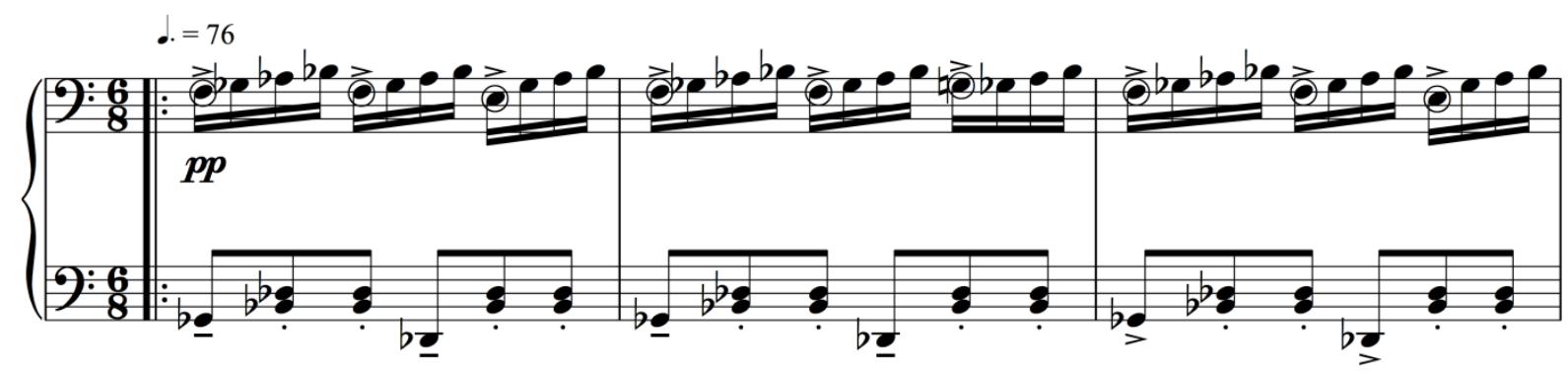

Finding the length of each phrase is important to shape and create direction. The length of each phrase is mainly four bars. Moreover, practicing melodies only with the left hand will help the performer know the direction of the piece. 


\section{Tempo and Time Signature}

"Vals Brutal" is a fast waltz. Its time signature alternates between $3 / 4$ and $6 / 8$. The use of hemiolas makes the rhythm of this waltz similar to Chopin’s "Waltz in A flat major”, Op. 42 (“Two-Four”). There is also use of 10 against 6, 18 against 6, and 6 against 8, making this piece more difficult to count and play. While practicing, pianists should keep the main beat steady, dividing the notes into groups and practicing in very slow tempos.

Del Aguila indicated tempo markings many times throughout this piece. Students should observe tempo markings to determine whether the feel of the piece should be moving forward or holding back.

\section{Pedaling and Dynamics}

In the introduction, mm. 1-7, pianists should use the sustain pedal to accent the half note chords, first beat chord, and dotted half note chord, and they should lift the pedal on the eighth note chords. In addition, the last chord in this section uses a short sustain to create a decisive ending (Figure 4.1.13)

Figure 4.1.13: Using sustain pedal for introduction, mm. 1-7

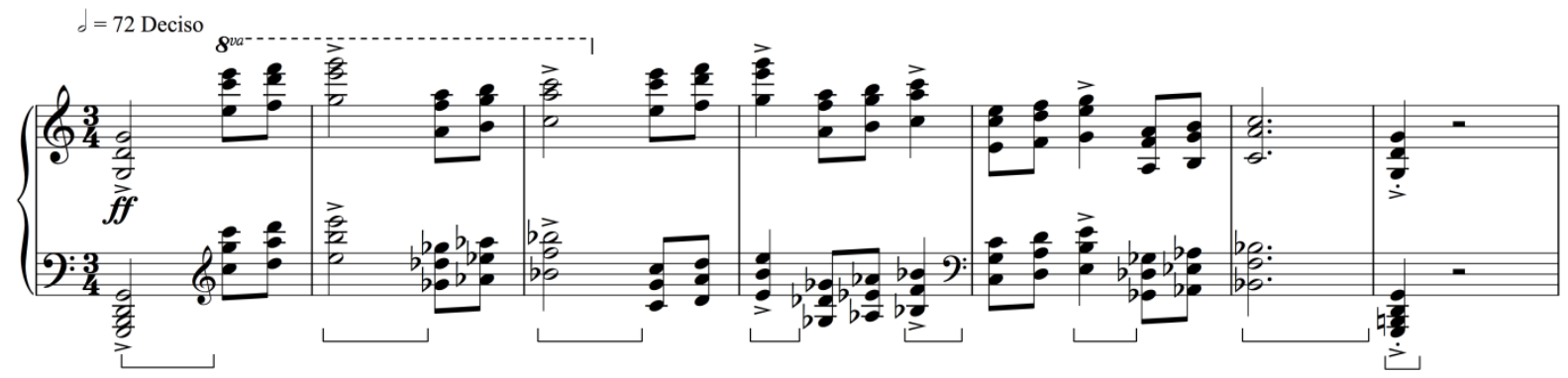


A thin touch of sustain pedal is used on the first and fourth beats in the $p p$ section (Figure 4.1.14) to represent a waltz character. For the glissandi, clusters, and louder sections, using a longer pedal will create a more dramatic effect for this piece.

Figure 4.1.14: Using pedal for the $1^{\text {st }}$ and $4^{\text {th }}$ beat, m. 8

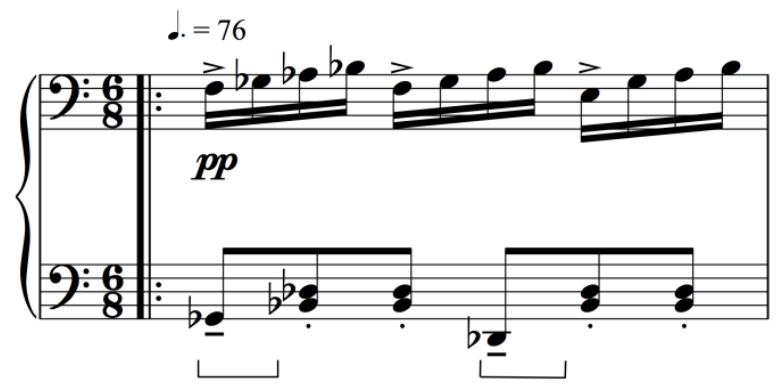

Using a deeper sustain pedal is necessary for the forte sections, broken chords, glissandi, and clusters. Furthermore, the performer should pay attention to the abrupt dynamic changes which will create drama for this piece if used effectively. A lack of dynamic changes can cause boredom in this piece. 


\section{ii) “Nocturne”, Op. 62}

\section{Overview and General Characteristics}

Del Aguila’s “Nocturne”, Op. 62 for solo piano was composed in 1998, and it was premiered by Karen Corbett in Ventura, California in the same year. The length of this composition is eight minutes. A significant influence from Jazz and 1940's South American Song style in Brazilian chôro can be observed in the slow and lyrical melodies and the melancholy and sorrowful mood. ${ }^{67}$ Del Aguila described his nocturne in the following way:

"I wrote Nocturne in just a few hours on a foggy afternoon in California. Its form and harmonic structure are very basic and the lack of development give this piece an almost folk-style flow where emotions are expressed with spontaneous simplicity and sincerity. 15 years later, I unknowingly returned to this style in Silence, a work for violin and piano that seems to continue the mood of this piece and to be related to it in its mood." 68

The theme of this piece is very significant because it became the material for del Aguila's Piano Concerto, Op. 57, and “Half of Me” for piano left hand, Op. 70.

\section{$\underline{\text { Form }}$}

This nocturne is in AB form with an introduction and codetta (Table 4.2). The introduction section begins with lyrical, broken chords in mm. 1-19 (Figure 4.2.1). In the A section, mm. 11-50, the right hand presents a simple and conjunct melody while being accompanied by a left hand broken chord pattern. The left hand accompaniment is in an irregular time signature (5/4), which is similar to the rhythmic pattern of the jazz composition "Take Five" (1959) by Dave Brubeck (1920-2012) (Figure 4.2.2). In the B section, mm. 51-77, the time signature changes back to $4 / 4$. The melody in this section is more lyrical and expressive, and it has a broken chord accompaniment (Figure 4.2.3). This section presents conversation between

\footnotetext{
${ }^{67}$ E-mail correspondence with Miguel del Aguila, March 13, 2016.

${ }^{68}$ Ibid.
} 
the melody in the right hand and countermelody in the left hand, mm. 59, 61, 63 and 69. The piece ends with a three-bar codetta, mm. 78-81. This codetta draws from the broken chord accompaniment, which is now used in both hands, seeming to reference the cadenzas of Chopin’s nocturnes (Figure 4.2.4).

Table 4.2: Structure of del Aguila’s “Nocturne”, Op. 62 for piano

\begin{tabular}{|l|l|l|l|}
\hline Introduction & A & B & Codetta \\
\hline mm. 1-10 & $\mathrm{mm} .11-50$ & $51-77$ & $\mathrm{~mm} .78-81$ \\
\hline
\end{tabular}

Figure 4.2.1: Introduction, mm. 1-4

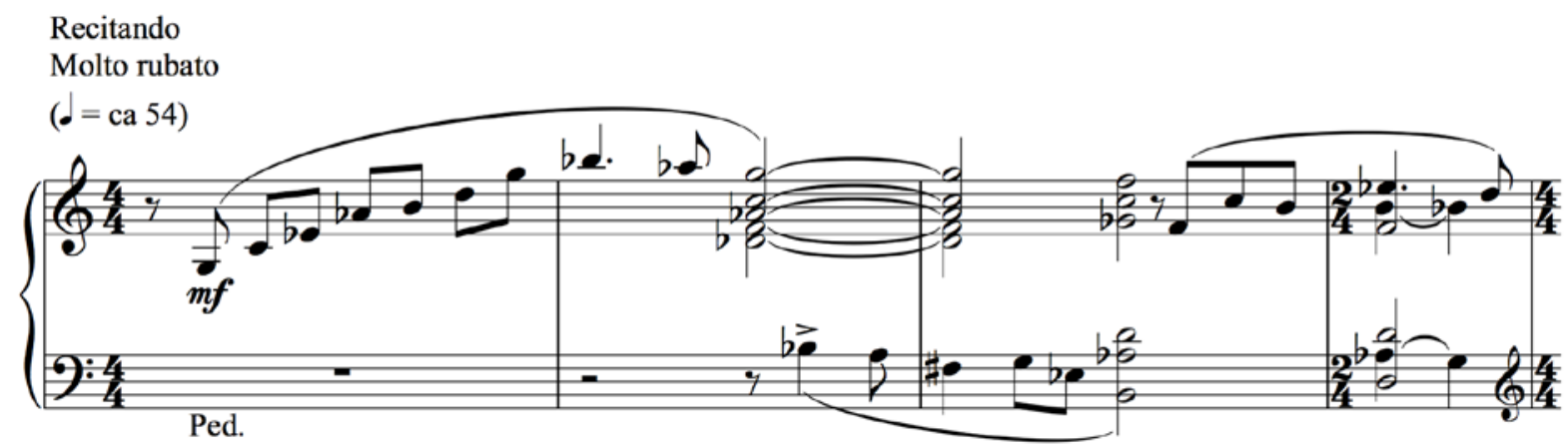

Figure 4.2.2: Melody and accompaniment in A section, mm. 13-14

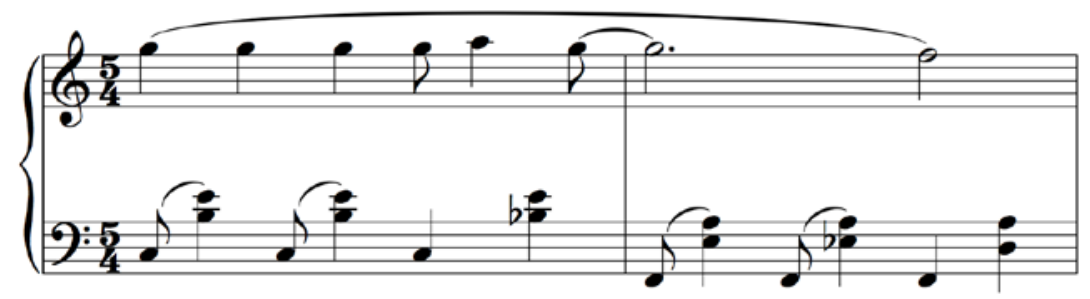

Figure 4.2.3: B section, mm. 54-55

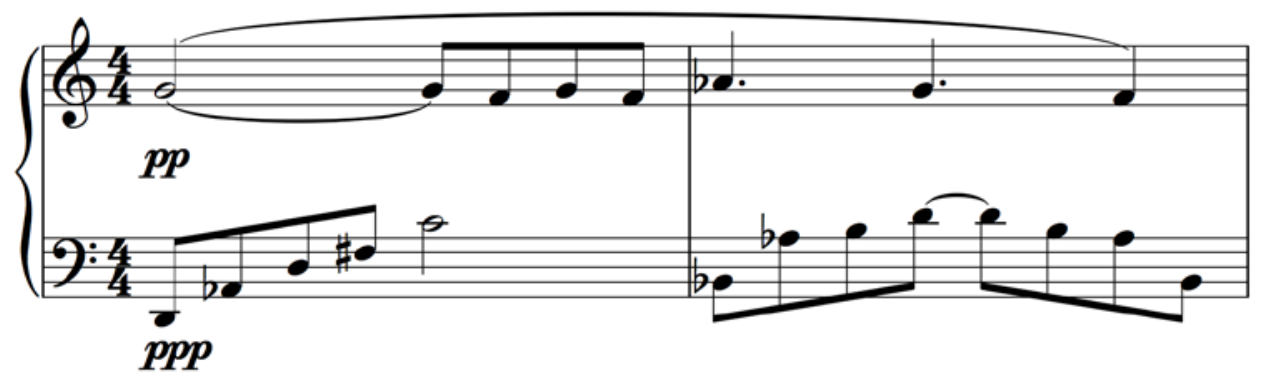


Figure 4.2.4: Codetta, mm. 78-81
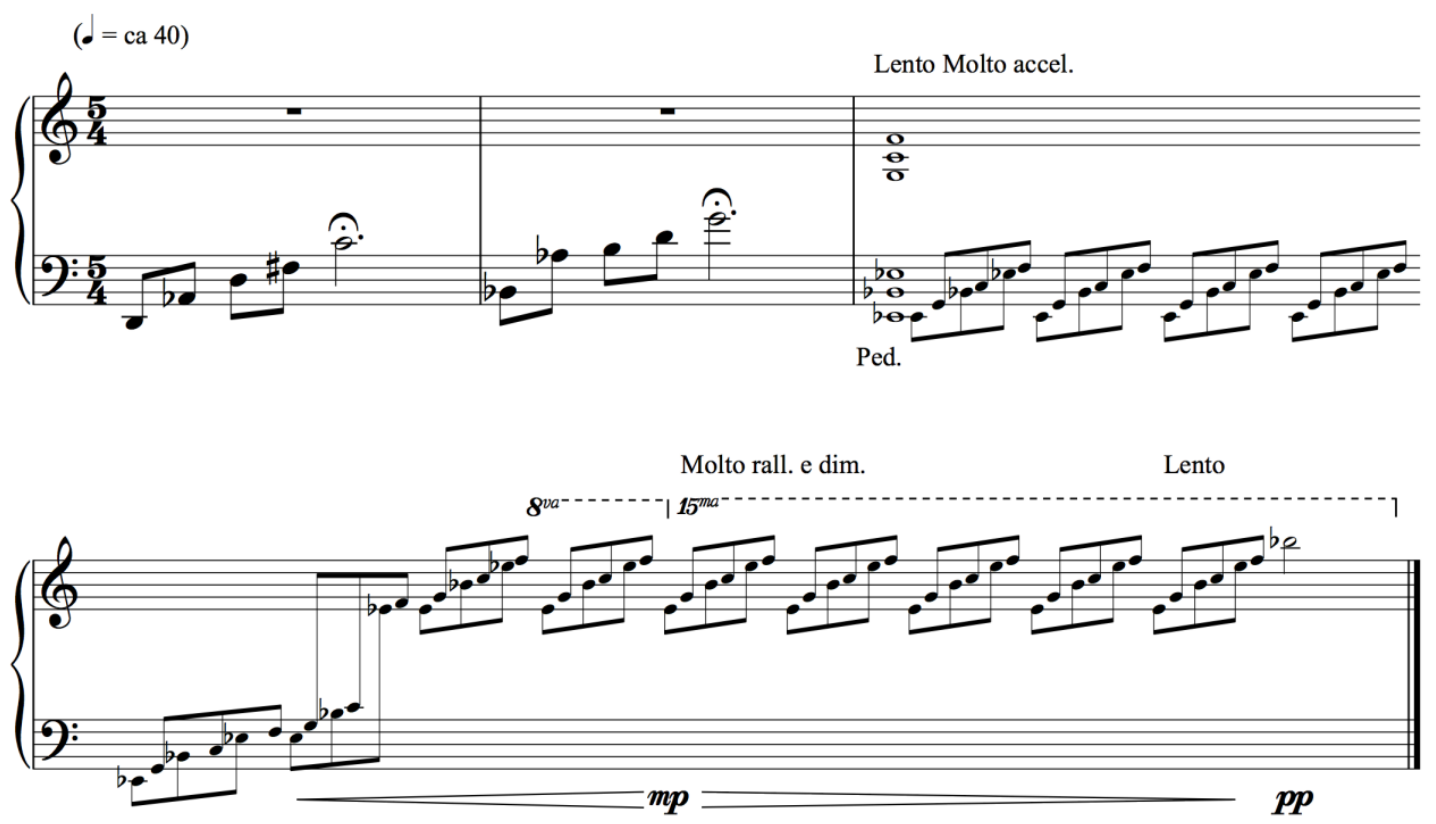

\section{$\underline{\text { Pedagogical Concerns }}$}

"Nocturne”, Op. 62 is suitable for intermediate level pianists. However, the irregular time signature in 5/4 and its rhythmic complexity in some places can easily confuse the performer.

\section{Melody, Texture, Voicing, Direction and Shaping}

Two different textures are presented in this nocturne: contrapuntal texture and melody with broken chord accompaniment. In the contrapuntal texture in the introduction and B section there are two to four lines, and each line is lyrical and uses leaping counter melodies. Another texture is in the A section; one simple melodic line with broken chord accompaniment. This piece uses four bar phrases, and del Aguila indicates the tempo in each section. 


\section{Fingering}

In some places, the left hand can help play the right hand part. For example, the broken chord in $\mathrm{m} .1$ in the introduction can be played with the left hand first, using 5-3-2-1, and the right hand following with 1-2-4-5 (Figure 4.2.5). Another place is in mm. 9-10, where the left hand can play the lowest note of the series of descending half diminished chords (Figure 4.2.6).

Figure 4.2.5: Using left hand fingering 5-3-2-1 and right hand fingering 1-2-4-5, mm. 1-2

Recitando

Molto rubato

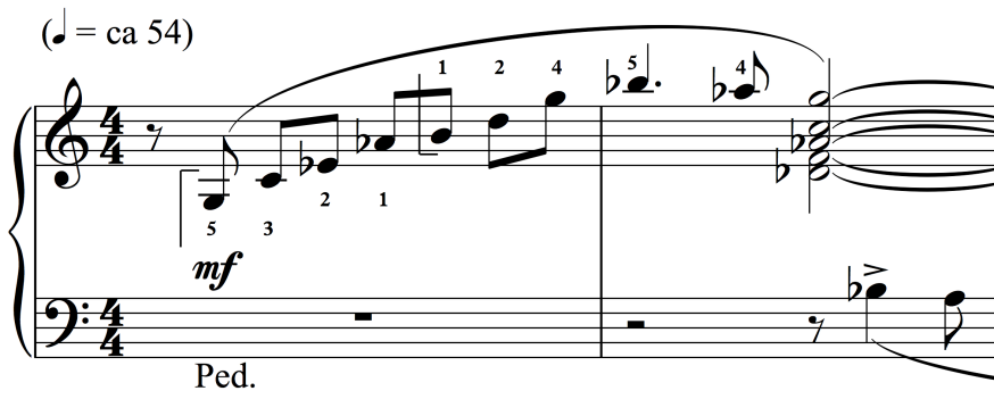

Figure 4.2.6: Using the left hand to play the lowest of the series of descending half diminished chords, mm. 9-10

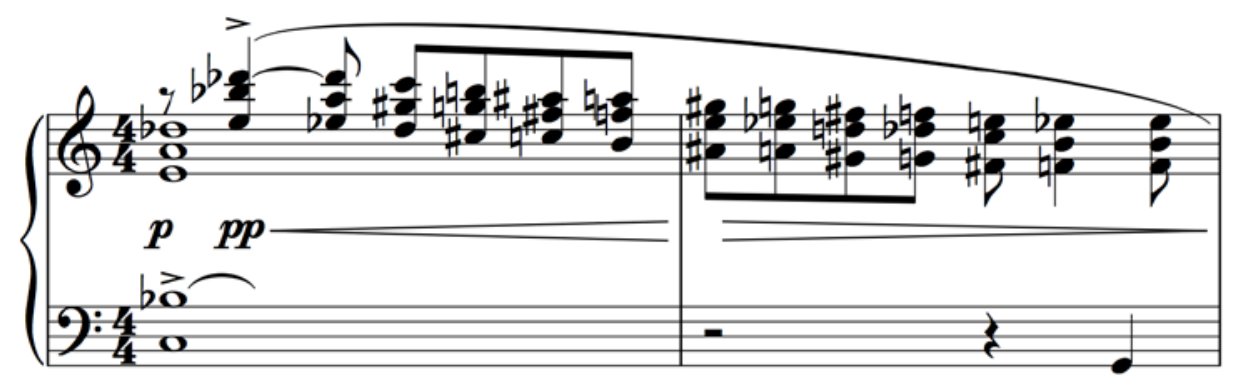

\section{Technique}

The difficulty level of del Aguila's nocturne is suitable for the upper intermediate student. When compared to his other solo piano works, this piece is the least difficult. 
The B section, mm. 54-74, is a technically difficult part: the complicated left hand broken chords and contrapuntal texture contribute to the difficulty of bringing out the melody line.

In the codetta, both hands play broken chords in the same position and move up to higher registers, similar to a cadenza. Instead of playing broken chords, it can be helpful to practice this section by playing block chords in both hands in order to establish the hand position.

\section{Rhythm and Tempo}

The rhythm and time signature in the A section can present difficulties for pianists who are learning this piece. Grouping the beat to $3+2$ will make this section less confusing when playing three against eight and three against two; for example, mm. 26, 37-38 and 41-43 (Figure 4.2.7).

Figure 4.2.7: Rhythmic complexity, m. 26

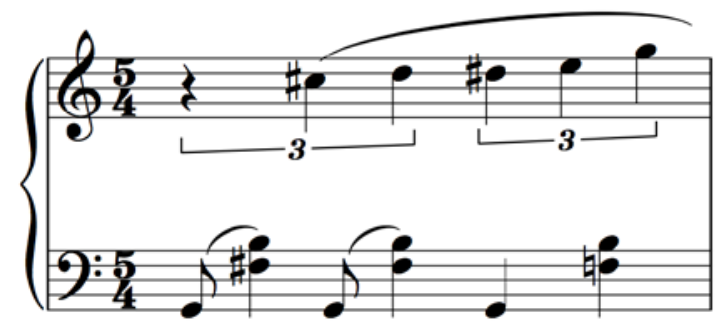

The tempo for this piece is slow. Del Aguila includes metronome markings in each section to guide the mood and feeling of each section. He indicated the following remark in the score in mm. 12-15 “play accents simile except when changes are needed to follow the R.H.’s rubato phrasing," meaning that the performer should play the right hand melody with rubato in order to shape the musical phrase. 


\section{Pedaling and Dynamics}

Shorter sustain pedals are used for the $5 / 4$ in the A section, while a longer sustain pedal is used for the broken chord accompaniment in the B section (Figure 4.2. 8). The soft pedal is essential for changing color, especially for the $p p$ and $p p p$ parts. In the codetta, the hand crossing the broken chords should use long pedal and soft pedal in mm. 80-81, in order to change color and create a dreamy atmosphere at the end of this nocturne.

Figure 4.2.8: Using sustain pedal in 1) A section and 2) B section

1) A section, mm. 14-15

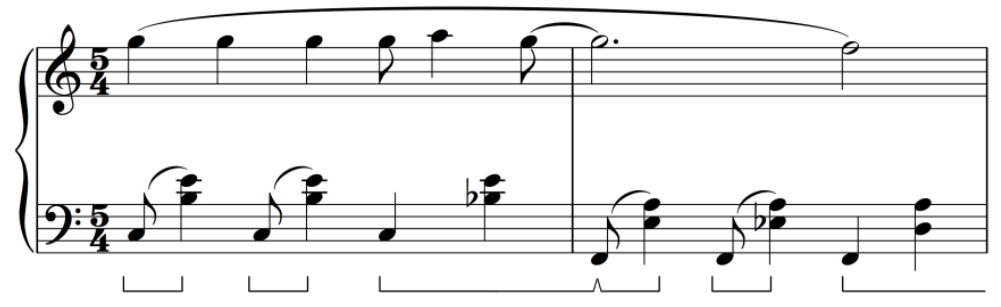

2) B section, mm. 54-55

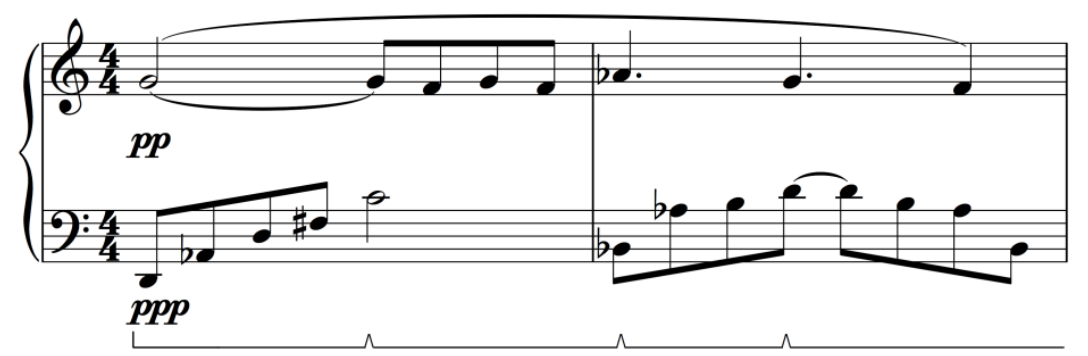

Being sensitive to the level of dynamics, especially for repeated notes, is an important aspect to consider. This will create nice, long phrases and it will ultimately shape the piece more successfully. 


\section{iii) “Music in a Bottle”, Op. 67}

\section{$\underline{\text { Overview and General Characteristics }}$}

"Music in a Bottle” for piano, Op. 67 was dedicated to James Miltenberger by Miguel del Aguila in 1999. The performance time is around ten minutes. This character piece is divided into three sections: I The Bottle’s Journey, II The Message, and III Bottle Sinks. It was recorded by James Miltenberger on Scotwood Music Label CD, $20^{\text {th }}$ Century Dances and Improvisations. The journey of the bottle is illustrated throughout this character piece, starting with the bottle carrying a message across the ocean but then sinking before it has been delivered. ${ }^{69}$ "Music in a Bottle” reveals some of del Aguila's views about life; “The bottle and its journey represent to me our own selves and our own lives' journey and how when we die we take with us most of the memories within us, many of which were undisclosed to everyone else.”70 This composition also related to a significant event in del Aguila's life. His father died in the same year in October $1999 .^{71}$

According to James Miltenberger, "I commissioned him to write a character piece. He sent me the first version and later he sent another version to me which was different from the first one. He added more dissonance in some places which make the color of this piece much more interesting. It was premiered in the spring of 1999 at West Virginia University»72

This character piece demonstrates del Aguila’a connection to Debussy’s musical tradition in his use of descriptive titles, which are reminiscent of Debussy’s works such as Images Book I, L. 110 and Image Book II, L. 111. Image Book I includes the movements: I Reflets dans l'eau (Reflections in the Water), II Hommage à Rameau (Hommage to Rameau) and III Mouvement

\footnotetext{
${ }^{69}$ E-mail correspondence with Miguel del Aguila, March 13, 2016.

${ }^{70}$ Ibid.

${ }^{71}$ Miguel del Aguila, interview by Sornsuang Tangsinmonkong, January 12, 2017, Camarillo, CA.

${ }^{72}$ James Miltenberger interview by Sornsuang Tangsinmonkong, November 5, 2016, College of Creative Arts, West Virgnia University, Morgantown, WV.
} 
(Movement). Images Book II also includes descriptive titles like I Cloches à travers les feuilles (Bells Through the Leaves), II Et la lune descend sur le temple qui fut (And the Moon Sets over the Temple That Was) and III Poissons d'or (Goldfish). Furthermore, "Music in a Bottle" was also strongly influenced by minimalism. This can be heard in its long and consistent motives which illustrate waves in the ocean.

\section{$\underline{\text { Form }}$}

The structure of this character piece is ternary form, or ABA' form. There are three main sections: I The Bottle’s Journey, II The Message, and III Bottle Sinks (Table 4.3).

Table 4.3: Structure of Music in the Bottle

\begin{tabular}{|l|l|l|}
\hline \multicolumn{1}{|c|}{ A } & \multicolumn{1}{c|}{ B } & \multicolumn{1}{c|}{ A' $^{\prime}$} \\
\hline I The Bottle's Journey & III The Message & III Bottle Sinks \\
\hline mm. 1-57 & mm. 58-111 & mm. 112-122 \\
\hline
\end{tabular}

In the A section, The Bottle's Journey, the texture is stable with series of sixths in the right hand and an open fifth in the left hand, another quality which demonstrates the strong influence of minimalism (Figure 4.3.1). In the B section, The Message, del Aguila uses a beautiful and expressive melodic line with a broken chord accompaniment (Figure 4.3.2). The A' section returns with the left hand changing to octave and block chords crossing the right hand.

Figure 4.3.1: A section, mm. 1-3

\section{THE BOTTLE'S JOURNEY}

• $=62$ TRANQUILLISSIMO SEMPRE LEGATO E CON MOLTO PEDALE, "FLOATING"

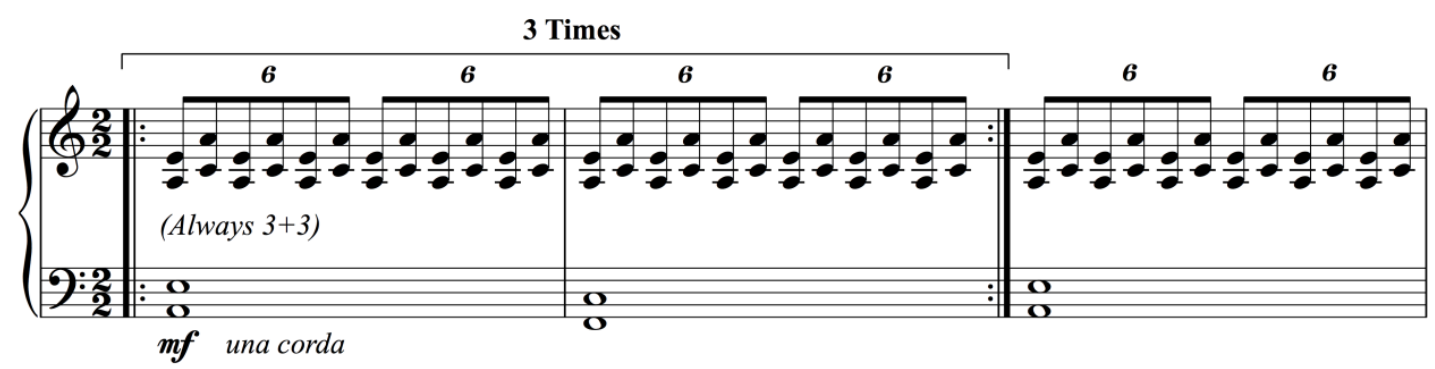


Figure 4.3.2: B section, mm. 58-61

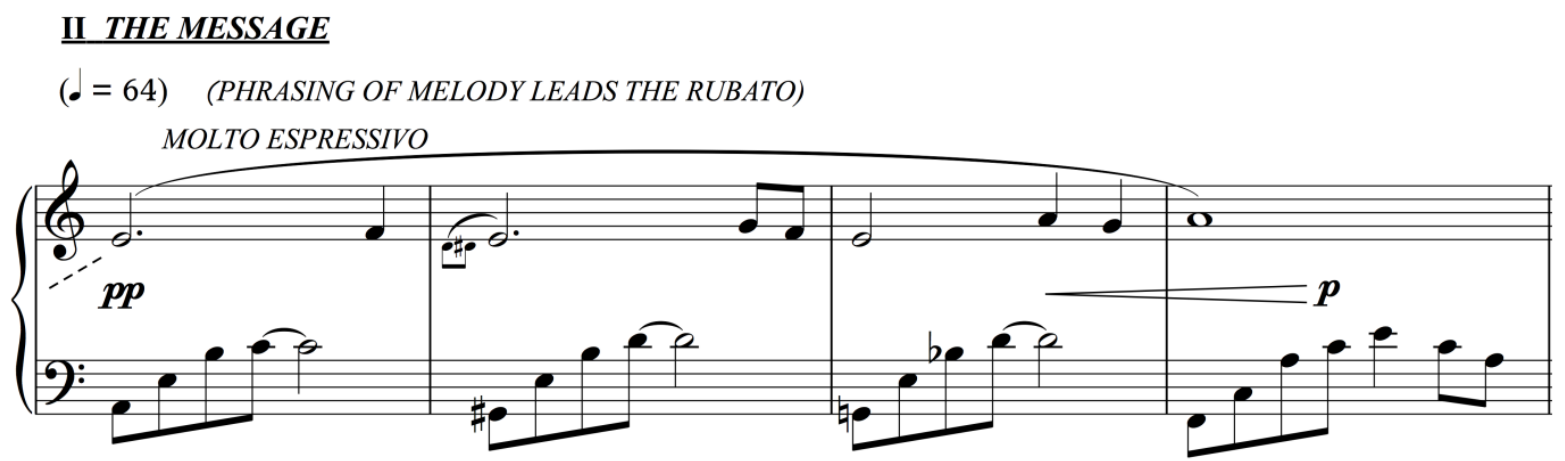

In the A' section, Bottle Sinks, mm. 120-122, the series of descending diminished fifths depict the bottle sinking down to the bottom of the ocean, ending with ppppp.

\section{Pedagogical Concerns}

At first glance, "Music in a Bottle" can be played by intermediate students due to the simple notation and repetition. However, it could be argued that it would be more suitable for advanced students because it requires great concentration to play and memorize. The emotions and colors of this composition are so heartfelt that the performer must treat every sound with utmost care. The concepts behind this piece, because they are centered on deep aspects of life, are not easy to interpret.

\section{Melody, Direction, Shaping and Phrasing}

The series of sixths in the A and A' sections play a significant role in this piece. The direction of these sections comes across as unpredictable and wandering, portraying the floating bottle across the ocean.

On the other hand, the B section contains a long melodic line. The direction and phrasing is based on the right hand melody, which del Aguila indicates in the score on page 4 line 4 (m. 
58): “Phrasing of melody leads the rubato.” Thus, practicing the right hand melody alone will help the performer understand the direction of this section and how to shape the phrases.

The long accelerando and ritardando on page 3-4 (mm. 37-57) are notable because they act like a transitional section which connects to the B section.

\section{Notation}

The notation in Music in the Bottle is consistent with the style of minimalism, which consists of repetitive figures (Figure 4.3.3).

Figure 4.3.3: Minimalism in Music in the Bottle, m. 14

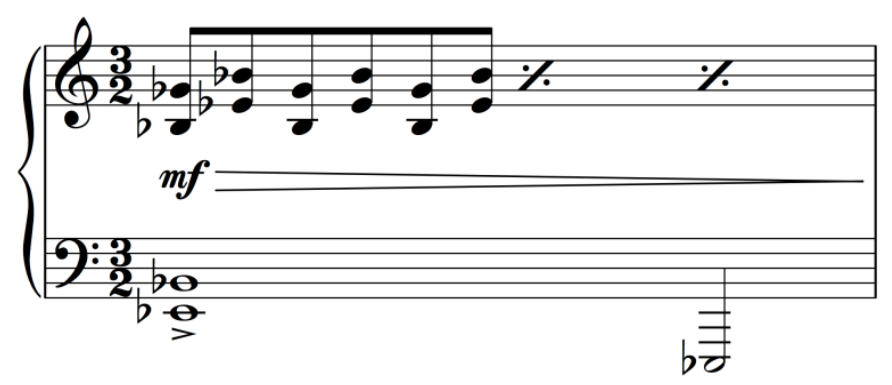

Fingering and Techniques

The sixths in the right hand should be played with 1-4 and 2-5. However, playing endless sixths with incorrect hand posture can cause stiffness, especially in the wrist. Arm movement and wrist relaxation while playing this series of sixths in the right hand are essential to release tension.

In Bottle Sinks, page 7 (mm. 112-119), the left hand crossing over the right hand is not an easy passage to play. Practicing the leap between the F-sharp major blocked chords in the left hand as quickly as possible for the correct position will help to play this part. Furthermore, relaxing the left shoulder while moving to the upper register is critical when playing this part (Figure 4.3.4). 
Figure 4.3.4: The F-sharp major chord left hand crossing over the right hand sixth intervals, mm.

\section{2-113}

\section{BOTTLE SINKS}

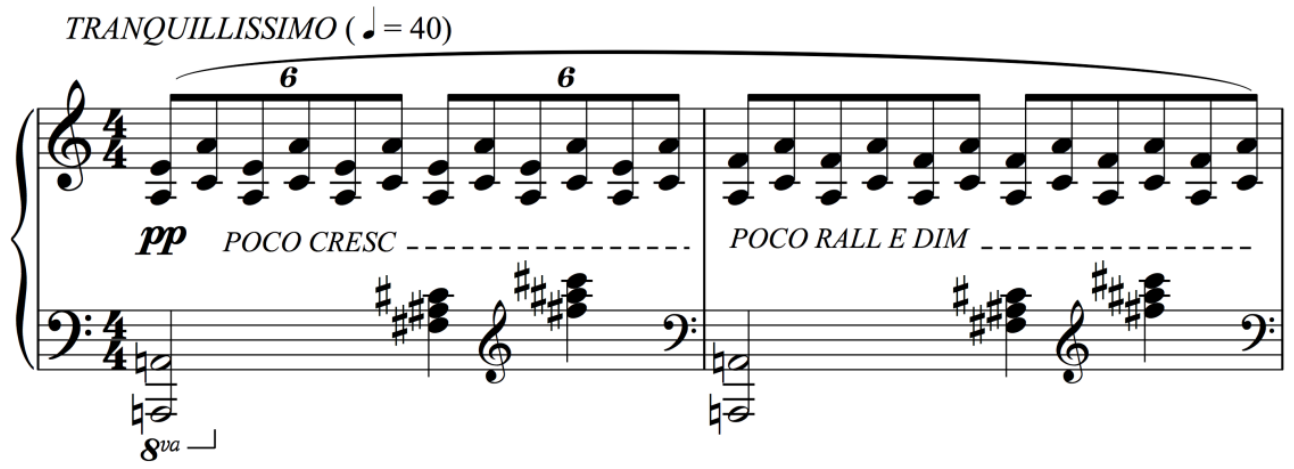

The A section of this piece is very difficult to memorize. Practicing sixths in blocked chords with the left hand will help the performer to memorize this section more easily.

\section{Dynamics, Color, Pedaling and Articulation}

The color of the piece mainly relies on dynamics. The dynamic range of this piece is from ppppp to $\mathrm{ff}$. Soft sounds dominate this piece. Sensitivity to a various palate of touches creates an incredible effect. In this case, the performer should clearly understand the piano on which they will perform; how deep of touch he/she should play, the action of the piano, and how loud and soft the sounds are that the piano can produce. The unusual dynamic sign, ppppp, appears at the end of the piece to illustrate the sinking bottle (Figure 4.3.5).

Figure 4.3.5: The bottle is sinking down, mm. 120-122

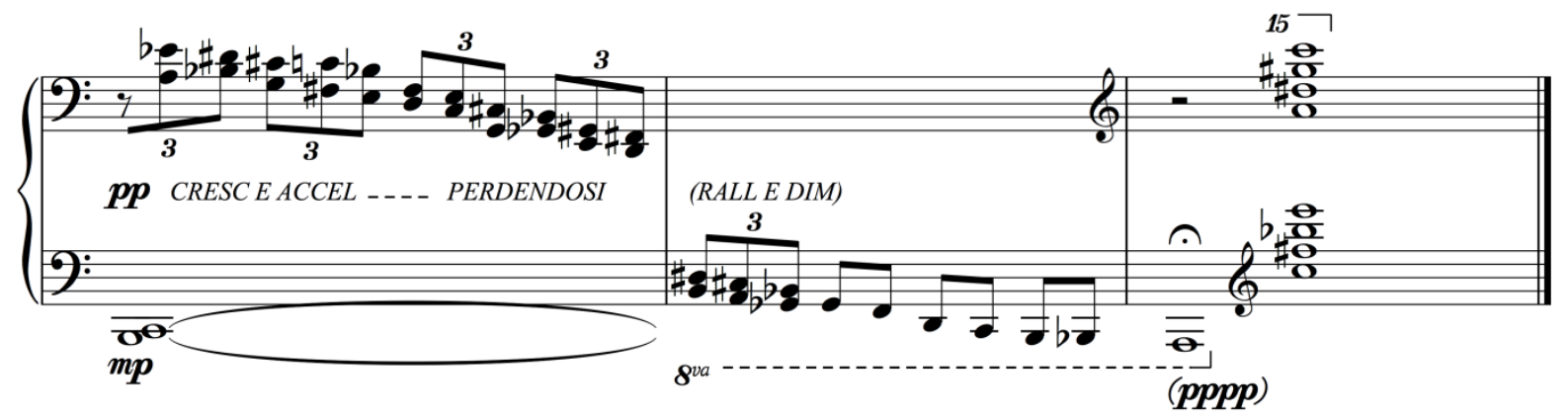


A long sustain pedal is necessary for the entire piece in order to blend the sounds together which depict the floating bottle across the ocean. However, changing the sustain pedal is necessary when changing chords. Overlapping pedal is employed throughout the piece.

Using the una corda pedal might be necessary for changing the color and creating a cloudy atmosphere; especially for the ppppp in m. 122 at the end of the piece.

The character of this character piece is dissimilar to other del Aguila’s piano works, being much more calm and peaceful. Connecting the long legato line is the main articulation consideration for this piece.

\section{Miscellaneous}

The performer's gestures are an important aspect to create the appropriate atmosphere and to convince the audience. Visual presentation is also vital. The performer's posture should be relaxed and he or she should sit in an open position to let the upper body move naturally, in order to create calm and hypnotic feeling like a bottle floating across the ocean. 


\section{iv) “Half of Me" for Piano Left Hand, Op. 70}

\section{Overview and General Characteristics}

Many of the most well-known twentieth-century left hand piano compositions were composed when Paul Wittgenstein (1887-1961), an Austrian American concert pianist who lost his right arm during World War I, commissioned many famous composers to write pieces for him to perform. In response, these composers wrote important works for left hand such as Piano Concerto No. 4 (1931) by Sergei Prokofiev (1891-1953); Diversions (1942) by Benjamin Britten (1913-1976); Piano Concerto in D major for the Left Hand (1930) by Maurice Ravel (18751937), and others. ${ }^{73}$ Since then, many other compositions for left hand piano have been written, including one that this chapter will examine.

"Half of Me" for piano left hand, Op.70, is a short character piece which is eight minutes in length. This piece was not commissioned by Wittgenstein, but rather it was commissioned by the Van Cliburn Foundation for the 2000 International Piano Competition. According to del Aguila, "It was performed in 2000 by Van Cliburn competition pianists but not in public."74 This means this piece was never performed as a world premiere. This piece will be performed in public at Bloch Learning and Performance Hall at College of Creative Arts, West Virginia University on April 22, 2017 by Sornsuang Tangsinmonkong. ${ }^{75}$ The theme of this character piece is derived from his "Nocturne”, Op. 62. "Half of Me" dramatically develops the ideas in "Nocturne", to create a lengthy and technically demanding composition.

\footnotetext{
${ }^{73}$ Ronald Kinloch Anderson and Katherine K. Preston, "Wittgenstein, Paul," Grove Music Online. Oxford Music Online. Oxford University Press, accessed November 5, 2016, http://www.oxfordmusiconline.com/subscriber/article/grove/music/30460.

${ }^{74}$ E-mail correspondence with Miguel del Aguila, November 25, 2016.

75 Ibid.
} 
While the theme of "Half of Me" is derived from "Nocturne", the tempo is faster and the character is more dramatic. ${ }^{76}$ This piece is a programmatic work. Del Aguila described the emotions in this piece in the following way,

"It illustrates the feelings of sadness and loneliness that arise when someone loved is gone, when love ends; when one is left alone. This feeling that a "half of yourself" is missing is expressed in the music and of course, in the title of the piece and the fact that you play it with only one hand." 77

Jazz and blues are the main styles of this composition. Tango rhythms also appear in this piece. It has a tuneful melody with a complex, broken chord accompaniment, and this increases the drama and expressiveness. The intensity of the music is built by extended chords and detailed tempo markings, such as accelerando and ritardando in almost every phrase. As a concert pianist, del Aguila knows how to compose piano compositions in pianistic way. However, a variety of techniques are used, such as scales, voicing, blocked chords, arpeggios, and jumping up and down between high and low registers to play both melodic lines and accompaniment. This variety of techniques causes this piece to be complicated and difficult to play.

\section{Form}

The structure of "Half of Me", Op. 70, is ternary form: ABA'. There are two subsections in the A and the B sections (Table 4.4). The entire piece based on the theme from "Nocturne", Op. 62, which was composed two year earlier.

Table 4.4: Structure of "Half of Me”, Op. 70

\begin{tabular}{|l|l|l|l|l|l|}
\hline \multicolumn{2}{|c|}{ A } & \multicolumn{3}{c|}{ B } & \multicolumn{1}{c|}{$\mathbf{A}^{\prime}$} \\
\hline a1 & a2 & b1 & Transition & b2 & a1 \\
\hline mm. 1-15 & mm. 16-60 & mm.61-94 & mm. 95-96 & mm. 97-102 & mm. 103-143 \\
\hline
\end{tabular}

\footnotetext{
${ }^{76}$ E-mail correspondence with Miguel del Aguila, March 13, 2016.

${ }^{77}$ Ibid.
} 
The A section, mm. 1-60, is divided into two subsections: a1 and a2, In a1, mm. 1-15, del Aguila uses the theme from introduction of "Nocturne”, Op. 62, mm. 1-8. This theme uses broken chords to create a conversation between the right hand and the left hand (Figure 4.4.1).

Figure 4.4.1: Comparison of the theme from (1) "Nocturne”, Op. 62, mm. 1-8, and (2) "Half of Me”, Op. 70, mm. 1-11

(1) Introduction from del Aguila’s “Nocturne”, Op. 62, mm. 1-8

Recitando

Molto rubato
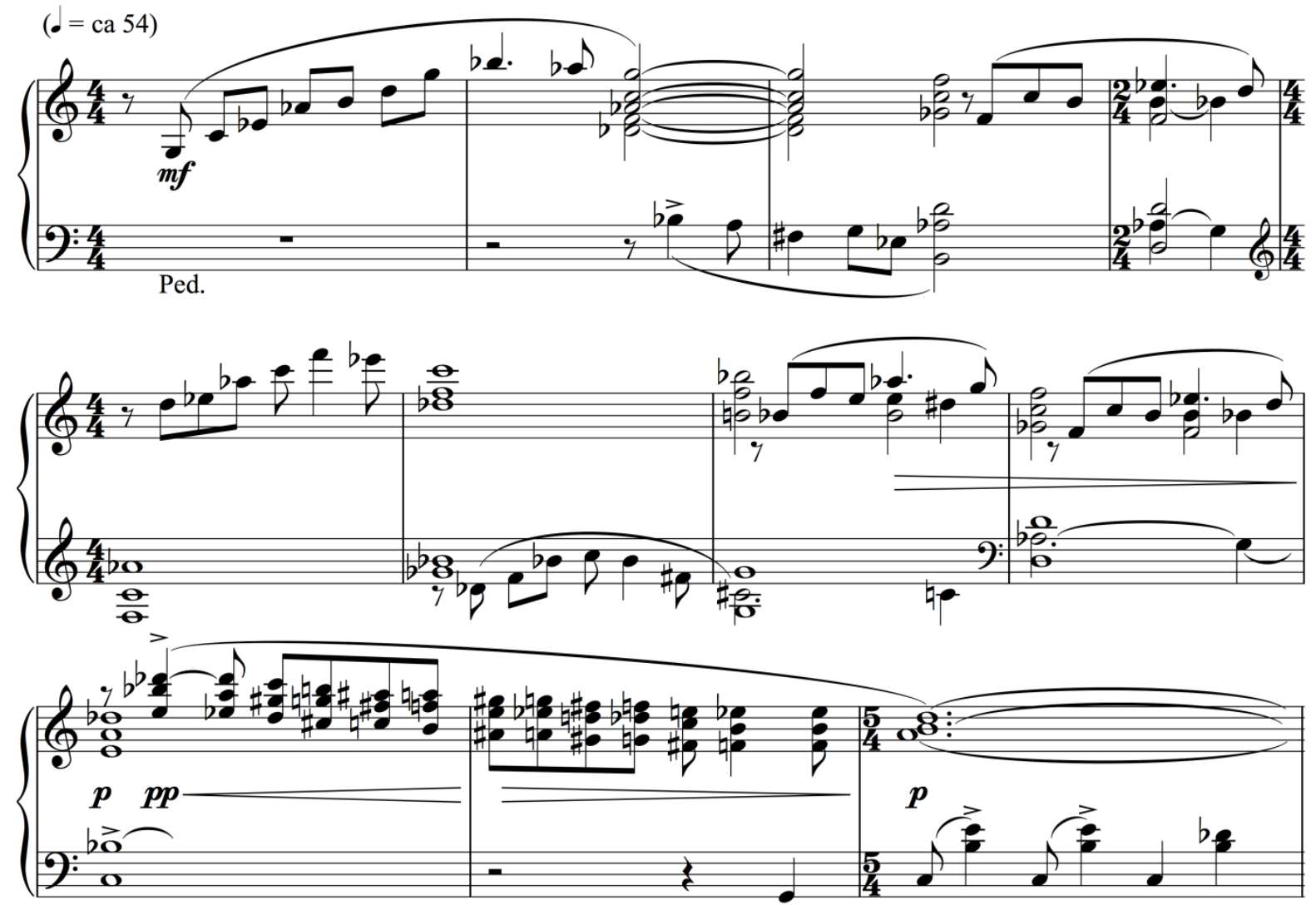
(2) a1 section from “Half of Me”, Op. 70, mm. 1-11
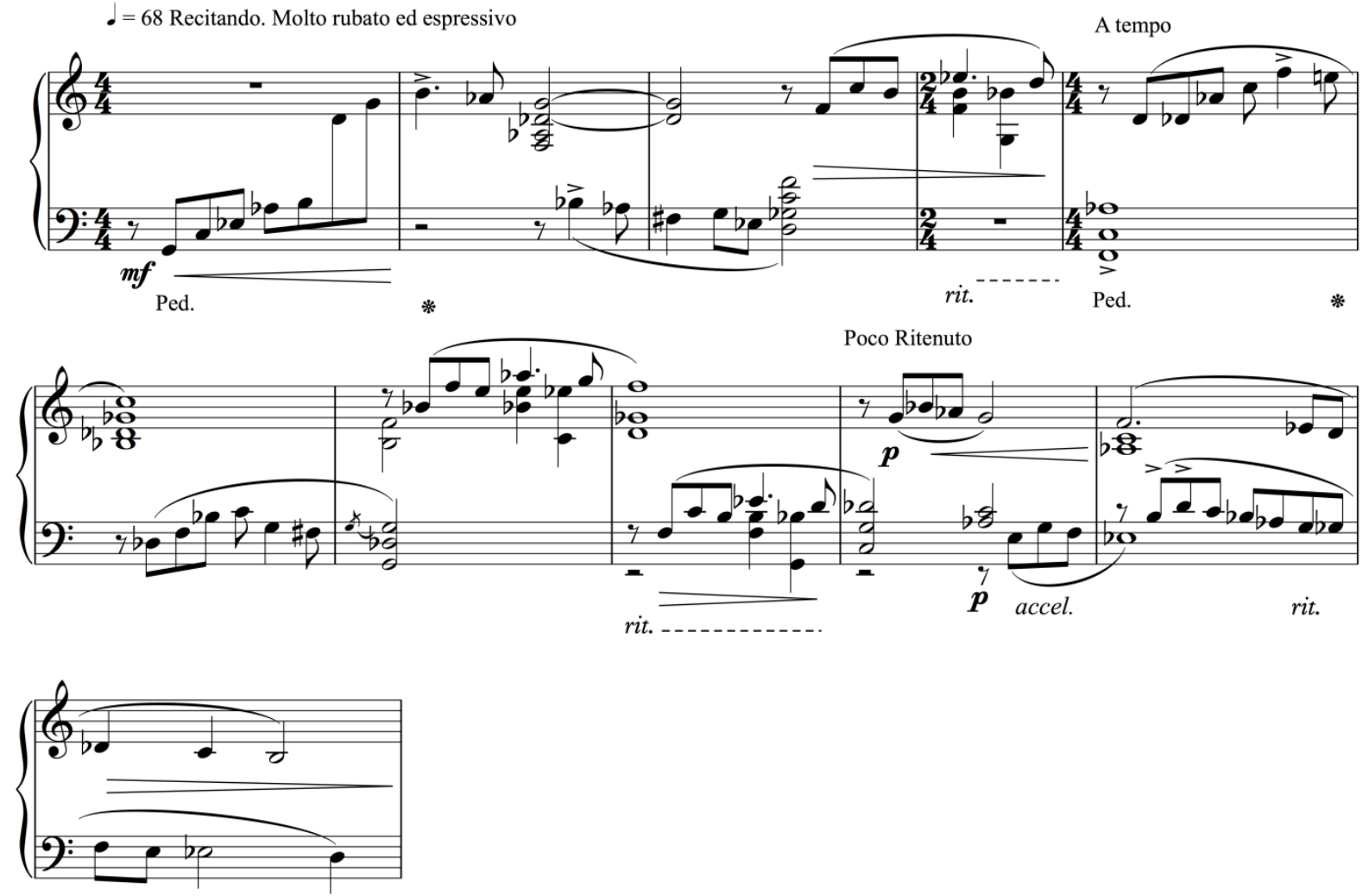

In a2, mm. 16-60, the theme is derived from the the B section of "Nocturne", mm. 54-74 (Figure 4.4. 2). Del Aguila added another fifteen bars, mm. 16-30, before the theme from the B section of "Nocturne” was used. The B theme from "Nocturne” appears in mm. 31-36. 
Figure 4.4.2: Comparison of the theme (1) the B section from del Aguila's "Nocturne”, Op. 62, mm. 54-57, and (2.1) the a2 section from "Half of Me”, Op. 70, mm. 16-19 (2.2) Appearance of the theme from the B section of "Nocturne”, Op. 62 in "Half of Me”, mm. 31-36 mm. 31-31

(1) “Nocturne”, Op. 62, mm. 54-57

Recitanda $(\bullet=$ ca 55) Molto rubato

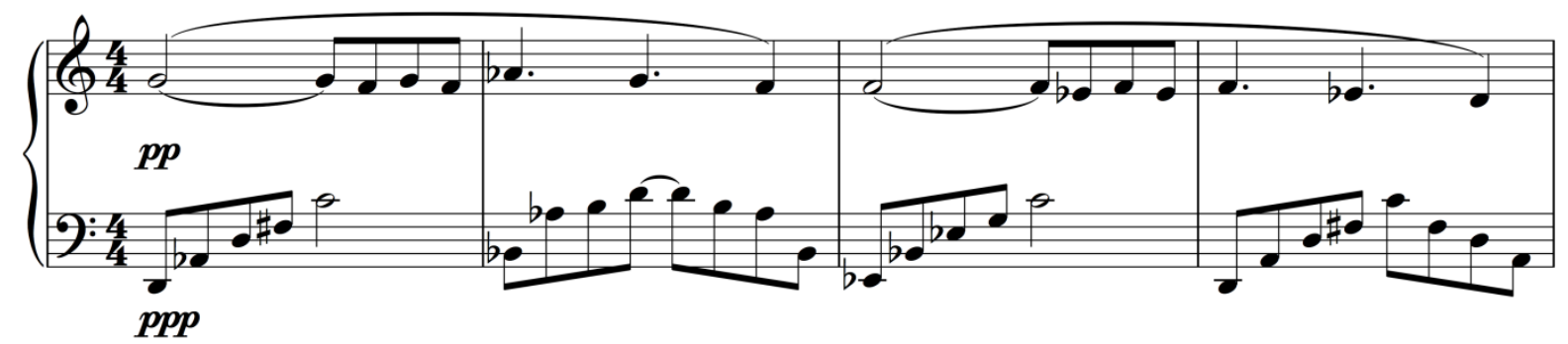

(2.1) “Half of Me”, Op. 70, mm. 16-19

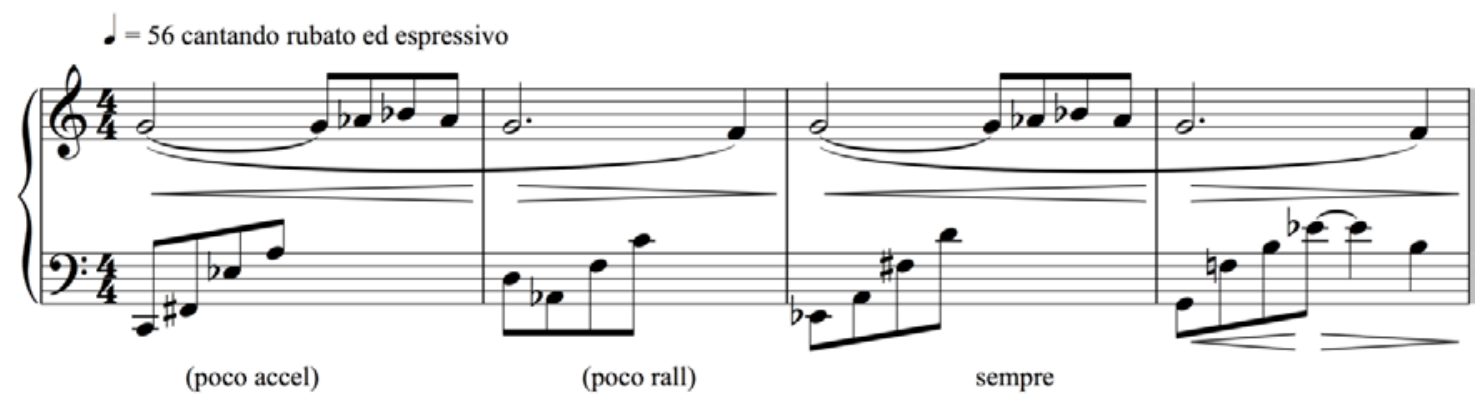

(2.2) “Half of Me”, Op. 70, mm. 31-36
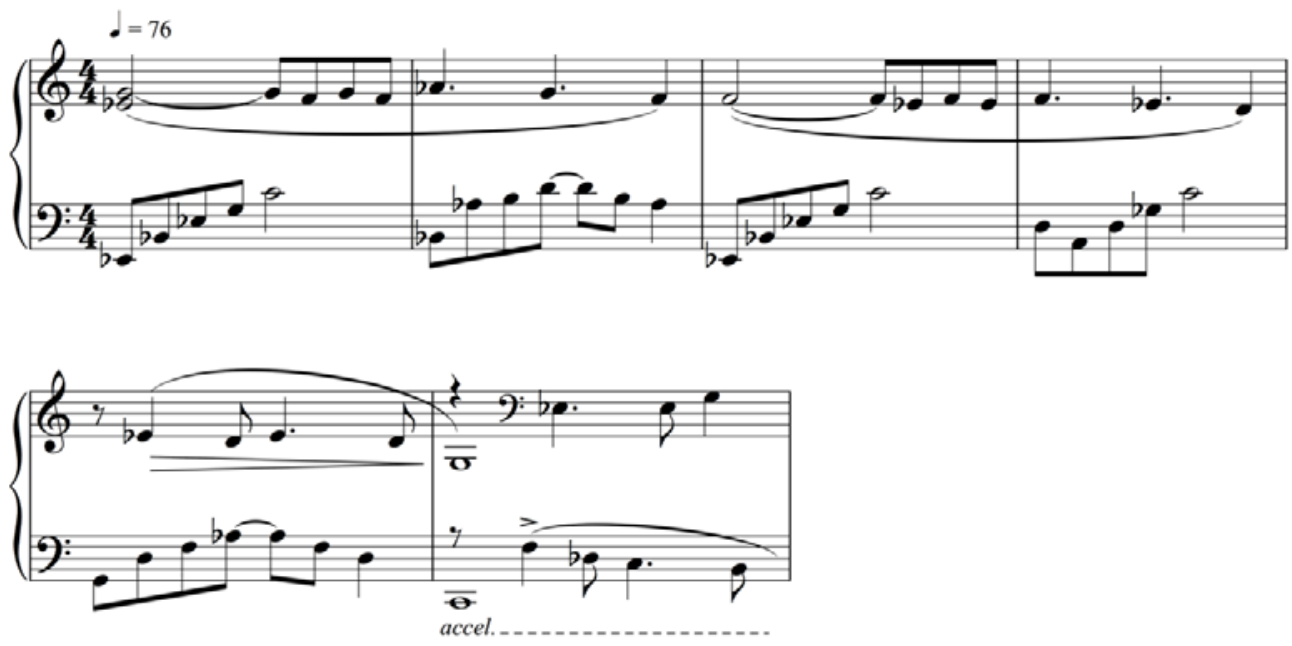
The B section, mm. 61-102, introduces a new idea which is divided into two subsections: b1, mm. 61-94, and b2, mm. 97-.102 (Figure 4.4.3). Between b1 and b2, there is a short transition, mm. 95-96, which uses material from a1 (Figure 4.4.4). The primary difference between these subsections is the texture: $\mathrm{b} 1$ is based on sixteenth-note figures, and b2 is more elaborate and uses thirty second-note figures. The melody in the B section is conjunct, constantly alternating between the highest and lowest voice of the broken chord texture.

Figure 4.4.3: the B section (1) b1, m. 61; (2) b2, mm. 97

(1)

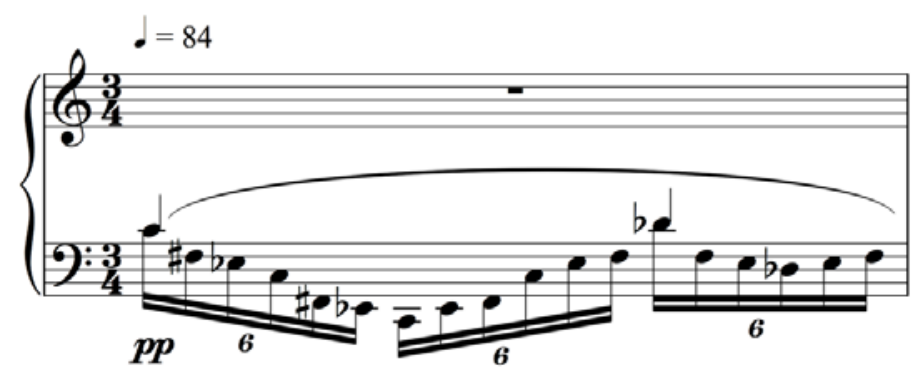

$8^{b a}-(-0)$

(2)

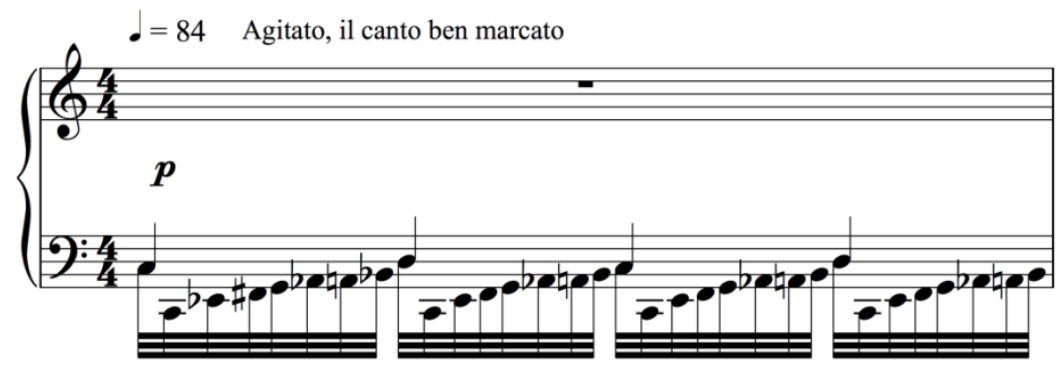

Figure 4.4.4: Transition in the B section, mm. 95-96

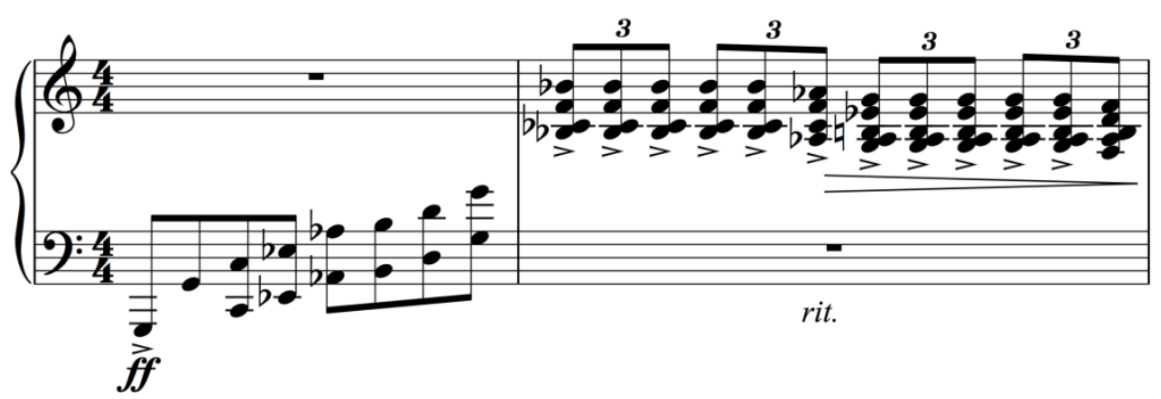


The A' section employs the a1 theme in a series of block chords with melodies in octaves, as can be observed mm. 103-125 (Figure 4.4.5). The original a1 theme appears in the A' section in mm. 125-143.

Figure 4.4.5: A’ section, mm. 103

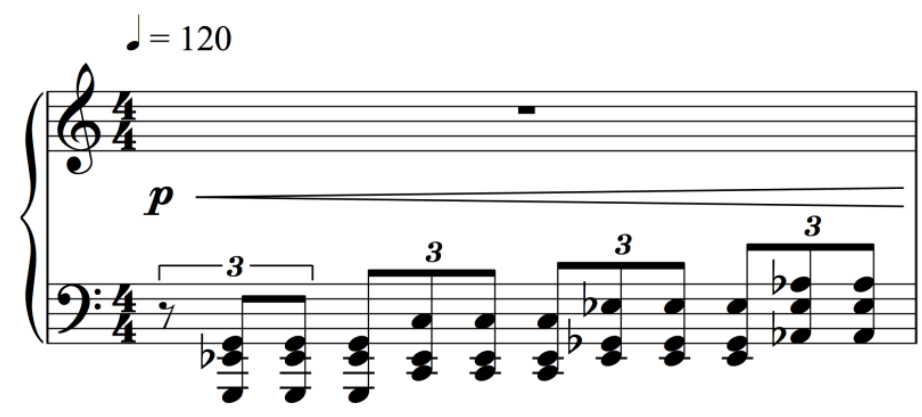

\section{$\underline{\text { Pedagogical Concerns }}$}

"Half of Me" should be categorized as an advanced level composition. It is a technically and musically demanding piece to play.

\section{Texture}

Many varieties of texture are presented in this character piece. The A section is characterized by a contrapuntal texture, and the conversation between many lines is the central concept in this section (Figure 4.4.6).

Figure 4.4.6: Contrapuntal texture in A section

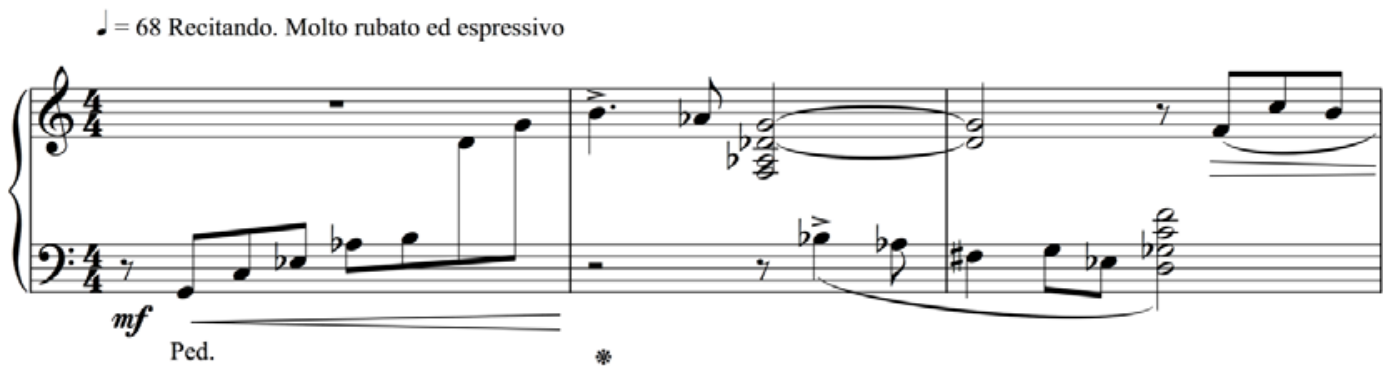


In the B section, the texture turns to a single melodic line found in the highest and lowest line, with both arpeggiated and blocked chord accompaniments (Figure 4.4.7).

Figure 4.4.7: Texture in the B section (1) melody with arpeggiated accompaniment, m. 61 (2) block chord accompaniment, m. 103

(1)

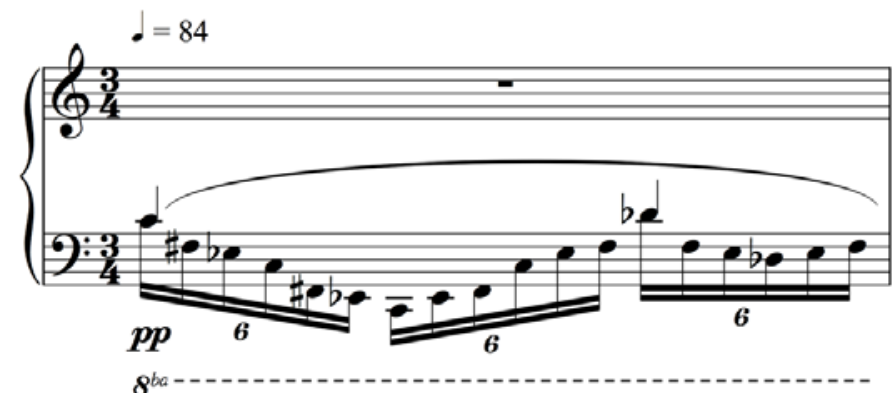

(2)

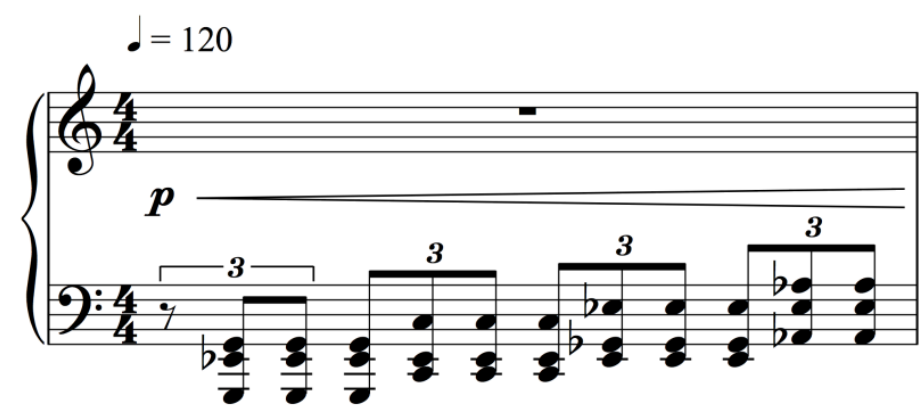

Melody, Harmony, Phrasing, Shaping and Direction

“Half of Me” is filled with expressive and lyrical melodies which are derived from the theme of del Aguila’s “Nocturne”, Op. 62. It uses mostly tertian harmonies with extended chords, reflecting the strong jazz influence. Furthermore, tango rhythms appear in mm. 23, 25, 32, 34, 36, 37, 39, 40, 43-46, 50, 52, 48 and 50 (Figure 4.4.8). 
Figure 4.4.8: Tango, mm. 43-46

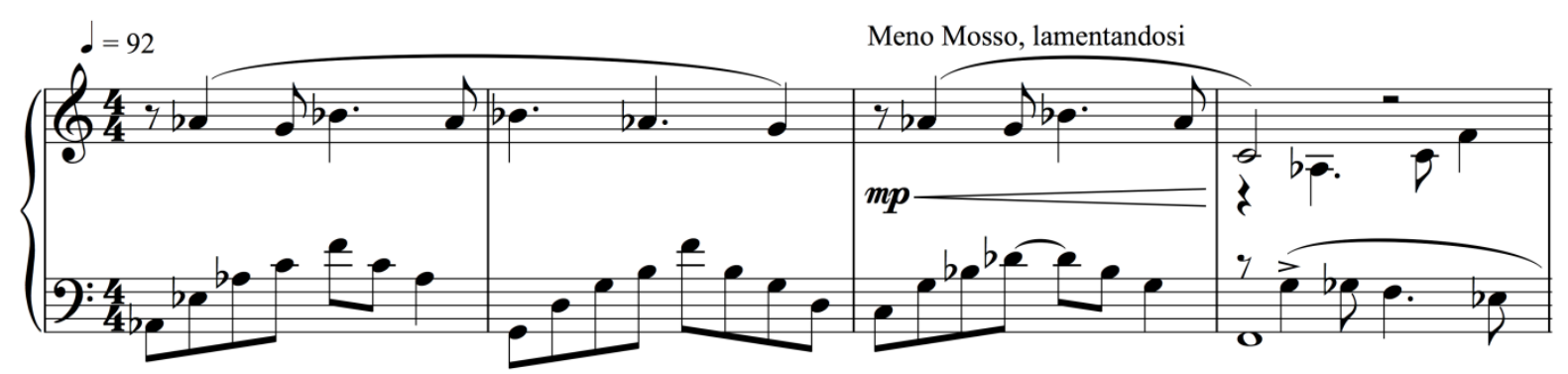

The phrases are four bars in length in the A section, and the B section has three-bar phrases. Direction and shaping in this composition are informed by the phrasing and also the location of the climax of the piece. The climax of the piece is at the end of the B section, and the performer should use rubato for the climax. It is noteworthy that the tempo markings indicated by the composer, such as accelerando and rallentando, are crucial for understanding the phrasing and direction of the piece. These indications will help the performer know the proper direction of the piece.

\section{Dynamics and Voicing}

The dynamic range is from $p p$ to $f f$. An important aspect to consider about this piece is the need to differentiate between the dynamics of melody and accompaniment. The drama of this character piece is anchored in its dynamics. Thus, the performer has to think carefully about the volume of every note in order to successfully connect the main melodic line, counter melody and accompaniment.

\section{Pedaling}

The dramatic quality of this piece is also driven by the long, lyrical melodies. There are some pedal markings indicated by the composer. Long sustain pedals are suitable for broken 
chord accompaniments. However, the sustain pedal should change when there is a half-step melody in order to avoid unnecessary dissonances.

\section{Technique and Tempo}

In the A section, the performer should pay attention to the connection of the melody while jumping to play the accompaniment. For example, on the first beat of each bar in the a2 section, mm. 16-60, the left hand should play the bass note accompaniment before jumping up to the higher register melody, in order to create the sense of a strong beat and to avoid a bumpy feeling. This is the appropriate way to play this passage, even though it is more difficult than playing the melody before accompaniment (Figure 4.4.9).

Figure 4.4.9: Playing bass accompaniment before melody mm. 16-17

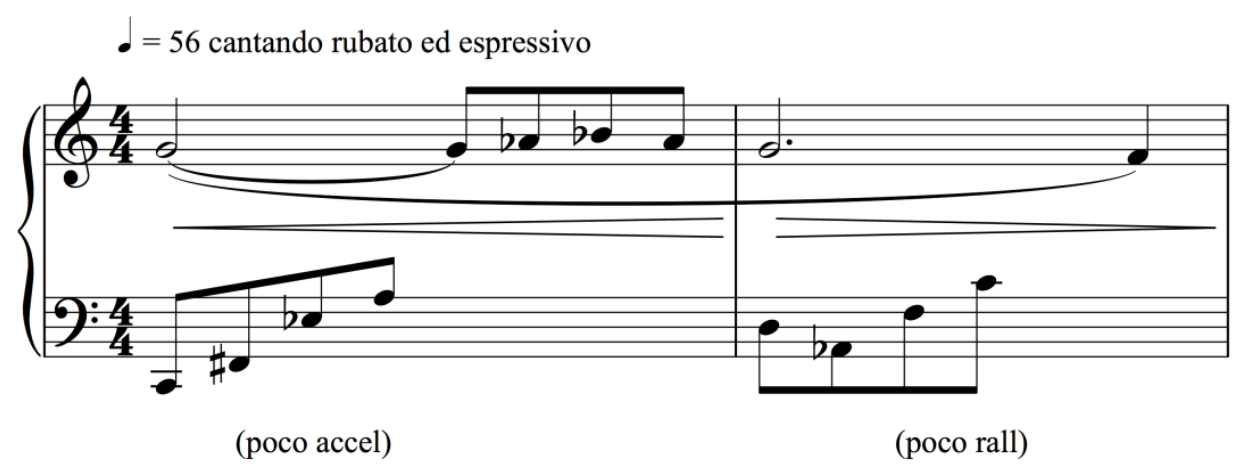

Practicing the melody and accompaniment separately will help to differentiate the lines and let the performer hear each line more clearly. Furthermore, using both hands to play this piece will help the performer hear the connection of melodic lines and also to differentiate melodic and accompaniment lines.

Arpeggiated passages in the B section should be played by using rotation while bringing out the melodies from the top notes and bottom notes. 
The most difficult aspect of this piece is the fast tempo. Del Aguila indicates metronome marks at almost every phrase. Rhythmic practice in sections will help the performer to see the music as a bigger picture. In addition, slow practice with isolated lines will secure the memory and the physical movements when increasing the speed. To reach the final tempo, increasing the tempo slightly by using the metronome until reaching the right tempo is an essential way to practice this piece.

\section{Miscellaneous}

Exercising and building muscles is necessary for this character piece because it requires so much body and left arm strength. Posture is another important aspect to consider. Playing in the higher register can cause waist pain and arm stiffness because the performer has to twist his/her body and lift his/her left arm. While practicing in the high register, moving the seating position to the right can reduce the risk of waist and left arm pain. There can be a tendency to lift the shoulder during performing. Unnecessarily lifting the shoulder while playing can cause fatigue and soreness and should be avoided. 


\section{CHAPTER V}

\section{CONCLUSIONS AND RECOMMENDATIONS FOR FURTHER RESEARCH}

The selected eight of del Aguila's piano works show eclectic styles. Various stylistic traits such as jazz, Latin folk music, minimalist, romantic, pop, and ragtime are presented in their eight piano compositions. Due to the extensive use of Latin folk dance in his music, we can recognize del Aguila as a twentieth-century nationalist composer. However, Miguel del Aguila sees himself as a postmodernist composer. ${ }^{78}$

His piano works are tonal but they do not strictly use functional harmony. Augmented, diminished chords, and tritone intervals are widely used. Influence from jazz music is presented in extended chords, and swing style. The use of unusual rhythms and frequently changing time signatures are some of his music’s unique characteristics. In Conga and "Music in a Bottle”, motoric rhythms and repetitive figures show great influence from minimalism.

Del Aguila incoporated Uruguayan and other Latin American folk dances in his piano music. These folk elements are the conga, tango, salsa, gaucho, candombe and Brazilian chôro.

Table 5.1 presents the Latin dances and other stylistic traits in each piano piece.

Table 5.1: Latin dances and folk dances in del Aguila's piano music

\begin{tabular}{|l|l|}
\hline Composition & Latin Dance and Folk Music \\
\hline “Toccata”, Op. 23 & Uruguanyan candombe \\
\hline Piano Sonata No. 2, Op. 29 & Gaucho and Caribbean dance \\
\hline Conga, Op. 39 & Conga, salsa, tango and candombe \\
\hline Piano Concerto, Op. 57 & Uruguayan candombe, tango \\
\hline “Nocturne”, Op. 62 & Brazilian chôro \\
\hline "Half of Me” for left hand, Op. 70 & Tango \\
\hline
\end{tabular}

\footnotetext{
${ }^{78}$ Miguel del Aguila, interview by Sornsuang Tangsinmonkong, January 12, 2017, Camarillo, CA.
} 
His music is full of drama, expressiveness, and storytelling. This shows strong influence of romanticism. Another significant characteristic of del Aguila's piano music is that it consists of extremely wide registers, from the lowest $\mathrm{A}$ to the highest $\mathrm{C}$, and dynamic ranges from ffff to ррррр. For del Aguila’s lyrical pieces such as “Nocturne”, Op. 62, “Half of Me”, Op. 70, the second movement of Piano Sonata No. 2, and the Piano Concerto, the melodic lines are simple and conjunct.

\section{Form}

The most common form in his piano music is the ABA structure. However, according to the composer, in many of his pieces he used stories to determine the musical structure. ${ }^{79}$ Therefore, it is not easy to identify clearly the musical structure in many of his piano pieces.

Many of del Aguila's compositions share the exact same theme; for example, the theme of the third movement of Piano Sonata No. 2, Op. 29 is the theme for the last movement of String Quartet no. 2 (1988), and his Presto II. Other examples of pieces with the same theme are the second movement of Piano Concerto, Op. 57 (1997); “Nocturne”, Op. 62 (1998); and "Half of Me” for left hand, Op. 70 (2000). Another example is the third movement of Piano Concerto , Op. 57 (1997) which shares the same theme as the last movement, "The Joy of Keeping Time” from Clocks, Op. 58 (1998). Del Aguila addressed this issue explaining that these themes show continued growth as they appear in several pieces.

\footnotetext{
${ }^{79}$ E-mail correspondence with Miguel del Aguila, December 6, 2016
} 


\section{Pedagogical Concerns}

His piano compositions are suitable for advanced-level players because of their musical depth and technical challenges, with the exception of the "Nocturne” Op. 62, which is also suitable for intermediate level.

His piano compositions are highly pianistic, but many of his compositions are not suitable for small-hand pianists because they contain thick chords and wide-range intervals. The performer's hands should be able to reach ninths and tenths. The techniques that Miguel del Aguila frequently employed in his piano works are motoric rhythms, mirrors (both hands playing together with the same fingers but in opposite positions, for example, the ostinato and its inversion in m. 55 from Piano Sonata No. 2, Op. 29. He also uses scales, repetitive figures, arpeggiated passages, tremolo, glissandi, and clusters. Cluster is an important technique that del Aguila used at the end of sections, movements and pieces. It creates climax and drama for the piece; examples include the third movement of Sonata No. 2, "Vals Brutal”, the first and third movements of Piano Concerto, and “Toccata”.

An unusual scale that he often applies in his piano works is the two-tetrachord scale (BC-D-E, F-Gb-Ab-Bb). According to del Aguila, "I don't know if it(this scale) existed before and have no name for it. I'm sure somebody may have use(d) those notes before as the whole tone scale is included in it but I think I invented its systematic use in piano music back in the 70's." 80

Del Aguila was concerned about the tempo of the pieces. Metronome marks and other tempo indications are clearly set in the piano compositions. Del Aguila uses more specific tempo indications such as poco più mosso, meno mosso, accelerando, and ritardando, rather than using only rubato to show the direction and musical phrase. Concerning the tempo and direction of his

${ }^{80}$ Ibid. 
music, del Aguila suggested that most of the pieces should be played by pushing forward or holding back. ${ }^{81}$

The sonority of other instruments can be found in his piano compositions, for instance, the percussive sonority of candombe drum in “Toccata” and open guitar's strings of the beginning of the second movement of Sonata No. 2, Op. 29. The performer should recognize and imitate these different sonorities into his/her playing. In addition, performer gestures are very important to convince audiences what he/she is playing. An example of this is the tango dance in Conga, Op. 39. The performer should relax and move his/her upper body to give the impression that he/she is dancing.

\section{Recommendations for Further Research}

Del Aguila has composed fifteen piano compositions. Only eight works are selected for study in this research. Therefore, there are another seven pieces which are not pursued in this research: Piano Sonata No. 1, Op. 15; Dance Suite, Op. 19; Four Spanish Songs, Op. 22; Caribbean Bacchanal for two pianos/ eight hands, Op. 51; “Four Hand Etude”, Op. 68; Congaline in Hell arranged for six pianos, Op. 73; and Lieutenant Kije (from Sergei Prokofiev Suite) arranged for two pianos/ four hands, Op. 75. A pedagogical study of these piano pieces is an interesting topic for future research. Another possible topic would be a detailed analysis for each composition.

Furthermore, del Aguila also composed another two compositions for the left hand: Fantasie, Op. 10 for cello and left-hand piano and Burlesques, Op. 11 for flute and left-hand piano. For the researcher interested in left-hand piano, these compositions could be an interesting topic.

\footnotetext{
${ }^{81}$ Miguel del Aguila, interview by Sornsuang Tangsinmonkong, January 12, 2017, Camarillo, CA.
} 
It is hoped that this study will encourage pianists and piano teachers to incorporate the music of del Aguila in their repertoire. His piano music is very worthwhile and deserves exploration and more performances. 


\section{Bibliography}

\section{Dissertation}

Chai, Tse Wei. "Pedagogical and Performance Aspects of Three American Compositions for Solo Piano: John Corigliano’s Fantasia on an Ostinato, Miguel del Aguila’s Conga for Piano, and William Bolcom's Nine New Bagatelles.” DMA diss., West Virginia University, 2016.

Cheong, Yew Choong. "An Introduction to the Solo Piano Works of Three Latin AmericanComposers: Miguel Del Aguila, Tania Leon, and Juan Maria Solare." DMA diss., West Virginia University, 2009.

Choi, Moonson. “A Brief Evaluation of Selected Solo Piano Music by Latin American Composer.” DMA diss., Ohio State University, 1995.

\section{Monograph}

Béhague, Gerard. Music in Latin America: An Introduction. Edited by H. Wiley Hithcock. Englewood Cliffs, NJ: Prentice-Hall, 1979.

Del Aguila, Miguel. “Preface.” In Miguel del Aguila Conga for Solo Piano. Peer International Corporation: New York, Hamburg.

Ficher, Miguel, Martha Furman. Schleifer, and John M. Furman. Latin American Classical Composers: A Biographical Dictionary. Lanham, MD: Scarecrow Press, 1996.

Olsen, Dale A. The Garland Handbook of Latin American Music. Edited by Dale A. Olsen and Daniel E. Sheehy. New York: Garland Pub., 2000.

Slonimsky, Nicolas. "Uruguay." In Music of Latin America, 282-287. New York: Thomas Y. Crowell Company, 1946.

\section{Journal}

Schulslaper, Robert. "Composer Miguel Del Aguila: Rhythm, Romance, and Reality." Fanfare: The Magazine for Serious Record Collectors 33, no. 5 (May 2010): 162-167.

\section{Recording}

Miltenberger, James. Piano Music of the Americas. ACA Digital Recording CM 20021, 1993. CD. 


\section{Website}

Béhague, Gerard. "Uruguay." Grove Music Online. Oxford Music Online. Oxford University Press. Accessed March 29, 2016.

http://www.oxfordmusiconline.com/subscriber/article/grove/music/28853.

"Candombe Terms."accessed September 6, 2016. http://www.candombe.com/english.html.

Cervetti Sergio. "Biography." accessed September 2, 2016.

http://www.sergiocervetti.com/biography.php.

Coriún Aharonián. "Candombe." Grove Music Online. Oxford Music Online. Oxford University Press, accessed September 5, 2016, http://www.oxfordmusiconline.com/subscriber/article/grove/music/52431.

Granata, Donna. "One Man Voice." Ventana Fine Living in Ventura County. Accessed October 8, 2016. http://www.ventanamonthly.com/article.php?id=394\&IssueNum=39.

"IN THE NEWS Miguel Del Aguila." Los Angeles Times. Accessed March 13, 2016. http://articles.latimes.com/keyword/miguel-del-aguila.k.

Jann Pasler. "Postmodernism." Grove Music Online. Oxford Music Online. Oxford University Press, accessed July 29, 2016. http://www.oxfordmusiconline.com/subscriber/article/grove/music/40721.

Kaliss, Jeff, Lee Stacy, and Lol Henderson. "Latin America." Encyclopedia of Music in The 20th Century (January 1, 2013): 358-363. RILM Music Encyclopedias, EBSCOhost (accessed March 29, 2016).

Kinloch Anderson, Ronald and Katherine K. Preston. "Wittgenstein, Paul." Grove Music Online.

Oxford Music Online. Oxford University Press, accessed November 5, 2016, http://www.oxfordmusiconline.com/subscriber/article/grove/music/30460.

Del Aguila, Miguel. "Miguel Del Aguila." Migueldelaguila. Accessed March 13, 2016. http://www.migueldelaguila.com/.

"Complete Works List.” accessed September 5, 2016.

http://www.migueldelaguila.com/other-works.html.

"Miguel Del Aguila - Composer Interview - Documentary Composers of Classical Music." YouTube. December 21, 2015. Accessed March 13, 2016. https://www.youtube.com/watch?v=vcixHYBUnM4. 
Mukhamedzyanova, Dina. "Miguel Del Aguila: 'Write the music that comes from your heart without caring about what's fashionable or what the rest of the world thinks you should be writing. "' Musika Rossii (The Music of Russia). Accessed December 4, 2016. http://eng.music-gazeta.com/article/3882/.

"Peermusic Classical : Composer Miguel Del Aguila." Peermusic Classical : Composer Miguel Del Aguila. Accessed March 13, 2016.

http://www.peermusicclassical.com/composer/composerdetail.cfm?detail=Aguila.

Rocamora, Martín. "Automatic Transciption and Analysis of Percussion Music, the Afro Uruguan Candombe Drumming as a Case Study: Candombe in Uruguayan Culture." accessed September 6, 2016. http://iie.fing.edu.uy/ rocamora/phdthesis/candombe.html.

Schulslaper, Robert. "Composer Miguel Del Aguila: Rhythm, Romance, and Reality." Fanfare: The Magazine for Serious Record Collectors 33, no. 5 (May 2010): 162-167.

Salgado, Susana. "Barradas, Carmen." Grove Music Online. Oxford Music Online. Oxford University Press, accessed September 2, 2016, http://www.oxfordmusiconline.com/subscriber/article/grove/music/44195.

Salgado, Susana. "Mastrogiovanni, Antonio." Grove Music Online. Oxford Music Online. Oxford University Press, accessed May 15, 2016, http://www.oxfordmusiconline.com/subscriber/article/grove/music/18040.

Trigona, Marie. "Uruguay: Spirit of Afro Resistance Alive in Candombe." accessed September 6, 2016. http://upsidedownworld.org/main/content/view/1145/48/. 


\section{Appendix I}

Notation errors from the seperated leaflet of del Aguila's Piano Sonata No. 2 score ${ }^{82}$

\section{MIGUEL DEL AGUILA, SONATA NO. 2}

\section{$\underline{\text { ERRATA }}$}

First movement:

m. 19 Last eight note chord of the right hand (A-C\#-F) should not be tied over to the pervious chord.

m. 76 Right hand "A", (on lower stave, second sixteenth note) should be A\#, as in bar 89.

m. 118 Second and sixth notes in the left hand should be D instead of C.

m. 191 Bottom note of the fourth chord in the right hand should be B instead of C.

Second movement

m. 27 The "ppp" in the right hand should be under the following notes instead of under the rest.

m. 37 First notes in the right should be the same as the notes they are tied over to: D-F\#. Top of last eighth note in the right hand should be C-natural instead of C-flat.

m. 41 First note of left hand (grace note) must have a small fermata.

m. 52 Left hand chords should be the same as in the previous bars ( $\mathrm{C}$ and E-flat have

m. 81-82 been written twice by mistake).

m. 84 First chord in right hand is the same as previous ones.

m. 106 Second and third notes in the right hand (both A-flat) should be tied over.

Third movement:

m. 1 First note of both hands in "fp" instead of "p".

m. 61 The "p" should be in the preceeding bar (m. 60).

m.128 Fifth note in the left hand should be $\mathrm{E}$ instead of $\mathrm{F}$.

m. 130 First note of the left hand should be F instead of A.

Notation errors from email correspondence with Miguel del Aguila, November 18, 2016 and interview with Miguel del Aguila, January 12, 2017.

Second movement:

m. 41 In the sixth beat, the right hand should play Ab-C (major third) instead of Ab-Cb

Third movement:

m. 74 Left hand should play F instead of G like in m. 29 (D-B-G-F-D-B-G)

\footnotetext{
${ }^{82}$ Leaflet from del Aguila’s Piano Sonata No. 2 score
} 


\section{Appendix II}

Detailed orchestration in the Piano Concerto, Op. 57

Orchestra

2 Flutes ( $2^{\text {nd }}$ double on Picc.) 2 Oboes ( $2^{\text {nd }}$ doubles on E. Horn), 2 Clarinets in Bb, 2 Bassoons, 2 Horns, 2 Trumpets in C, 2 Trombones, 1 Tuba

Timpanist and 2 Percussionists.

Instruments:

Timpani, Brake Drums, Tam-Tam, Tubular Chimes, 2 Gongs (lowest and higher), Crash Cymbals, Suspended Cymbal, Bass Drum, Thunder Sheet, Glockenspiel, Triangle, Metal Wind Chimes, Bird Whistle (filled with water, played from backstage), Police Whistle, Xylophone, 4 Tom-Toms, Tambourline, Snare Drum, Hi-Hat

Strings

Solo Piano (If piano available is not bright or loud enough it should be lightly amplified) 


\section{Appendix III}

Miguel del Aguila’s Contact

Tel: +1 (805)218-7958

Email: miguel@migueldelaguila.com

Official Website: http://www.migueldelaguila.com/

Publisher: Peermusic Classical (USA)

250 W. 57th Street, Suite 820

New York, NY 10107

Contact: Todd Vunderink

+1 (212)265-3910 Ext 117

peerclassical@peermusic.com 


\title{
Appendix IV
}

\section{Permission for using excerpt from Ginastera’s Piano Sonata No. 1, Op. 22}

Sornsuang Tangsinmonkong

West Virginia University

1234 Forest Green Dr.

Coraopolis, Pennsylvania 15108

USA

\author{
RE: $\quad$ Piano Sonata No. 1, Op. 22 by Alberto Ginastera
}

Dear Sornsuang:

We hereby grant you gratis permission to include excerpts from the above referenced work in your PhD dissertation for West Virginia University.

We do require that you include the following copyright notice immediately following the excerpts for which it pertains:

Piano Sonata No. 1, Op. 22 by Alberto Ginastera

(C) 1954,1982 by Boosey \& Hawkes, Inc., Copyright Renewed.

Reprinted by Permission of Boosey \& Hawkes, Inc.

Permission is also granted for you to deposit one copy of your paper with ProQuest. Should you wish to place your paper elsewhere, beyond that which is required for the degree, you will have to contact us in advance as a royalty may be payable.

With kind regards,

BOOSEY \& HAWKES, INC.

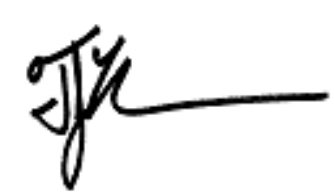

Tyler Rubin

Assistant, Copyright Administration

\section{TYLER J. RUBIN}

Assistant, Copyright Administration

Email: tyler.rubin@imagem.com

Imagem

229 West 28th Street, 11th fl, New York, NY 10001

$\mathrm{T}:+1$ (212) 6995321

$\mathrm{F}:+1(212) 4896637$

www.imagem.com 